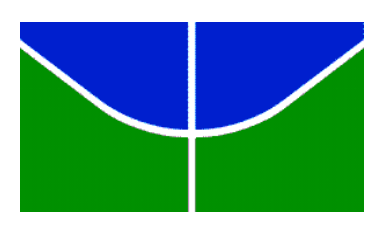

UNIVERSIDADE DE BRASÍLIA

FACULDADE DE AGRONOMIA E MEDICINA VETERINÁRIA

MODELO BIOENERGÉTICO NUTRICIONAL E BALANÇO DE MASSAS PARA O MONITORAMENTO E ESTIMATIVA DE EFLUENTES DA PRODUÇÃO COMERCIAL DE TILÁPIA DO NILO (Oreochromis niloticus) EM RESERVATÓRIO TROPICAL

GUILHERME WOLFF BUENO

TESE DE DOUTORADO EM CIÊNCIAS ANIMAIS

BRASÍLIA/DF

JUNHO DE 2015 


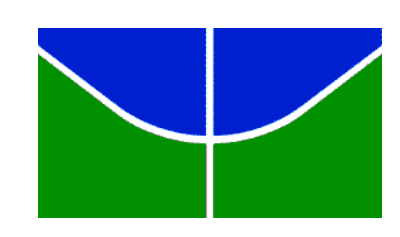

\author{
UNIVERSIDADE DE BRASÍLIA \\ FACULDADE DE AGRONOMIA E MEDICINA VETERINÁRIA
}

\begin{abstract}
MODELO BIOENERGÉTICO NUTRICIONAL E BALANÇO DE MASSAS PARA O MONITORAMENTO E ESTIMATIVA DE EFLUENTES DA PRODUÇÃO COMERCIAL DE TILÁPIA DO NILO (Oreochromis niloticus) EM RESERVATÓRIO TROPICAL
\end{abstract}

GUILHERME WOLFF BUENO

ORIENTADOR: Ph.D. FRANCISCO ERNESTO MORENO BERNAL CO-ORIENTADOR: Ph.D. RODRIGO ROUBACH E Ph.D. DOMINIQUE P. BUREAU

TESE DE DOUTORADO EM CIÊNCIAS ANIMAIS

PUBLICAÇãO: 134D/2015

BRASÍLIA/DF

JUNHO DE 2015 


\section{REFERÊNCIA BIBLIOGRÁFICA E CATALOGAÇÃO}

BUENO, G. W. Modelo bioenergético nutricional e balanço de massas para o monitoramento e estimativa de efluentes da produção comercial de tilápia do Nilo (Oreochromis niloticus) em reservatório tropical. Brasília: Faculdade de Agronomia e Medicina Veterinária, Universidade de Brasília, 2015, 127p. Tese de Doutorado.

Documento formal, autorizando reprodução desta tese de Doutorado para empréstimo ou comercialização, exclusivamente para fins acadêmicos, foi passado pelo autor à Universidade de Brasília e achase arquivado na Secretaria do Programa. O autor e seu orientador reservam para si os outros direitos autorais, de publicação. Nenhuma parte desta tese de doutorado pode ser reproduzida sem a autorização por escrito do autor ou do seu orientador. Citações são estimuladas desde que citada a fonte.

\section{FICHA CATALOGRÁFICA}

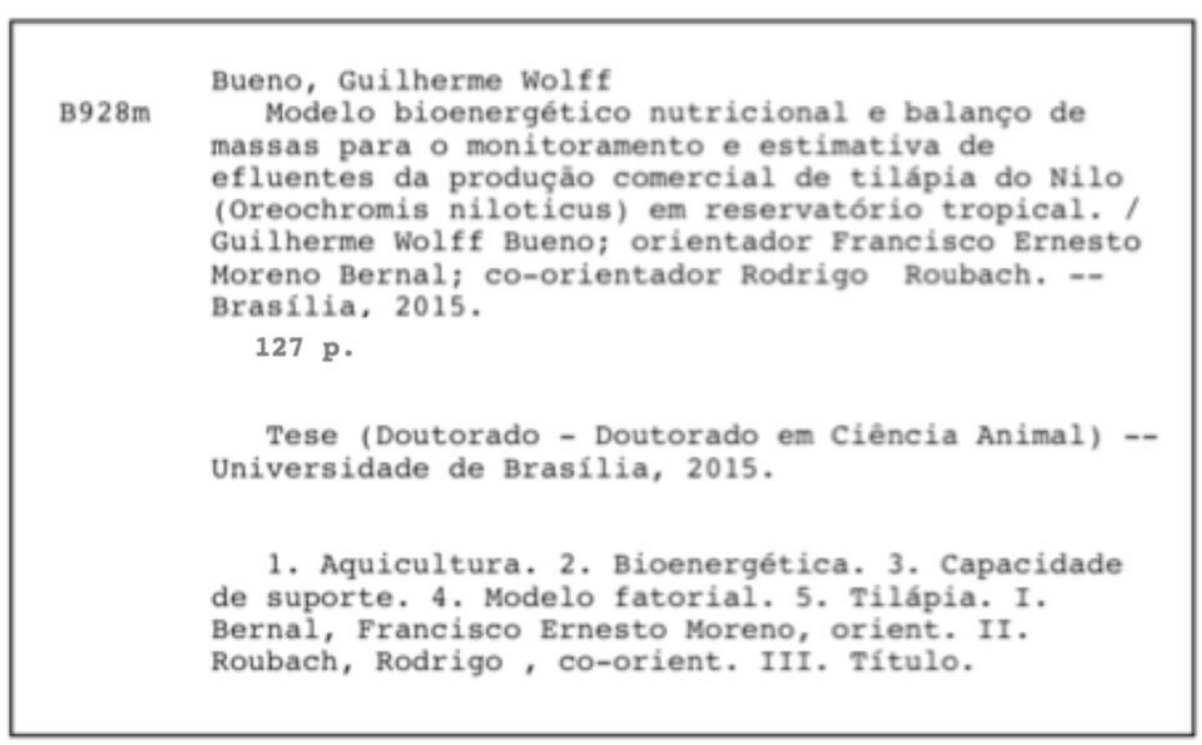


UNIVERSIDADE DE BRASILIA

FACULDADE DE AGRONOMIA E MEDICINA VETERINÁRIA

\begin{abstract}
MODELO BIOENERGÉTICO NUTRICIONAL E BALANÇO DE MASSAS PARA O MONITORAMENTO E ESTIMATIVA DE EFLUENTES DA PRODUÇÃO COMERCIAL

DE TILÁPIA DO NILO (Oreochromis niloticus) EM RESERVATÓRIO TROPICAL
\end{abstract}

\author{
GUILHERME WOLFF BUENO
}

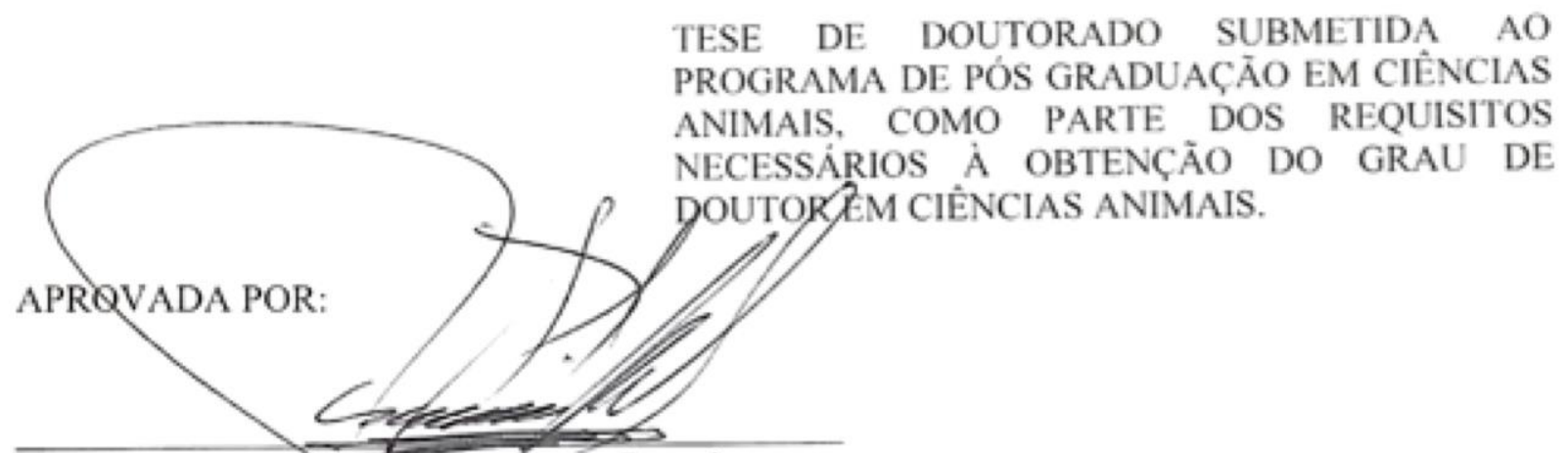

Prof. Ph.D. Francisce.trnesto Moreno Bernal.

Faculdade de Agronomià e Medicina Veterinária - Universidade de Brasília - UnB (ORIENTADOR)

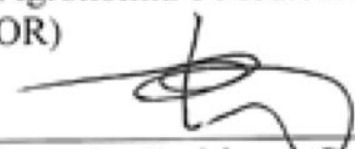

Prof. Ph.D. Alexandre Rodrigues aetano, Embrapa Recursos Genéticos e Biotecnologia Faculdade de Agronomia e Medicina Veterinária - Universidade de Brasilia - UnB (EXAMINADOR INTERXO)

Prof. Ph.D. Levy de Carvalho Gomes

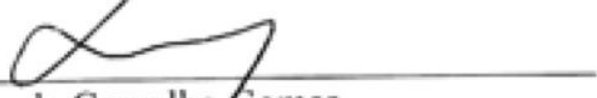

Departamento de Ecologia de Ecossistemas - Universidade de Vila Velha - UVV (EXAMINADOR EXTERNO)

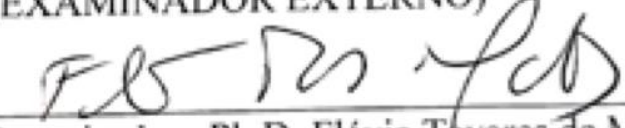

Pesquisadora Ph.D. Flávia Távares de Mattos

Empresa Brasileira de Pesquisa Agropecuária - Embrapa Pesca, Aquicultura e Sistemas Agrícolas (EXAMINADOR EXTERNO)

$$
\text { (f re Or. }
$$

Prof. Ph.D. Edgar de Alencar Teixeira

Departamento de Zootecnia - Universidade Federal de Minas Gerais - UFMG (EXAMINADOR EXTERNO)

BRASILIA/DF, 15 de junho de 2015. 
Não é o que você não sabe o que te machuca é o que você sabe que não é assim.

Mark Twain

Dedico ao meu pai que me direcionou para o caminho da aquicultura. 


\section{AGRADECIMENTOS}

Apesar da tese de doutorado ser um produto de responsabilidade de natureza individual, sem o apoio contínuo e incondicional da família e a contribuição e dedicação coletiva dos amigos e orientadores, certamente este trabalho não chegaria a bom termo. A todos eles registro minha mais profunda gratidão.

Ao Professor Francisco Ernesto Moreno Bernal, meu orientador, por acreditar e me apoiar neste desafio, pela disponibilidade e generosidade reveladas ao longo destes anos de trabalho, assim como as críticas, correcções e sugestões relevantes feitas durante a orientação.

Aos Professores Rodrigo Roubach e Dominique P. Bureau, meus co-orientadores, pela competência científica e orientação dada, me ensinando os verdadeiros valores científicos e humanos, bem como pela disponibilidade e amizade.

Ao Professor Antônio Ostrensky e Flávia Tavares de Matos pelos consenhos, críticas, correcções e sugestões relevantes ao meu trabalho.

Ao Mauro Yoshio Nakata da piscicultura Cristalina Ltda e sua equipe por acreditar e apoiar a realização deste experimento.

A equipe do Laboratório de Análises Avançadas e Biotecnologia da Universidade Federal de Lavras - UFLA: Renato Leal, Guilherme C. Carvalho, Bruno O. Mattos e Jeicielle Macedo pelo auxílio nas análises.

A equipe do Departamento de Ciência Animal da UnB e do Núcleo de Tecnologia em Piscicultura e Pecuária na Secretaria de Agricultura do Distrito Federal - SEAGRO/DF: Ângelo A. Costa, Lincoln N. Oliveira, Leonardo Carranzza e Thiago D. Trombeta pela amizade e auxílio durante o experimento.

A equipe do Laboratório de Nutrição de Peixes (FNRL) da Universidade de Guelph: Owen Skipper-Horton, Jorge Palma, Pato Saez, Jamie Hooft, Justin Chain, Guillaume Pfeuti, Chris Powell, Amanda Smith, Ping Wu, Yi Xinwen e Naor Fialho pela amizade e apoio durante o desenvolvimento desta pesquisa. 
Aos amigos da Organização das Nações Unidas para Agricultura e Alimentação - FAO, Agência Nacional de Águas e Ministério da Pesca e Aquicultura - MPA pelo apoio, críticas e sugestões.

Ao Conselho Nacional de Desenvolvimento Científico e Tecnológico - CNPq, a International Science and Technology Partnerships Canada (ISTP Canadá) pelos recursos financeiros e a Coordenação de Aperfeiçoamento de Pessoal de Nível Superior - Capes pelo apoio com bolsas de pesquisa.

A minha família, que sempre me apoia e incentiva com suas palavras e atos de estímulo em todos os momentos.

A família Vinhal Costa pelo carinho. A Luisa C. Vinhal Costa, minha companheira, pelo seu amor e apoio incondicional, base para eu alcançar este objetivo.

E principalmente a Deus por me dar condições e proporcionar o convívio com todos aqueles que contribuíram para a realização deste trabalho. 


\section{ÍNDICE}

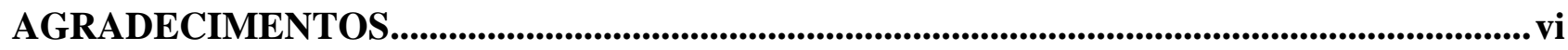

MODELO BIOENERGÉTICO NUTRICIONAL E BALANÇO DE MASSAS PARA O MONITORAMENTO E ESTIMATIVA DE EFLUENTES DA PRODUÇÃO COMERCIAL DE TILÁPIA DO NILO (Oreochromis niloticus) EM RESERVATÓRIO TROPICAL.............

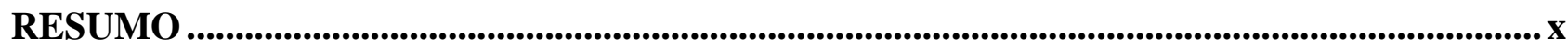

BIOENERGETIC NUTRITIONAL MODEL AND MASS BALANCE FOR ESTIMATE AND MONITORING THE EFFLUENT IN COMMERCIAL PRODUCTION OF NILE TILAPIA (Oreochromis niloticus) IN TROPICAL RESERVOIR ..........................................xii

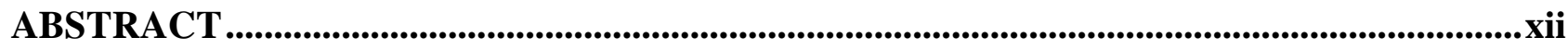

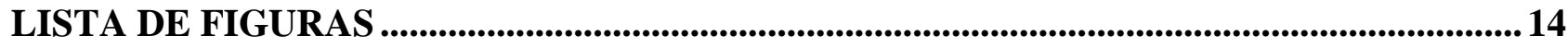

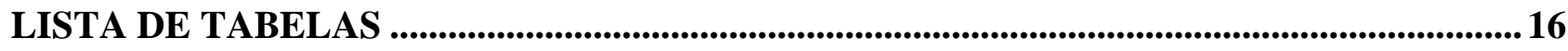

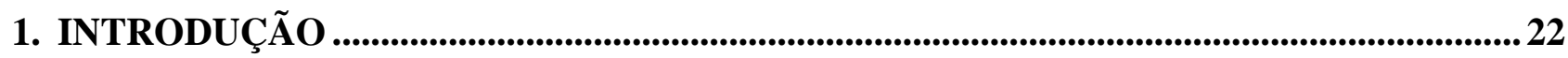

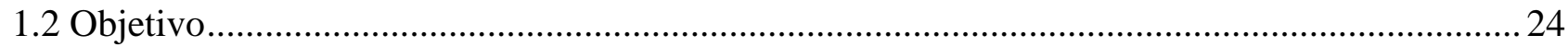

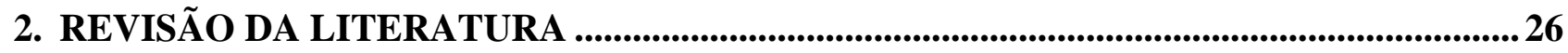

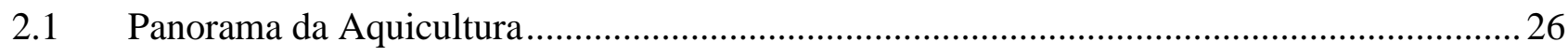

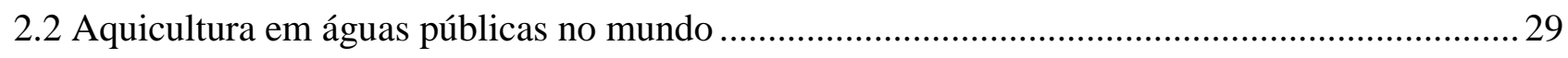

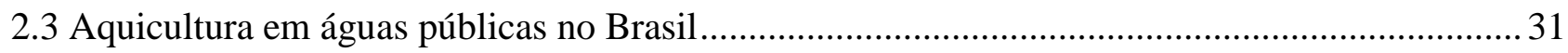

2.4 Impacto ambiental da aquicultura em reservatórios ............................................................. 34

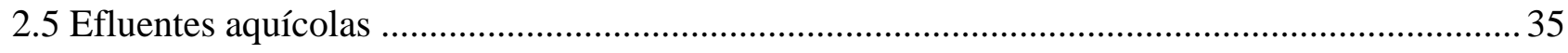

2.6 Estratégias para a estimativa e mitigação de efluentes aquícolas ............................................ 43

2.7 Modelos Matemáticos Aplicados à Produção Animal ................................................................ 44

2.7.1 Integração entre modelos de crescimento e exigência energética para peixes ........................ 48

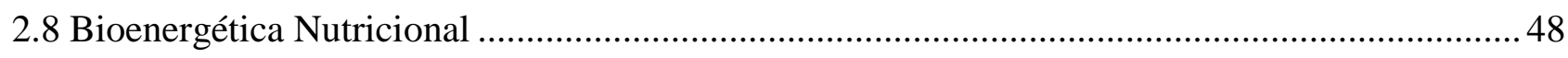

2.9 Vantagens e desvantagens do uso de modelos bioenergéticos ...............................................53

3. REFERÊNCIAS BIBLIOGRÁFICAS ................................................................................55

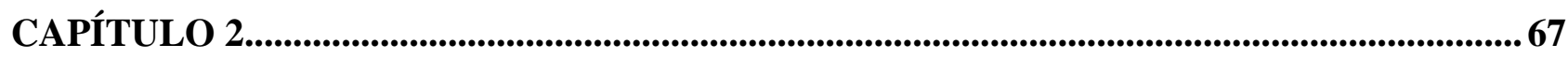

BIOENERGÉTICA NUTRICIONAL PARA A ESTIMATIVA DA EXIGÊNCIA ALIMENTAR E EFLUENTES DA PRODUÇÃO COMERCIAL DE TILÁPIA DO NILO (Oreochromis niloticus) EM RESERVATÓRIO NA REGIÃO SUDESTE DO BRASIL ..........67

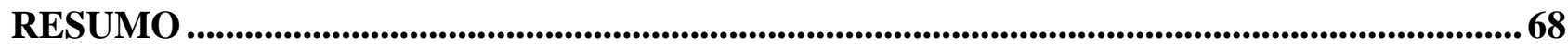




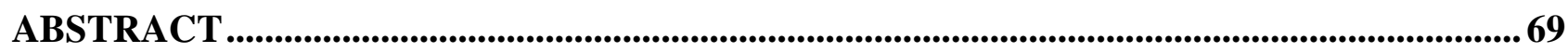

1. INTRODUÇÃO....................................................................................................70

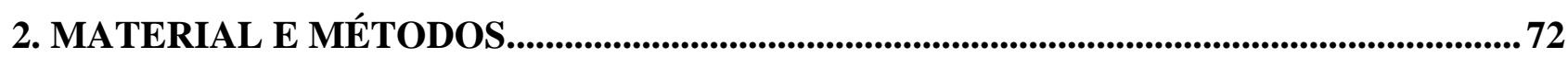

2.1. Local experimental e coleta de dados ..............................................................................72

2.2 Dieta e alimentação ............................................................................................................................... 73

2.3 Composição corporal e analises químicas ...........................................................................................74

2.4 Desempenho zootécnico e qualidade da água...................................................................................75

2.5 Aplicação dos diferentes modelos de crescimento corporal ...............................................................76

2.6. Ensaios de digestibilidade aparente (CDA) in vivo das rações comerciais ....................................77

2.7 Metabolismo Basal (HeE) e Incremento de Calor da Alimentação (HiE) ........................................78

2.7 Estimativa dos resíduos da piscicultura .............................................................................................79

2.8 Análises estatísticas.....................................................................................................................79

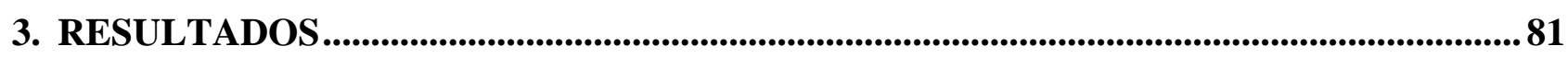

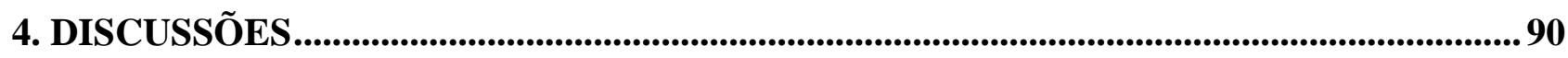

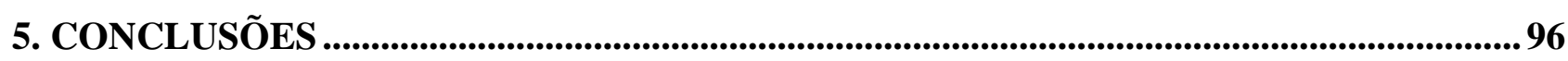

6. AGRADECIMENTOS..................................................................................................................97

7. REFÊRENCIAS BIBLIOGRÁFICAS............................................................................98

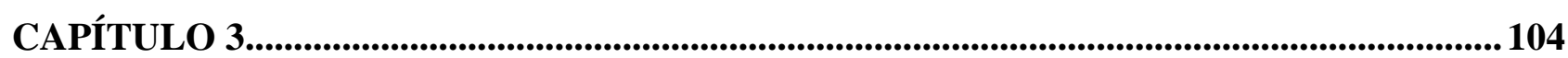

INTEGRAÇÃO DA MODELAGEM HIDRODINÂMICA COM O MODELO BIOENERGÉTICO NUTRICIONAL FISH-PRFEQ ${ }^{\circledR}$ PARA DETERMINAÇÃO DA CAPACIDADE DE SUPORTE PARA PRODUÇÃO DE TILÁPIA NO RESERVATÓRIO DE CHAVANTES, SP, BRASIL ..................................................................................................104

RESUMO ................................................................................................................................................ 105

ABSTRACT ............................................................................................................................... 106

1. INTRODUÇÃO.............................................................................................................. 107

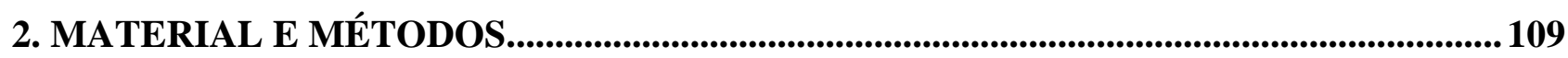

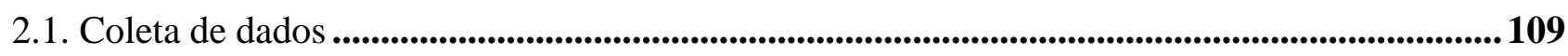

2.2 Cálculo da Capacidade de Suporte (CP) .................................................................................................110

2.3 Determinação da proporção de resíduos da aquicultura .................................................................... 111

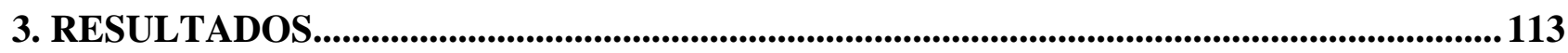

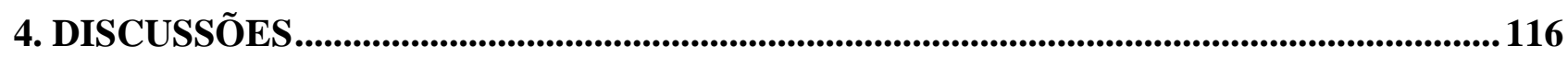

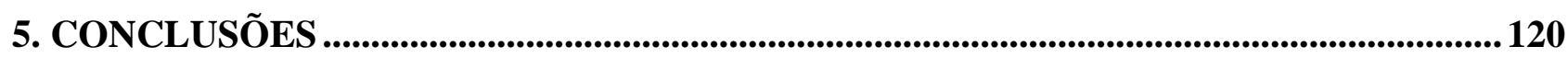

6. AGRADECIMENTOS.............................................................................................................. 121

7. REREFÊNCIAS BIBLIOGRÁFICAS .............................................................................122 


\title{
MODELO BIOENERGÉTICO NUTRICIONAL E BALANÇO DE MASSAS PARA O MONITORAMENTO E ESTIMATIVA DE EFLUENTES DA PRODUÇÃO COMERCIAL DE TILÁPIA DO NILO (Oreochromis niloticus) EM RESERVATÓRIO TROPICAL
}

\author{
MSC. Guilherme Wolff Bueno \\ PhD. Francisco Ernesto Moreno Bernal \\ PhD. Rodrigo Roubach \\ MSc. James Owen Skipper-Horton \\ PhD. Dominique P. Bureau
}

\begin{abstract}
RESUMO
A aquicultura no Brasil cresceu $56 \%$ nos últimos 12 anos e tem condições para continuar se desenvolvendo, considerando que o país possui cerca de 5,5 milhões de hectares de água, aproximadamente 208 reservatórios potenciais para a atividade e uma costa marítima de $8.000 \mathrm{~km}$. Projetos e solicitações para o uso de águas públicas para a aquicultura de 2008 a 2014 tiveram um acréscimo de $48 \%$. Portanto, torna-se necessária a utilização de ferramentas de monitoramento, observação e simulação do real impacto desta atividade nos recursos hídricos. Atualmente, para a emissão da outorga de água dos projetos aquícolas, os órgãos de fiscalização e regulação brasileiros utilizam como ferramenta a equação da capacidade de suporte dos recursos hídricos baseados no modelo hidrodinâmico de Dillon e Rigler (1974). Esta não considera fatores zootécnicos específicos e podem estar sub ou superestimando a situação real dos efluentes originários da produção de peixes em tanques-rede. Como consequência, a ausência de valores mensuráveis mais adequados, pode vir a comprometer a integridade dos recursos hídricos onde os sistemas produtivos são instalados. Dessa forma, é de extrema importância o uso de ferramentas que auxiliem na definição de limites corretos para o auxílio no planejamento e direcionamento da produção de peixes em águas tropicais, a fim de minimizar os impactos da aquicultura no ecossistema aquático. Neste contexto, o presente estudo tem como objetivo estimar cenários de lançamento de efluentes sólidos e dissolvidos (fósforo e nitrogênio) da produção comercial de tilápia do Nilo (Oreochromis niloticus) em reservatório tropical por meio do modelo fatorial bioenergético nutricional Fish-
\end{abstract}


PrFEQ $^{\circledR}$ e do cálculo do balanço de massas. Para tanto, houve a aplicação do modelo bioenergético nutricional em uma fazenda comercial de $O$. niloticus onde determinou-se a exigência alimentar e a estimativa de resíduos sólidos e dissolvidos para as fases de juvenil I (JVI: 30 a 100 g), juvenil II (JVII: 100 a 500 g) e peso final de mercado (PM: > $500 \mathrm{~g}$ ). Além da aplicação das equações de predição do crescimento e da validação de novos exponenciais de crescimento térmico (ECT) para esta espécie realizou-se a quantificação dos parâmetros de desempenho zootécnico e análises de qualidade da água. Posteriormente, o modelo bioenergético nutricional Fish-PrFEQ ${ }^{\circledR}$ foi integrado ao modelo hidrodinâmico de Dillon e Riegler (1974) para simulações de cenários de lançamento de resíduos a partir do uso de rações comerciais brasileiras com diferentes percentuais de fósforo total $(0,8 ; 1,5$ e $2,4 \%)$ e, em seguida realizou-se a determinação da capacidade de suporte para produção de pescados no reservatório. Com a obtenção de todos esses dados, foi possível apresentar, a aplicação prática para a predição de resíduos do cultivo de tilápias em lagos e reservatórios no Brasil, bem como, demostrar uma abordagem para auxiliar no desenvolvimento sustentável da aquicultura.

Palavras chave: balanço de massa, bioenergética, capacidade suporte, nutrição de tilápias, resíduos aquícolas, sistema de observação. 
BIOENERGETIC NUTRITIONAL MODEL AND MASS BALANCE FOR ESTIMATE AND MONITORING THE EFFLUENT IN COMMERCIAL PRODUCTION OF NILE TILAPIA

\title{
(Oreochromis niloticus) IN TROPICAL RESERVOIR
}

\author{
MSc. Guilherme Wolff Bueno \\ $\mathrm{PhD}$. Francisco Ernesto Moreno Bernal \\ $\mathrm{PhD}$. Rodrigo Roubach \\ MSc. James Owen Skipper-Horton \\ PhD. Dominique P. Bureau
}

\begin{abstract}
Aquaculture in Brazil increased up to $56 \%$ in the last 12 years, and has adequate conditions to maintain its growth, considering that the country has 5.5 million hectares of water, approximately 208 potential reservoirs for the activity and a coastline of $8,000 \mathrm{~km}$. Projects and requests for the use of public waters for fish culture increased by $48 \%$ during the period from 2008 to 2014 . Therefore, it is necessary the use of monitoring tools, observation and simulation of the real impact of this activity in the water bodies. Currently, considering the issue of water granting for aquaculture projects, regulatory agencies and environmental institutions use as a tool the hydrodynamic model from Dillon and Rigler (1974), for estimating the water resources carrying capacity. This does not consider specific husbandry factors and may be under or overestimating the actual situation of waste originated from fish cage production. As a result, the absence of more appropriate measurable values can compromise the integrity of water resources where production systems are installed. Thus, it is extremely important to use tools that assist in setting correct limits for assistance in planning and directing the fish production in tropical waters in order to minimize the impacts of aquaculture on the aquatic ecosystem. In this context, this study aims to estimate the discharge of solid waste scenarios and dissolved phosphorus and nitrogen from Nile tilapia (Oreochromis niloticus) under commercial production in tropical reservoir through the bioenergetic nutritional factor model Fish-PrFEQ ${ }^{\circledR}$ and the calculation of the mass balance. Therefore, in Chapter 2, it is presented the application of nutritional bioenergetic model in commercial farm of $O$. niloticus, which was determined by the feed requeriment and estimation of solid and dissolved waste for the following fish growth phases: juvenile I (JVI: 30-100 g), juvenile II (JVII: 100 to 500 g) and final market weight (MW>500 g). In addition, for the application of growth prediction
\end{abstract}


equations and validation of new exponential thermal growth (ECT) for this species, there was the quantification of live performance and water quality parameters. In Chapter 3, it was integrated the nutritional bioenergetic model Fish-PrFEQ ${ }^{\circledR}$ with the hydrodynamic model Dillon Riegler (1974) for simulations of waste release scenarios from the use of diets with different percentages of total phosphorus $(0.8,1.5$ to $2.4 \%)$. Then, the carrying capacity for fish production in reservoir was determined. In addition, a practical application for the prediction of tilapia production waste in lakes and reservoirs in Brazil was presented, as well as, demonstrated this approach to be used in the sustainable development of aquaculture.

Keyword: bioenergetics, carrying capacity, effluent, factoral model, tilapia. 


\section{LISTA DE FIGURAS}

Figura 1. Distribuição de empreendimentos aquícolas registrados no Ministério da Pesca e Aquicultura de acordo com a espécie de cultivo.

Figura 2. Espacialização dos cultivos de tilápia em Águas da União com suas respectivas produtividade calculadas a partir dos dados cadastrados no MPA/SINAU. 28

Figura 3. Modelo representativo de parque aquícola, área de produção e área aquícola em

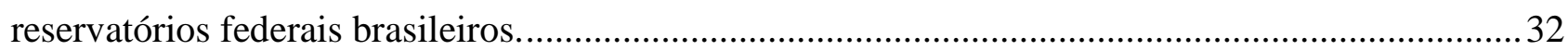

Figura 4. Representação da situação dos parques aquícolas continentais em águas da União......... 34

Figura 5. Fluxos anuais de nutrientes e componentes para a criação do salmão norueguês............. 37

Figura 6. Estimativa de resíduos sólidos, não digeríveis (VI) e resíduos dissolvidos, excreção branquial e urinária (V2) para produção de $1000 \mathrm{~kg}$ de O.niloticus em sistema fechado. 38

Figura 7. Ilustração do princípio básico de modelos de balanço de massa, baseado no modelo de Vollenweider e Dillon e Rigler.

Figura 8. Representação do Modelo Lakeweb, ilustrando os nove grupos de organismos e as sete variáveis envolvidas (Concentração total de fósforo, cor da água, pH, profundidade média, profundidade máxima, a área do reservatório e temperatura).

Figura 9. Desenho esquemático do mesocosmo com os balanços de massa de nitrogênio e de fósforo 42

Figura 10. A relação entre a produção e o consumo de alimentos, ilustrando pontos-chave relacionados com a limitação de energia. .49

Figura 11. Fluxograma da estrutura de partição de energia no modelo bioenergético. 50

Figura 12. Fluxo do fósforo na produção de peixes. 52

Figura 13. Mapa identificando o estado de São Paulo, rio Paranapanema 72

Figura 14. Tanques-rede comerciais utilizados durante o experimento. 73 
Figura 15. A) Curva de crescimento corporal da O. niloticus observada e predita pelos modelos: taxa de crescimento específico (TCE), coeficiente crescimento diário (CCD) e crescimento Linear. $B$ ) Curva de crescimento corporal predita pelos modelos de coeficiente de crescimento térmico (TGC - tradicional) e (TGC revisado).

Figura 16. Simulação de curvas de crescimento corporal para diferentes condições de temperatura da água por meio do modelo bioenergético Fish-PrFEQ®. 85

Figura 17. Relações alométricas e isométricas da massa corporal da $O$. niloticus em relação a deposição de proteína, lipídios, cinzas e energia bruta da tilápia cultivada em condições tropicais. 86 Figura 18. Composição corporal da O. niloticus (MS - matéria seca, lipídio, proteína bruta, $\mathrm{P}$ fósforo total, $\mathrm{N}$ - nitrogênio) para diferentes categorias de peso. .87

Figura 19. Taxa de arraçoamento observada, estimada pelo modelo bioenergético. 88 


\section{LISTA DE TABELAS}

Tabela 1. Estimativas do intervalo de percentagem de nitrogênio recuperado por peixes e liberada para o meio ambiente em vários sistemas de produção aquícola ${ }^{1}$. 36

Tabela 2. Saídas de resíduos sólido e dissolvidos (N e P) (kg por tonelada de peixe produzido) de truta arco-íris com peso inicial de $100 \mathrm{~g}$ para final de $1.000 \mathrm{~g}$ durante 2003 e 2004, utilizando-se cinco cenários de resíduos da alimentação.

Tabela 3. Média das variáveis da água coletada na piscicultura Cristalina durante o ciclo de produção.

Tabela 4. Composição centesimal (\%), nutrientes digestíveis e energia das dietas comerciais utilizadas em três fases de produção na fazenda Cristalina (juvenil I (JVI), juvenil II (JVII) e peso de mercado $(\mathrm{PM}))$.

Tabela 5. Parâmetros zootécnicos da tilápia em tanques-rede no reservatório de Chavantes - SP para as fases de juvenil I (JVI), juvenil II (JVII) e peso de mercado (PM) durante o ciclo de produção na fazenda Cristalina. 82

Tabela 6. Histórico dos parâmetros zootécnicos da tilápia em tanques-rede no reservatório de Chavantes, $\operatorname{SP}(n=30)$.

Tabela 7. Coeficientes e soma residual (RSS) dos modelos: taxa de crescimento específico (TCE), coeficiente de crescimento diário (CCD), linear e coeficiente de crescimento térmico (TGC) ajustado para $O$. niloticus produzidas em tanques-rede com temperatura média de $26^{\circ} \mathrm{C}$.

Tabela 8. Composição química da carcaça da tilápia do Nilo (Oreochromis niloticus). 85

Tabela 9. Coeficientes das equações para a estimativa da composição química corporal da tilápia cultivada em tanques-rede em condições tropicais.

Tabela 10. Energia, oxigênio e modelagem da expectativa da eficiência e da conversão alimentar da tilápia do Nilo cultivada em tanques-rede sob condições comerciais no Brasil. 88

Tabela 11. Estimativa de efluentes da produção comercial de tilápia (Oreochromis niloticus) em tanques-rede simulados para diferentes categorias de peso durante o ciclo de produção. 
Tabela 12. Conteúdo nutricional calculado para dietas comerciais recomendadas para tilápia do Nilo obtido na indústria aquícola brasileira $(\mathrm{N}=152 *)$.

Tabela 13. Estimativa de resíduos da produção de tilápia do Nilo (Oreochromis niloticus) em tanques-rede alimentadas com dietas contendo diferentes níveis de fósforo calculado pelo modelo nutricional bioenergético. 114

Tabela 14. Aplicação do modelo bioenergético integrado com modelo hidrodinâmico para a determinação da capacidade de suporte para produção de pescados no reservatório de Chavantes, São Paulo, Brasil 


\section{LISTA DE SÍMBOLOS E ABREVIAÇÕES}

\section{Abreviações Descrição}

[P] Concentração de fósforo na água do reservatório $\left(\mathrm{mg} / \mathrm{m}^{3}\right)$

A Área do reservatório $\left(\mathrm{m}^{2}\right)$

B Produção autorizável de peixes $\left(\mathrm{t}_{\mathrm{ano}}{ }^{-1}\right)$

BF Biomassa final

BT Biomassa total

C Energia da alimentação/energia ingerida

CCD Coeficiente de crescimento diário

CCE Coeficiente de crescimento específico

CDA Coeficiente de digestibilidade aparente

CE Condutividade elétrica $\left(\mu \mathrm{S} . \mathrm{cm}^{-1}\right)$

E Excreção endógena

EA Eficiência alimentar

EAE Eficiência alimentar esperada

EB Energia bruta

ED Energia digestível

EDF Energia digestível fornecida $\left(\mathrm{MJ} \mathrm{kg}^{-1}\right)$

EDreq Requisito de energia digestível $\left(\mathrm{MJ} \mathrm{kg}^{-1}\right)$

Edt Exigência dietética

EL Energia líquida

EM Energia metabolizável

ENN Extrativo não nitrogenado

ERE Eficiência na retenção de energia

FE Fezes excretadas

GM Gasto metabólico

GP Ganho de peso vivo

GPD Ganho de peso diário 


\begin{tabular}{|c|c|}
\hline $\mathrm{G}_{\mathrm{R}}$ & Crescimento relativo \\
\hline $\mathrm{G}_{\mathrm{RR}}$ & Taxa de crescimento relativo \\
\hline $\mathrm{HeE}$ & Metabolismo basal $\left(\mathrm{MJ} \mathrm{kg}^{-1}\right)$ \\
\hline HEf & Produção de calor do animal em jejum \\
\hline $\mathrm{HiE}$ & Incremento de calor da alimentação $\left(\mathrm{MJ} \mathrm{kg}^{-1}\right)$ \\
\hline JVI & Fase de peso da tilápia de 30 a 100g (juvenil I) \\
\hline JVII & Fase de peso da tilápia de 100 a 300g (juvenil II) \\
\hline $\mathrm{L}$ & Lipídio \\
\hline LD & Lipídio digestível \\
\hline $\mathrm{La}$ & Carga anual de fósforo no reservatório $\left(\mathrm{mg} / \mathrm{m}^{2}\right.$.ano) \\
\hline $\ln P f$ & Logarítimo do peso final \\
\hline $\ln P i$ & Logarítimo do peso inicial \\
\hline $\mathrm{Lr}$ & Carga de fósforo autorizável em todo reservatório $\left(\mathrm{mg} / \mathrm{m}^{2}\right.$.ano) \\
\hline MO & Mortalidade \\
\hline MS & Matéria seca \\
\hline MSD & Matéria seca digestível \\
\hline $\mathrm{N}$ & Nitrogênio (proteína bruta/6,25) \\
\hline $\mathrm{O}_{2} \mathrm{D}$ & Oxigênio dissolvido $\left(\mathrm{mg} \mathrm{L}^{-1}\right)$ \\
\hline $\mathrm{P}$ & Fósforo \\
\hline PDi & Fósforo digestível \\
\hline $\mathrm{PB}$ & Proteína bruta \\
\hline PD & Proteína digestível \\
\hline $\mathrm{Pd}$ & Produção \\
\hline $\mathrm{P} i$ & Peso corporal no início do período \\
\hline $\mathrm{P} f$ & Peso corporal no final do período \\
\hline Pf.med & Profundidade média do reservatório na cota mínima (m) \\
\hline $\mathrm{pH}$ & Potencial hidrogênionico \\
\hline PM & Fase de peso da tilápia $>500 \mathrm{~g}$ (peso de mercado) \\
\hline PRA & Resíduos da perda de ração aparente durante a alimentação \\
\hline Qfi & Fator de ajuste para entrada de alimentação \\
\hline Qmlt & Vazão média do afluente $\left(\mathrm{m}^{3} \mathrm{~s}^{-1}\right)$ \\
\hline Qox & Coeficiente oxicalorífico (13.64 Kj.g ${ }^{-1}$ oxigênio) \\
\hline QRT & Quantidade de ração teórica \\
\hline
\end{tabular}


Qtd Quantidade (unidade)

R Respiração

RC Retenção para o crescimento

RD Resíduos dissolvidos

$\mathrm{RE} \quad$ Energia retida $\left(\mathrm{MJ} \mathrm{kg}^{-1}\right)$

REB Retenção de energia bruta

RF Retenção de fósforo

RI Ração ingerida (\%peso)

RO Requisito de $\mathrm{O}_{2}\left(\mathrm{~g} \mathrm{~kg}^{-1}\right.$ sob o ganho de peso)

$\mathrm{Rp} \quad$ Coeficiente de retenção de fósforo no reservatório

$R P \quad$ Retenção de proteína

RS Resíduos sólidos

RSS Soma dos quadrados dos resíduos

RT Resíduos totais (RS+RD+PRA)

TCE Taxa de conversão alimentar esperada

TEP Taxa de eficiência protéica

TGC Coeficiente de crescimento térmico

$\Delta \operatorname{Tr} \quad$ Tempo de residência da água no reservatório (dias)

TR Transparência da água (m)

U Excreção urinária

UE Energia urinária

$\mathrm{V}_{90} \quad$ Volume da água do reservatório na cota com $90 \%$ de permanência

Z Excreção branquial

$z \quad$ Profundidade média do reservatório (m)

ZE Energia branquial

$\rho \quad$ Taxa de renovação da água do reservatório $\left(\operatorname{anos}^{-1}\right)$ 
CAPÍTULO 1

INTRODUÇÃO E REVISÃO DE LITERATURA 


\section{INTRODUÇÃO}

A crescente preocupação mundial visando uma produção de alimentos ambientalmente sustentável exige formas modernas de pensamento e, principalmente, de atuação. Essa tendência é ainda mais evidente nos casos em que a produção envolve diretamente o ambiente aquático continental, principalmente tratado-se do recurso água, o qual é limitado e finito (Macedo e Sipaúba-Tavares, 2010).

Em contra ponto, ressaltando a teoria Malthusiana, atualmente o planeta detém aproximadamente uma população de 870 milhões de subnutridos e estima-se que em menos de quarenta anos (2050) este valor chegue a nove bilhões (FAO, 2013) as quais estarão vivendo na zona de probreza absoluta. Novamente, tem-se o difícil desafio imposto ao campo, de produzir alimento de forma sustentável com maior eficiência e menor impacto ambiental, meta para uma ciência animal moderna e racional.

Diante deste cenário, a aquicultura passou por um intenso processo de desenvolvimento nos últimos anos, sendo que seu crescimento médio mundial, na última década foi cinco vezes maior, quando comparado a outras atividades do setor, tais como a bovinocultura, a suinocultura e a avicultura (FAO, 2013). No Brasil, a atividade tem se consolidado cada vez mais, em decorrência dos recursos hídricos disponíveis, clima favorável, mão de obra relativamente pouco onerosa e crescente mercado interno (Garcia et al. 2013). Nesta década, o país chegou ao sexto lugar como produtor de tilápia cultivada no mundo, o que representa aproximadamente $43 \%$ da produção total de pescados em aquicultura de água doce no país (MPA, 2013).

Segundo o relatório "Fish to 2030: Prospects for Fisheries and Aquaculture” - uma colaboração entre o Banco Mundial, Organização para Alimentação e Agricultura das Nações Unidas (FAO) e do Instituto Internacional Food Policy Research, cerca de 62\% dos peixes para o consumo humano virá da aquicultura (produção em cativeiro) até 2030, sendo que a produção de 
tilápia, carpa e bagre formam a base das principais espécies cultivadas. A produção global de tilápia esperada será quase o dobro, de 4,3 milhões de toneladas para 7,3 milhões de toneladas por ano.

A Organização das Nações Unidas para Agricultura e Alimentação (FAO, 2012) ressalta que o aumento do consumo mundial de pescados para 2030 passará de $16 \mathrm{~kg} / \mathrm{habitantes/ano} \mathrm{para}$ $22,5 \mathrm{~kg} /$ habitantes/ano. Isso representará um aumento no consumo de mais de 100 milhões de toneladas por ano. Portanto, o crescimento da indústria só poderá ser suportado pela intensificação da produção e aumento das áreas de produção de forma planejada e ordenada.

Visando atender esta demanda, o Ministério da Pesca e Aquicultura do Brasil (MPA) lançou em 2008 o Plano Mais Pesca e Aquicultura, o qual prevê um incremento produtivo nos 208 reservatórios e lagos potenciais para o desenvolvimento da atividade no país. Atualmente, já existem 42 parques aquícolas instalados em seis reservatórios e o MPA prevê a implantação de mais 39 parques aquícolas continentais para os próximos anos (Plano Plurianual 2013/2015). Uma vez instalados esses empreendimentos, será de extrema importância que existam ferramentas de monitoramento e controle dos resíduos gerados pela atividade.

Neste contexto, em 13 de Maio de 2011, foi publicada a Resolução do Conselho Nacional de Meio Ambiente - CONAMA N430/2011, que dispõe sobre as condições e padrões de lançamento de efluentes, que complementa e altera a Resolução n³57, de 17 de março de 2005. No documento, é informado no artigo $7^{\circ}$, que ao órgão ambiental competente poderá exigir, nos processos de licenciamento ou de sua renovação, a apresentação de estudo de capacidade de suporte do corpo receptor, ou seja, deve quantificar os resíduos sólidos do cultivo de peixes em águas brasileiras.

Atualmente, os órgãos ambientais não definiram qual seria a ferramenta ou modelo matemático ideal para quantificação de cargas do cultivo de peixes, além de não possuírem subsídios técnicos para avaliar tal parâmetro. Esse fato traz prejuízos para o setor, que necessita de tais estudos e valores para obter sua licença ambiental, o seguro aquícola, o crédito bancário e todas as autorizações legais preconizadas no Decreto 4.895/2013 e na Resolução $n^{\circ} 413$, de 26 de julho de 2009. Neste cenário, o empreendedor, cada vez mais, tem desistido da atividade ou praticado de forma irregular.

Portanto, os resíduos sólidos lançados pela aquicultura tornam-se uma preocupação para o desenvolvimento sustentável da atividade. Assim, vários pesquisadores (Cho e Bureau, 1998; Lupatsch e Kissil, 1998; Yi, 1999; Bureau e Hua, 2010; Azevedo et al., 2011) têm demonstrado que os produtos residuais provenientes de diferentes tipos de cultivos aquáticos podem ser estimados por meio de modelos matemáticos factoriais. 
Esta ferramenta tem sido aplicada por empresas e órgãos de fiscalização em diversos países para predição do crescimento corporal, das necessidades de alimentação, para a diminuição de custo com rações e para a determinação dos efluentes dos cultivos de diversas espécies de peixes e camarões (Schneider et al., 2004; Zhou et al., 2005; Sara et al., 2009; Bureau and Hua, 2010; Glencross et al., 2011; Trungetal., 2011; Bouwman et al., 2013).

\subsection{Objetivo}

Estimar cenários de lançamento de efluentes sólidos e dissolvidos (fósforo e nitrogênio) de uma fazenda comercial de tilápia do Nilo (Oreochromis niloticus) por meio do modelo bioenergético nutricional Fish-PrFEQ ${ }^{\circledR}$ e do cálculo do balanço de massas para integrar ao modelo hidrodinâmico Dillon e Riegler (1974) e determinar a capacidade de suporte para produção de pescados em um reservatório tropical.

\subsubsection{Objetivos Específicos}

- Acompanhar a trajetória de crescimento e os índices zootécnicos do cultivo comercial de tilápias em tanques-rede ao longo do ciclo de produção (nas fases: juvenil (JVI): 30 a 100g, juvenil II (JVII): 100 a $500 \mathrm{~g}$ e peso final de mercado (PM): >500g) em uma fazenda comercial localizada no reservatório Chavantes, estado de São Paulo, Brasil;

- Análisar a composição bromatológica e a digestibilidade das rações comerciais utilizadas nas três fases de produção (JVI, JVII e PM) pela fazenda comercial por meio de ensaios de digestibilidade in vivo sob condições controladas de temperatura;

- Aplicar equações de regressão do crescimento corporal e deposição de nutrientes na carcaça ao longo do cultivo;

- Desenvolver expoentes e coeficientes de crescimento térmico para a tilápia do Nilo cultivada sob condições comerciais em reservatório tropical;

- Aplicar a bioenergética fatorial nutricional para determinar o requisito de alimentação (estimado e observado) e estimar os resíduos sólidos e dissolvidos (nitrogênio e fósforo) de todo o ciclo de produção;

- Aplicar meta-análise de dados das composições de rações comerciais comumente utilizadas na indústria brasileira para tilápia (152 dietas comerciais); 
- Integrar o modelo bioenergético nutricional (Fish-PrFEQ ${ }^{\circledR}$ ) com o modelo hidrodinâmico (Dillon e Riegler, 1974) para simulações de cenários de lançamento de resíduos a partir do uso de rações com diferentes percentuais de fósforo total $(0,8 ; 1,5$ e $2,4 \%)$;

- Simular cenários de capacidade de suporte para produção de tilápias no reservatório de Chavantes, rio Paranapanema, São Paulo. 


\section{REVISÃO DA LITERATURA}

\subsection{Panorama da Aquicultura}

Ao compararmos os diversos segmentos da produção animal, a aquicultura destaca-se em nível mundial com 15,7\% de crescimento médio entre 2007 e 2010, enquanto os segmentos de bovinos, frangos e suínos obtiveram taxas de crescimento de $-8,6 \%, 9,2 \%$ e $12,9 \%$, respectivamente (FAO, 2013). A produção aquícola mundial aumentou substancialmente, de menos de um milhão de toneladas de produção anual em 1950, para os 55,7 milhões de toneladas reportados para 2009 (FAO, 2013).

Por outro lado, a pesca extrativa tem apresentado tendências de queda ou estagnação com a taxa de crescimento em $0,5 \%$ desde a década de 90 . Com a exaustão do setor pesqueiro extrativo nas últimas décadas, o rápido crescimento da aquicultura tem sido a única forma de acompanhar a crescente demanda do consumo de pescado no contexto mundial.

Segundo o Instituto Brasileiro de Geografia e Estatística (IBGE, 2013), a aquicultura no Brasil é um negócio de $\mathrm{R} \$ 3$ bilhões, envolve um milhão de empregos diretos e indiretos, além de uma produção de ração de aproximadamente 900 milhões por ano. Este agronegócio produziu no ano de 2013 em torno de 476 mil toneladas, o que representa uma taxa de crescimento de $56 \%$ nos últimos 12 anos. Assim, o setor aquícola está se consolidando como a principal fonte da produção de pescado, tendência evidenciada em vários outros países do mundo como China, Noruega, Chile (FAO, 2014).

Na Figura 1, verifica-se geograficamente a disposição da produção das principais espécies aquícolas brasileiras, onde se destacam a produção de camarão marinho (Litopennaeus vannamei) com aproximadamente 69 mil toneladas/ano, os peixes de água doce como a tilápia (Oreochromis niloticus) - espécie mais produzida em 2013, representando $43 \%$ do total de pescado - o tambaqui 
(Colossoma macropomum) com 22,6\% e o tambacu (Colossoma macropomum (fêmea) + Piaractus mesopotamicus (macho)) com 15,4\% (IBGE, 2013).

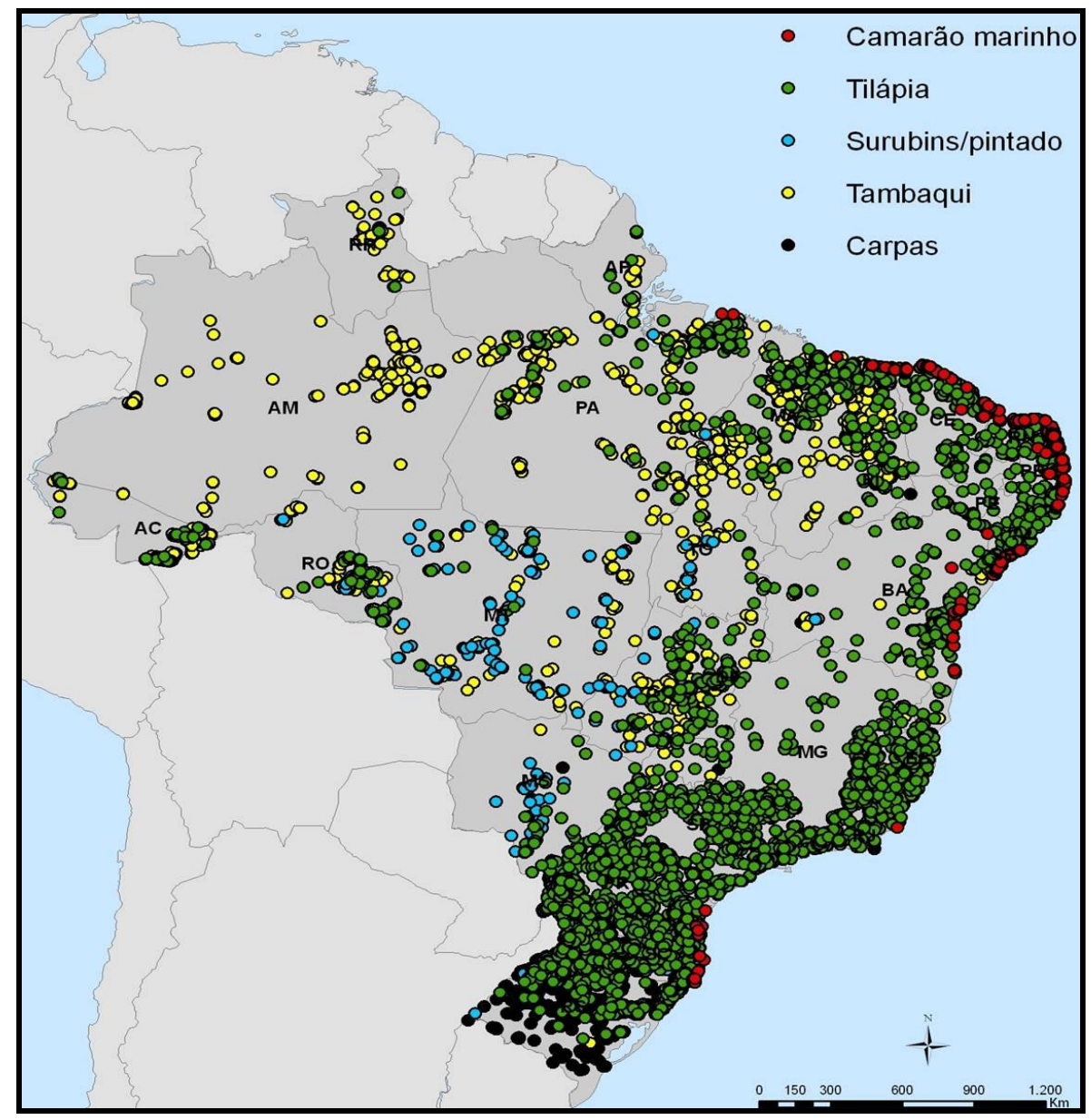

Figura 1. Distribuição de empreendimentos aquícolas registrados no Ministério da Pesca e Aquicultura de acordo com a espécie de cultivo. Fonte: MPA (2014).

Ainda, outras espécies apresentam potencial para serem produzidas em grande escala, principalmente devido à grande aceitação de sua carne pelo consumidor, como o pirarucu (Arapaima gigas) e os surubins: pintado (Pseudoplatystoma corruscans) e cachara (Pseudoplatystoma fasciatum). Entretanto, ainda estão em processo de desenvolvimento de pesquisas e de todo o processo tecnológico que permita alavancar a produção em escala comercial e profissional, semelhante à tilápia atualmente. 


\subsubsection{A produção Comercial de tilápias em águas da União}

Dentre aproximadamente 40 espécies de peixes de água doce potenciais de cultivo no Brasil (Godinho, 2007), a tilápia do Nilo (Oreochromis niloticus) é a mais estudada e produzida. Segundo o IBGE (2013), sua produção no país corresponde a 43\% e está em torno de 169 mil toneladas/ano. Espécie criada em diferentes latitudes, em diversos sistemas de produção, abrangendo distintos níveis tecnológicos (Neves et al., 2009). Tem como características a rusticidade ao manejo, carne saborosa, eficiência zootécnica e excelente aceitação pelo mercado consumidor (Stickney, 1997; Faria et al., 2002; Boscolo et al., 2005) tornado-se a espécie que melhor se adaptou ao sistema de cultivo em tanques-rede, os quais detém diversos níveis de intensificação (produtividade $/ \mathrm{m}^{3}$ ) em lagos e reservatórios no país (Figura 2).

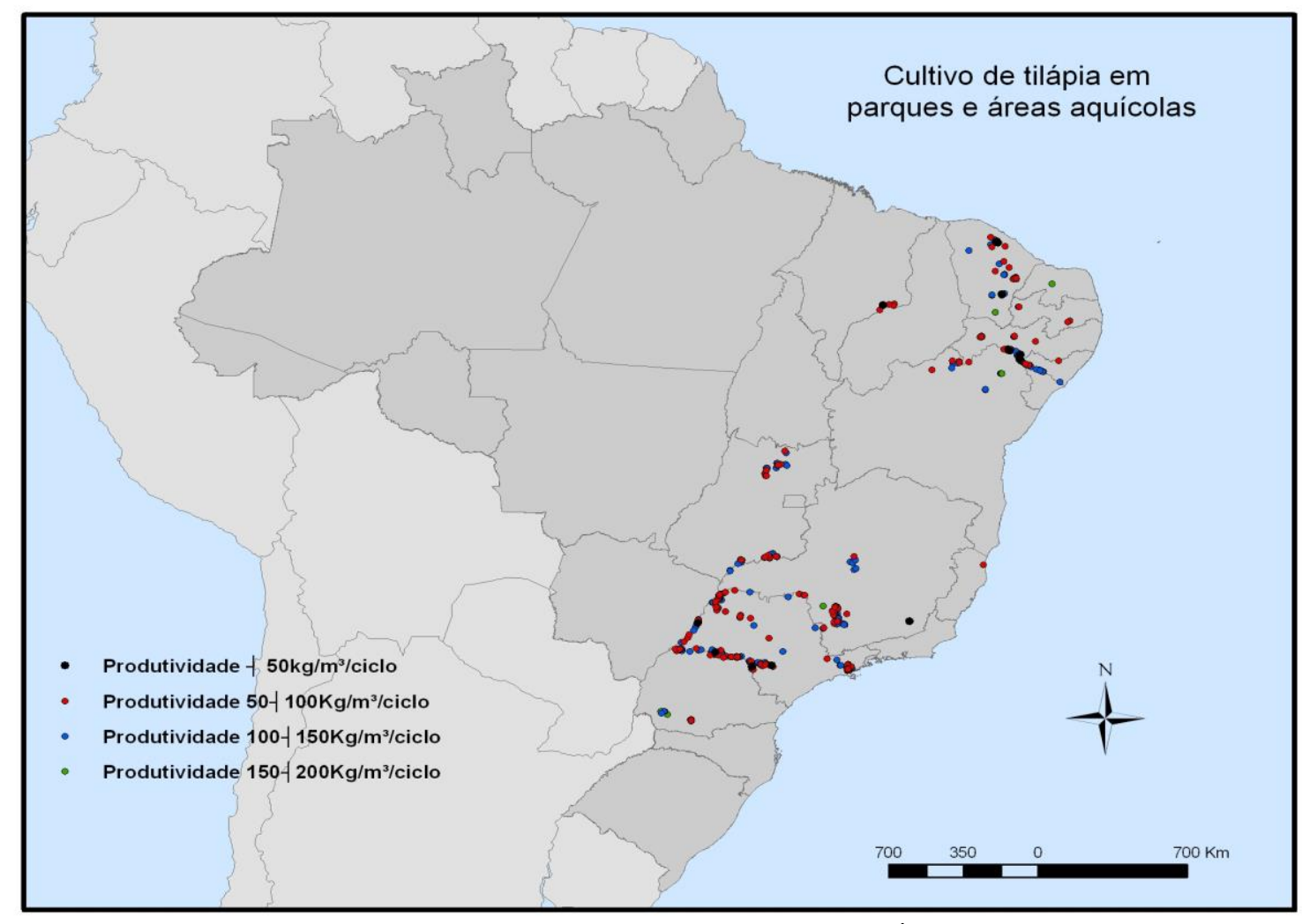

Figura 2. Espacialização dos cultivos de tilápia em Águas da União com suas respectivas produtividade calculadas a partir dos dados cadastrados no MPA/SINAU.

Garcia et al. (2013) ressaltam que no Brasil, os produtores têm optado em cultivar $O$. niloticus em gaiolas ou tanques-rede com densidades entre 80 e $120 \mathrm{~kg} / \mathrm{m}^{3}$, e estudos econômicos têm demonstrado que o custo de produção deste sistema é elevado (Ayroza et al., 2011) além do risco devido à burocracia para a legalização dos empreendimentos e fatores ambientais como 
períodos de estiagem dos reservatórios, inversão térmica da água, eutrofização, sanidade, entre outros.

Isto tem gerando uma pressão para que haja o correto planejamento, ordenamento e monitoramento da atividade para maior segurança e possibilidade de investimento, com destaque na determinação da capacidade de suporte para a produção de pescados e controle da integridade do ambiente aquático.

\subsection{Aquicultura em águas públicas no mundo}

Desde o início da civilização moderna, os seres humanos vêm alterando e transformando pântanos, lagos, lagoas, corredeiras e rios a fim de adaptá-los às suas próprias necessidades. Pesquisas realizadas no Oriente Médio e na Ásia indicam que os reservatórios são engenharias que estão sendo construídas há pelo menos 5.000 anos (Petts, 1984). O objetivo destas obras tem sido geralmente a descarga de águas residuais, a navegação, a pesca ( $\mathrm{Su}$ et al. 2010), mas, principalmente, controle de enchentes, irrigação e abastecimento de água doméstica (Petts, 1984).

Nos últimos séculos, as intervenções nos ambientes aquáticos têm sido particularmente dramáticas, especialmente aquelas causadas pelo aumento da população e industrialização (Barton e Fløysand, 2010) e pela necessidade de geração de energia hidrelétrica (Agostinho et al., 2007). Atualmente, a taxa de construção de reservatórios está perto de um por dia, com cerca de 50.000 grandes barragens construídas ao redor do mundo que, em conjunto, corresponde a mais de 6.500 $\mathrm{km}^{3}$ de água, ocupando uma área equivalente ao território da França (Nilsson, 2009).

De acordo com Cowx et al. (1998), a produção de peixes em reservatórios tem o potencial de contribuir significativamente para a oferta mundial de pescado, especialmente na Ásia (De Silva, 2002) e na América do Sul (Petrere, 1996).

El-Gayar e Leung (2000) ressaltam que aquacultura é considerada uma fonte viável e barata de proteína de alta qualidade, principalmente em países em desenvolvimento, que sofrem de uma falta deste alimento. Por esta razão, as áreas inundadas de lagos artificiais e lagoas estão sendo cada vez mais empregadas para a aquicultura (Ayer e Tyedmers, 2009; Barton e Fløysand, 2010). Além da produção de alimentos, a expansão dessa atividade em reservatórios gera benefícios para as economias regionais, na forma de emprego e renda em toda a cadeia de produção da aquicultura (Ross et al. 2011), constituindo uma importante alternativa produtiva para as populações afetadas por barragens, por exemplo (Abery et al. 2005). 
Os cultivos em águas públicas utilizando tanques-rede ou gaiolas já são os principais meios de produção de organismos aquáticos na Ásia, especialmente em rios e reservatórios (Beveridge, 2004), com destaque para a China, Tailândia, Camboja e Vietnã (Phouthavongs, 2006). Apenas em 2005, 704.254 toneladas de organismos aquáticos foram produzidos em lagos, rios e reservatórios na China (Chen et al., 2007).

$\mathrm{Na}$ Asia, as principais espécies cultivadas nesses sistemas são: carpa chinesa (Cyprinus carpio carpio), Pangas catfish (Pangasius pangasius), bagre (Ictalurus punctatus), espécies Snakehead (Channa spp.) e, mais recentemente, a tilápia (Oreochromis niloticus) (De Silva e Phillips, 2007). Um exemplo do grande crescimento do desenvolvimento da aquicultura em águas públicas na Ásia ocorreu na Laguna Bay, o maior reservatório nas Filipinas. A área ocupada pelas estruturas de cultivo de peixes saltou de 38 hectares em 1970 para mais de 30.000 hectares em 1983 (Nepomuceno, 2004), vindo a ocupar um terço de toda a superfície do lago (Hambrey et al., 2008).

De acordo com Rojas e Wadsworth (2007) na América do Sul e no Caribe, os empreendimentos realizados em tanques-rede e gaiolas envolvem principalmente ambientes marinhos, os quais são dedicados à cultura do salmão (Salmo salar), com destaque para o Chile. No entanto, existe um grande potencial regional para a produção de tilápia - as principais espécies de água doce cultivados na América do Sul e Caribe - em águas públicas.

Fitzsimmons (2000) estimou que, ao longo de um intervalo de 10 anos de produção de tilápias em tanques-rede e gaiolas saltaria de $10 \%$ para $30 \%$ do total produzido pela tilápia-cultura na região. O maior potencial, neste caso, é a do Brasil, que possui mais de $32.500 \mathrm{~km}^{2}$ de áreas inundadas por reservatórios (Agostinho et al., 2007).

Em geral, há uma grande falta de dados estatísticos relativos à produção de peixe e os valores gerados em águas públicas em todo o mundo, uma situação repetida na América do Norte. De acordo com Masser e Bridger (2007), o que se sabe é que a produção em rios e lagos dos Estados Unidos é insignificante e que alguns estados permitem a prática da aquicultura em águas públicas. A este respeito, o Canadá avança no desenvolvimento de uma estrutura e tecnologias que permitam o desenvolvimento sustentável da atividade. Brister e Kapuscinski (2000) citam que perto de $80 \%$ das 4.550 toneladas de truta arco-íris produzido em Ontário, no Canadá, foram cultivados em tanques-rede. No entanto, os cultivos em tanques-rede e gaiolas na América do Norte estão praticamente limitados à truta arco-íris (Oncorhynchus mykiss) e ao bagre do canal (Ictalurus punctatus).

Na Europa, o uso de tanques-rede e gaiolas também prevalece em ambientes marinhos. Em águas doces, a cultura de peixe em gaiolas só é praticada em pequena escala, gerando volumes 
insignificantes e envolvendo principalmente a produção de truta arco-íris, em países como Itália, Turquia, Chipre (Cardia e Lovatelli, 2007) e Noruega (Grøttum e Beveridge, 2007).

De acordo com Brummett et al. (2008), na África, apesar de 40 anos de pesquisa e desenvolvimento e centenas de milhões de dólares gastos, a aquicultura, como um todo, está longe de realizar seu elevado potencial ambiental. A atividade ainda é seriamente prejudicada por arranjos institucionais ineficazes, embora existam algumas experiências em grande escala de produção comercial de peixes de sucesso em águas públicas, principlamente na Tanzânia, Uganda e Zimbabwe (tilápia produzida em gaiolas e, principalmente, direcionadas à exportação) e na Zâmbia, Quênia e Gana (também produzida em gaiolas, mas abordando os mercados locais).

$\mathrm{Na}$ Oceania, os empreendimentos que utilizam tanques-rede ou gaiola apresentam grandes desvantagens competitivas em comparação com outras regiões, principalmente no que diz respeito à Ásia. Os custos de mão de obra na Austrália e Nova Zelândia são bastante elevados, o mesmo que para a maioria dos itens que compõem os custos de produção dos produtos da aquicultura (Tacon e Halwart, 2007). Isto tem inviabilizado o desenvolvimento efetivo da aquicultura em Águas da União deste país.

\subsection{Aquicultura em águas públicas no Brasil}

O Brasil possui cerca de 12\% da água doce disponível no planeta (Tundisi e Tundisi, 2008), 5,5 milhões de hectares de águas represadas em lagos e reservatórios (ANEEL, 2011) e um litoral que se estende com mais de $8.000 \mathrm{~km}$, portanto, é um dos poucos países em condições de produzir a crescente demanda mundial por peixes oriundos da aquicultura.

A utilização dos reservatórios para usos múltiplos no Brasil, entre eles a aquicultura, foi estabelecida pela Política Nacional de Recursos Hídricos, em 1997, com a Lei $n^{\circ}$ 9.433. Este quadro legal foi complementado pelo Decreto $n^{\circ} 4.895$, de 2003, e a Instrução Normativa Interministerial n 6, de 2004 que regulam o uso de águas brasileiras e espaços públicos, isto é, as "Águas Federais", para a prática da aquicultura. Em adição a isto, a Instrução Normativa Interministerial $\mathrm{N}^{\mathrm{0}} 7$ de 2005 , especifica que até $1 \%$ da área da superfície das águas federais está disponível para fins de aquicultura, desde que seja respeitada a capacidade de suporte do reservatório (ANEEL, 2011).

A partir deste marco regulatório, houve um incentivo do Governo Federal para a instalação de projetos de piscicultura em reservatórios de usinas hidrelétricas, como forma de aumentar a produção de alimentos e promover o desenvolvimento social (Plano Mais Pesca e Aquicultura, 2008). 
Porém, para que a ocupação dessas áreas ocorresse de forma responsável e respeitando as peculiaridades ambientais de cada reservatório, o Governo Brasileiro fomentou a realização de estudos técnicos para a implantação de empreendimentos aquícolas (Figura 3) nos principais reservatórios brasileiros, denominados da seguinte forma:

a) Parques aquícolas: são agrupamentos de diversas áreas aquícolas dentro de um contexto de economia ou produção em aglomeração ordenada;

b) Área de produção: seria apenas o espaço físico ocupado pelas estruturas de cultivos desprezando a área de diluição e sinalização náutica do parque aquícola;

c) Áreas aquícolas: são espaços individuais destinados à aquicultura, cedidos para pessoas físicas ou jurídicas.

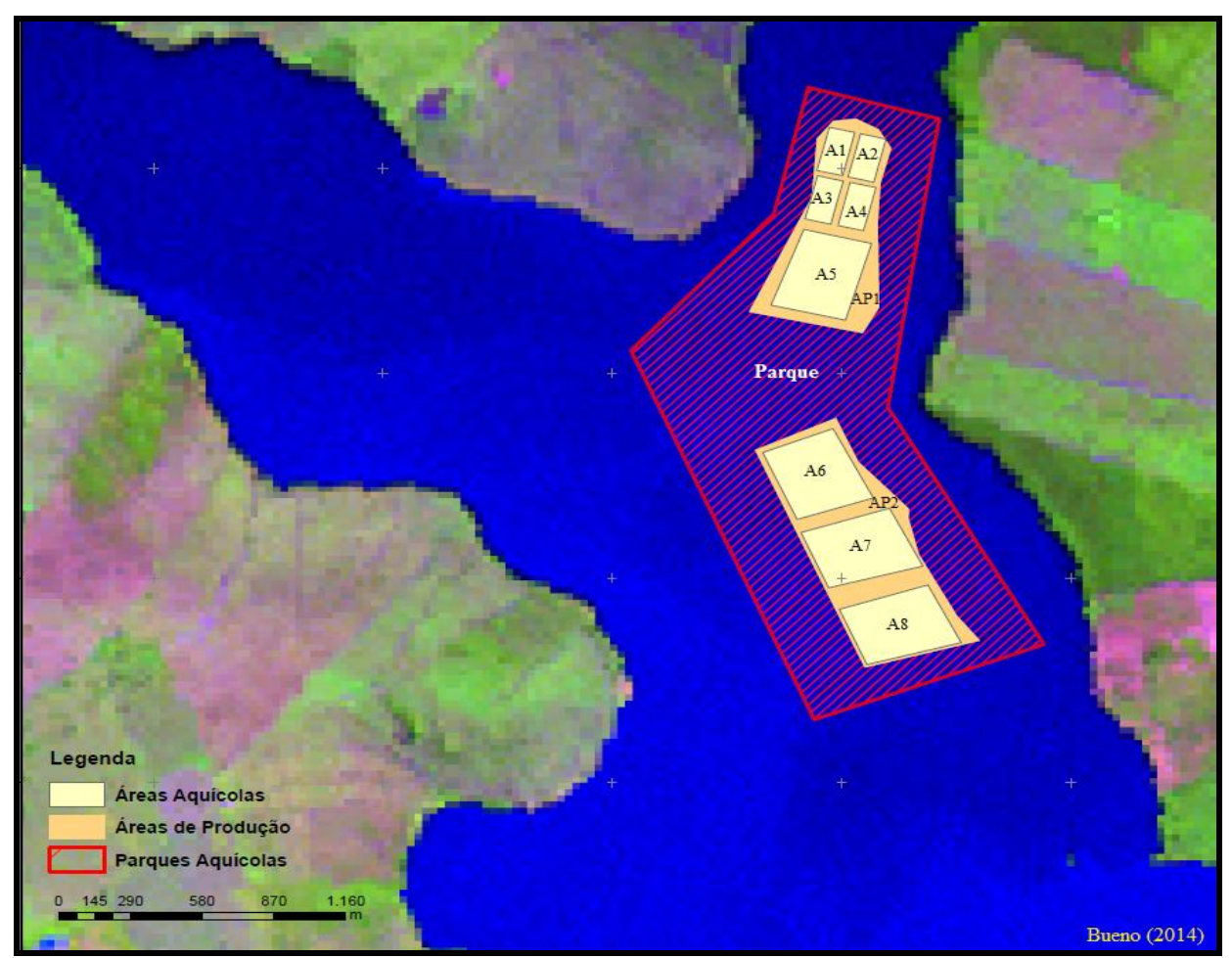

Figura 3. Modelo representativo de parque aquícola, área de produção e área aquícola em reservatórios federais brasileiros.

A localização de cada parque aquícola é feita a partir de um conjunto de estudos multidisciplinares (Bueno et al., 2015) e desta forma, identificam as melhores áreas e definem a produção máxima que poderia ser atingida nesses espaços sem o comprometimento da estabilidade ambiental local.

Depois de aprovados e tramitados nas respectivas instâncias de governo (Marinha, Agência Nacional de Águas, Secretaria de Patrimônio da União, órgãos de meio ambiente e o Ministério da 
Pesca e Aquicultura), os resultados desses estudos são utilizados para o licenciamento ambiental dos parques aquícolas. O passo seguinte é lotear e licitar as áreas aquícolas de cada parque ao público final (empreendedores, aquicultores, comunidades pesqueiras). As áreas são cedidas por um período de 20 anos, renovável. As licitações dão-se nas modalidades social e não onerosa ou então empresarial e onerosa.

Desta forma, o fomento desta atividade no Brasil está sendo realizado, ou planejado de certa forma, com base em critérios que englobam as questões sociais, ambientais e econômicas, possibilitando um ordenamento e a posterior gestão destes espaços destinados à produção de pescados.

Esta metodologia está de acordo com os conceitos defendidos por Butsic et al. (2010), que enfatizam que as ferramentas de ordenamento e zoneamento devem ser dirigidas para avaliar e programar o uso da área, de acordo com suas características potenciais e de aptidão, tomando em conta os recursos naturais, as atividades econômicas e sociais e a distribuição da população, no marco de uma política de conservação e proteção dos sistemas ecológicos.

A aplicação destes conceitos possibilitará ao Brasil o desenvolvimento de uma aquicultura ecossistêmica, que deverá ser enfocada sempre em três níveis distintos: o local, composto pela fazenda aquícola; o regional, representado pelo corpo d'água e por sua bacia hidrográfica; e o global, em relação à escala de mercado. Neste contexto, ressalta-se que a aquicultura ecossistêmica deve respeitar quatro princípios fundamentais:

i) de que atividade deve ser desenvolvida no contexto de funções e serviços dos ecossistemas, sem degradação desses além de sua capacidade de resiliência;

ii) de que a aquicultura deve promover o bem estar humano e a ser desenvolvida em equidade com outros intervenientes;

iii) de que aquicultura deve ser desenvolvida de forma integrada com outros setores socioeconômicos (Soto et al., 2008; Halide et al., 2009; Aguilar-Manjarrez et al., 2010), e

iv) de que a aquicultura deve respeitar o bem-estar das espécies animais envolvidas nos sistemas de produção.

Atualmente, existem aproximadamente três mil áreas aquícolas cadastradas e 216 licitadas para uso em reservatórios federais (MPA/SINAU, 2014), 42 parques aquícolas demarcados e outorgados nos reservatórios de Itaipu (PR), Tucuruí (PA), Castanhão (CE), Ilha Solteira 
(SP/MS/MG), Três Marias (MG) e Furnas (MG). A capacidade de carga disponível nesses reservatórios para a produção de pescados totaliza 269 mil toneladas de por ano, que serão produzidos em uma área superficial de 978 hectares (MPA/SINAU, 2014).

Corroborando com estas projeções, o Balanço da Pesca e Aquicultura de 2013 do MPA ressalta que foram ofertados 900 hectares de lâmina d'água em represas e no litoral para a produção de pescados em 2013. Sendo que esses novos parques aquícolas - implantados em 13 Estados permitirão a produção de mais de 210 mil toneladas de pescado por ano, entre peixes, ostras e mexilhões.

De acordo com o Plano Plurianual - PAA de 2012 a 2015 do Governo Federal, a meta do MPA é a demarcação e instalação de mais 39 parques aquícolas continentais (Figura 4) e parques aquícolas marinhos em sete estados costeiros para os próximos anos. Tais ações reforçam a necessidade de haver o conhecimento real do impacto que estes empreendimentos possam causar no ambiente aquático.

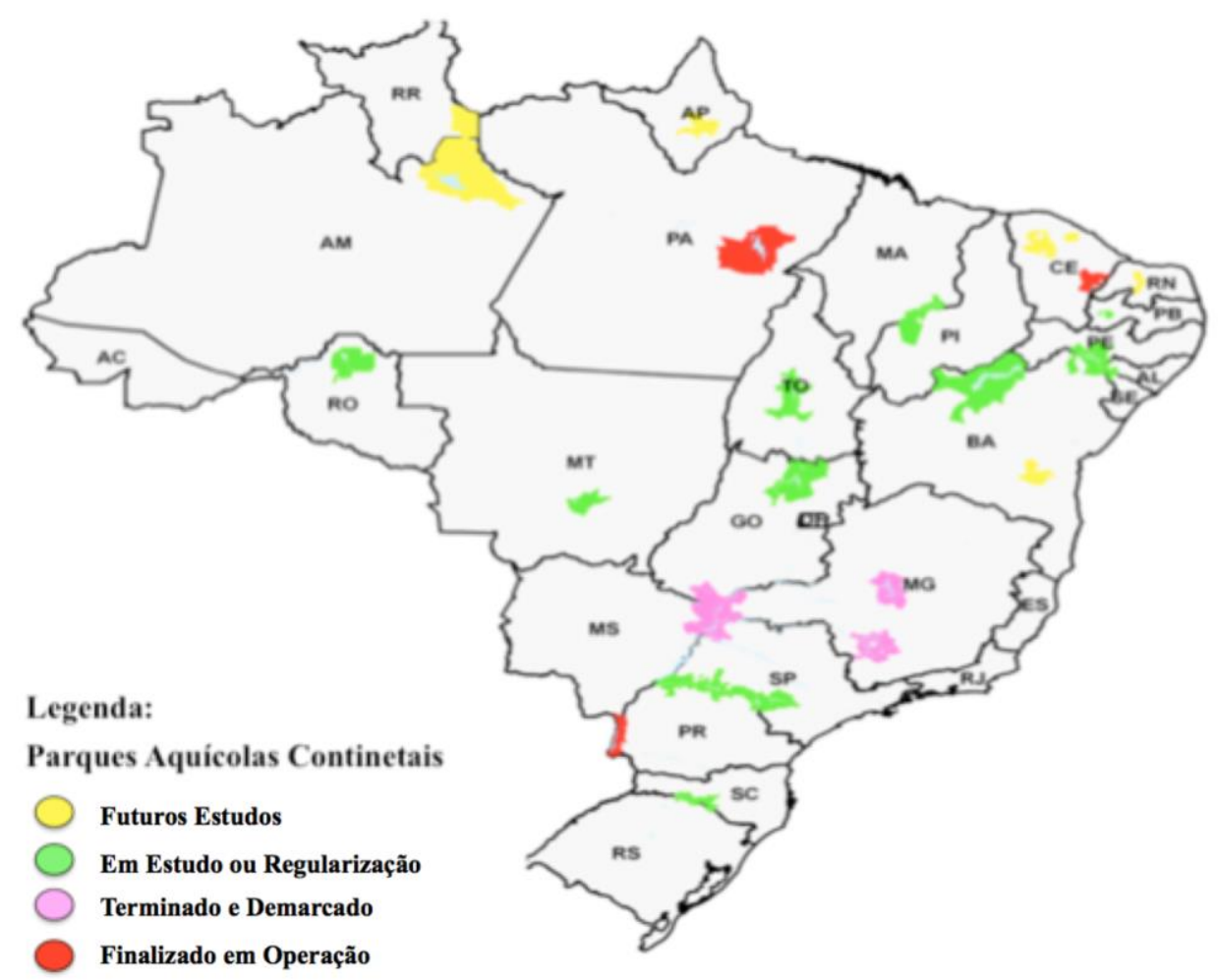

Figura 4. Representação da situação dos parques aquícolas continentais em águas da União. Fonte: MPA (2014).

2.4 Impacto ambiental da aquicultura em reservatórios 
Os principais impactos relacionados à aquicultura em rios, lagos e reservatórios estão ligados ao aumento do fluxo de partículas e nutrientes dissolvidos no ambiente, (Guo, 2003; Sugiura et al., 2006; Azevedo et al., 2011; Gondwe et al,. 2011) a ocorrência de mortalidade e perdas de biodiversidade de peixes (Sang, 2006); contaminação por compostos químicos (por meio do uso de antibióticos, antiparasitários, anestésicos e desinfetantes) (Burridge et al., 2010); reduções localizadas das concentrações de oxigênio dissolvido (Hamblin e Gale, 2002); ocorrência de florações de algas tóxicas (Sowles, 2009); no aumento da concentração de matéria orgânica e de metais no sedimento (Chou et al., 2004).

Além destes, observam-se alterações na biodiversidade da micro-flora e sedimentos bentônicos (Buschmann et al., 2009); influência na estrutura trófica e nos atributos biológicos da dieta dos peixes selvagens devido a introdução de espécies exóticas oriundas da aquicultura (Arthur et al., 2010; Carvalho et al., 2012; Ramos et al., 2014); disseminação de doenças que podem afetar as populações selvagens de organismos aquáticos (Israel, 2007) e, em alguns casos, conflitos diretos com outros usuários de recursos hídricos que geram impactos sociais adversos (Bene e ObirihOpareh, 2009).

\subsection{Efluentes aquícolas}

A principal contribuição dos efluentes oriundos da aquicultura provém das dietas e sobras de ração não consumida durante a alimentação, resultando em resídos sólidos e dissolvidos (Bureau e Hua, 2010).

Lançamentos de fósforo em corpos hídricos continentais (água doce), são mais preocupantes, pois este composto é geralmente o fator mais limitante para o crescimento das plantas (algas) neste ambiente. Em ambientes marinhos, as saídas de resíduos nitrogenados geram a maior preocupação quanto ao impacto ambiental (Persson, 1991), no entanto, em alguns reservatórios a elevada entrada de $\mathrm{N}$ (oriundo principalmente da proteína das rações) pode originar amônia tóxica na água e comprometer a sobrevivência dos peixes.

Gowen et al., (1991) e Lazzeri e Baldisserotto (2008) ressaltam que os resíduos sólidos (material fecal e alimentos perdidos na alimentação) podem sedimentar e ocasionar impacto sobre o ecossistema bentônico de águas interiores e marinhas, portanto, estimar os resíduos sólidos e dissolvidos é a principal estratégia para o monitoramento e planejamento de ações de mitigação ambiental nos ambientes onde estão instaladas as fazendas aquícolas. 


\subsubsection{Resíduos Nitrogenados}

O valor biológico de uma dada proteína na dieta depende tanto de sua digestibilidade quanto de seu equilíbrio de aminoácidos em relação às exigências nutricionais dos peixes (NRC, 2013). Desequilíbrio de aminoácidos pode levar à diminuição da deposição de proteína e ao aumento da excreção nitrogenada (Cowey e Cho, 1991).

Como dietas para peixes contêm quantidades elevadas de proteína (28 a 50\%), uma grande quantidade de energia na dieta é fornecida como compostos nitrogenados que levam ao aumento da produção de catabolitos nitrogenados (nitrito, nitrato e amônia, por exemplo). Estudos mostram que, poupar a proteína inserindo energia digestível pode reduzir consideravelmente a poluição devido ao acréscimo de produtos finais nitrogenados (Tabela 1).

Corroborando com esta afirmativa Botaro et al. (2007) demonstraram que é possível reduzir o teor de PB digestível de 27 para 24,3\% em dietas para tilápia do Nilo criadas em tanques-rede, sendo que essa redução pode ser obtida por meio da suplementação com aminoácidos.

Neste cenário, Cho e Kaushik (1985) destacaram a importância da proteína digestível (PD) e da energia digestível (ED) na dieta para aumentar a retenção de nitrogênio. Hargreaves (1998) ao realizar um levantamento bibliográfico para identificar o percentual de nitrogênio retido por peixes e liberado para o meio ambiente em vários sistemas de produção aquícola, demonstrou haver diferenças significativas quanto ao uso de dietas com níveis reduzidos de proteína e maiores níveis de ED, estes resultaram na diminuição do efeito poluidor das rações no ambiente aquático (Tabela $1)$.

Tabela 1. Estimativas da percentagem de nitrogênio retido nos peixes e liberado para o meio ambiente em vários sistemas de produção aquícola.

\begin{tabular}{|c|c|c|c|c|c|c|}
\hline \multirow{2}{*}{ Espécie } & \multirow{2}{*}{$\begin{array}{c}\text { Sistema de } \\
\text { Produção }\end{array}$} & \multirow{2}{*}{$\begin{array}{l}\text { Retido } \\
\text { no Peixe }\end{array}$} & \multicolumn{3}{|c|}{ Excretado } & \multirow{2}{*}{ Referências } \\
\hline & & & Total & Dissolvido & Sólido & \\
\hline Oreochromis niloticus & $\mathrm{P}$ & $18-21$ & 81 & & & Green e Boyd (1995) \\
\hline Ictalurus punctatus & $\mathrm{P}$ & 27 & 73 & & & Boyde (1985) \\
\hline Sparus aurata & $\mathrm{T}$ & 27 & & 66 & 7 & Neori e Krom (1991) \\
\hline Salmo salar & $\mathrm{C}$ & 25 & & 65 & 10 & Gowen e Bradbury (1987) \\
\hline Salmo Salar & $\mathrm{C}$ & 25 & & 62 & 13 & Folke e Kautsky (1989) \\
\hline Clarias macrocephalus & $\mathrm{C}$ & 24 & 76 & & & Lin et al. (1993) \\
\hline Ictalurus punctatus & $\mathrm{R}$ & 14 & 86 & & & Worsham (1975) \\
\hline Oncorhynchus myskiss & $\mathrm{R}$ & 19 & & 74 & 7 & Foy e Rosell (1991) \\
\hline
\end{tabular}

$\mathrm{P}=$ tanque de terra; $\mathrm{T}=$ tanque; $\mathrm{C}=$ tanque-rede; $\mathrm{R}=$ raceway. Fonte: Hargreaves (1998)

\subsubsection{Resíduos Fosfatados}


A forma na qual o fósforo (P) é excretado pelos peixes pode ter uma influência direta sobre o enriquecimento do ambiente aquático e o crescimento de algas. Geralmente o P é excretado em formas solúveis e em partículas: as formas solúveis de $\mathrm{P}$ consistindo de $\mathrm{P}$ orgânico e $\mathrm{PO}_{4}{ }^{3-}$, que afetam diretamente a qualidade da água, enquanto a forma de partículas sedimenta-se no fundo dos lagos e reservatórios ou acumulam-se no sedimento (Persson, 1991; Tundisi e Tundisi, 2008).

O fósforo solúvel está prontamente disponível como um nutriente para o crescimento das plantas, sendo que uma quantidade significativa da fração livre contida no fósforo total está na forma de ortofosfato inorgânico. Portanto, a forma de $\mathrm{P}$ consumido pelos peixes afetará a quantidade de $\mathrm{P}$ solúvel e particulado das excretas, bem como a quantidade de $\mathrm{P}$ que poderiam posteriormente ser biologicamente degradado no sedimento (Chou et al., 2004).

Contudo, a definição das entradas de nutrientes via rações da aquicultura é de extrema importância para o desenvolvimento sustentável desta atividade. Kubitza (1999) cita que rações para peixes podem gerar uma carga de poluente com 46 a 99\% de nitrogênio e 96 a $271 \%$ de fósforo, sendo que há uma relação direta entre o potencial poluente das rações e os índices de conversão alimentar.

Wang et al. (2012) relataram taxas de liberação de resíduos de fazendas de salmão na Noruegua em 2009 (principalmente nitrogênio e fósforo), a fim de avaliar a influência teórica sobre águas circundantes do ambiente e o potencial para desenvolver um consórcio com a aquicultura multi-trófica integrada (Figura 5).
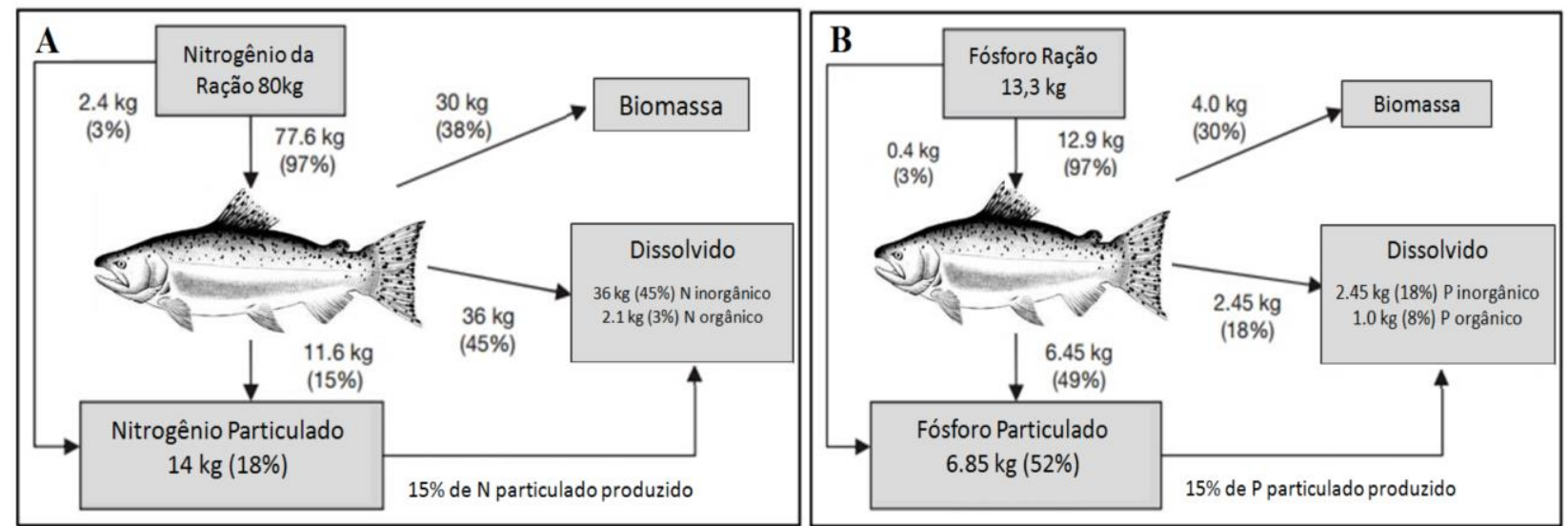

Figura 5. Fluxos anuais de nutrientes em $\mathrm{kg} \mathrm{t}^{-1}$ de salmão norueguês produzido em 2009. Fonte: Adaptado de Wang et al. (2012).

Neste estudo, da entrada de alimentação total, $70 \%$ carbono (C), $62 \%$ de nitrogênio total (Ntotal) e $70 \%$ fósforo total (P-total) foram libertados no ambiente, o equivalente a uma descarga anual de cerca de 404.000, 50.600 e 9.400 t de C, N e P, respectivamente, com base no total de produção de salmão de $1,02 \times 106 \mathrm{t}$. 
Corroborando com esta descrição, Chowdbury et al. (2013) obtiveram cenários de lançamento de P e N sólido e dissolvido ao simular níveis de proteína na dieta (40, 38 e 35\%) para diferentes fases de cultivo da O. niloticus (Figura 6). Montanhini Neto e Ostrensky (2015) também avaliaram a carga potencial de resíduos da produção comercial de $O$. Niloticus e estimaram que os totais de nutrientes gerados nos resíduos por tonelada de biomassa de tilápias produzidas foram de 1.040,63 kg de matéria orgânica (MO), 44,95 kg de nitrogênio (N) e 14,26 kg de fósforo (P), o que representam $78 \%$ de MO, $65 \%$ proteína e $72 \%$ de $\mathrm{P}$ respectivamente, das quantidades de nutrientes fornecidos pela alimentação.

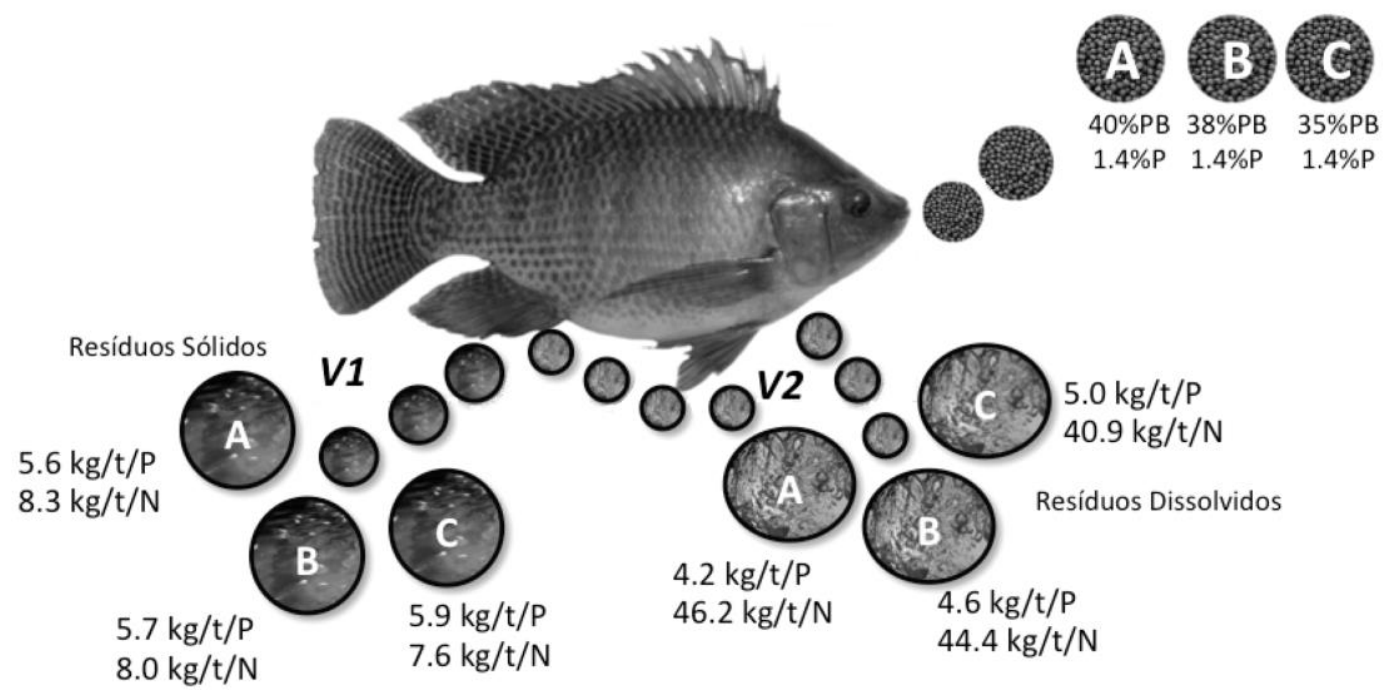

Figura 6. Estimativa de resíduos sólidos, não digeríveis (VI) e resíduos dissolvidos, excreção branquial e urinária (V2) para produção de $1.000 \mathrm{~kg}$ de O. niloticus em sistema fechado. Fonte: Chowdbury et al. (2013).

Estudos de Penczak et al. (1982) afirmam que somente 32\% do fósforo são utilizados para o metabolismo do peixe e os $68 \%$ restantes são transferidos para o meio. Reforçando esta idéia, Alves e Baccarin (2005) relatam que $66 \%$ do fósforo aportado pelo arraçoamento intensivo vão para o sedimento, $11 \%$ ficam dissolvidos na água e $23 \%$ são incorporados no peixe em cultivo, isto enfatiza a necessidade de programas de manejo e controle dos resíduos aquícolas.

Tacon (2005) cita que em 1985 as rações utilizadas em salmonicultura no Chile continham 60\% PB e apenas 6 a 8\% de lipídios, entretanto, em 2005 passaram a conter em média 35\% de cada um destes nutrientes, consequentemente, esta redução ocasionou no decréscimo dos níveis de excreção de metabolitos pelos peixes, resultados práticos para minimizar o potencial poluente das fazendas de peixe. 
Situação semelhante ocorreu com a indústria do salmão na Noruega e Canadá, onde uma série de medidas foram tomadas para reduzir a liberação de nutrientes das fazendas de criação de salmão, estas ações envolveram a otimização da composição alimentar, melhorias na digestibilidade do alimento e tecnologias de processamento (Cheshuk et al., 2003, Islam, 2005).

Islam (2005) cita que a redução da taxa média de conversão alimentar da indústria de salmão norueguês foi de 2,08, em 1974, para 1,00 em 2005. No Canadá, a conversão alimentar média da indústria na década de 80 estava em 1,50, e, vinte anos depois apresentava-se em 1,10. Como consequência, houve a diminuição de $14 \mathrm{~kg}$ de fósforo sólido por tonelada de peixe produzido (Bureau e Hua, 2010).

Azevedo et al. (2011) avaliando a quantificação deste P ingerido via rações comerciais ao longo do tempo e o input destes nutrientes oriundos do cultivo de truta no lago 375 em Ontário, Canadá, demonstraram haver influência do manejo alimentar (diferença entre rações e despercídio no arraçoamento) em relação à contribuição de resíduos gerados ao ambiente aquático, quando comparando ao acumulado entre os anos de 2003 e 2004 (Tabela 2).

Tabela 2. Saídas de resíduos sólido e dissolvidos (N e P) (kg por tonelada de peixe produzido) de truta arco-íris com peso inicial de $100 \mathrm{~g}$ para final de $1.000 \mathrm{~g}$ durante 2003 e 2004, utilizando-se cinco cenários de resíduos da alimentação.

\begin{tabular}{lccccc}
\hline & A & B & $1 \%$ FW & $5 \%$ FW & $15 \%$ FW \\
\hline 2003 & & & & & \\
AFW (\%) & 0 & 4 & 1 & 5 & 15 \\
TSW & 236 & 267 & 245 & 279 & 363 \\
SNW & 12.8 & 15.3 & 13.5 & 16.2 & 22.9 \\
SPW & 5.3 & 5.5 & 5.4 & 5.6 & 6.2 \\
DNW & 41.3 & 38.9 & 40.7 & 38.0 & 31.3 \\
DPW & 3.4 & 3.2 & 3.4 & 3.1 & 2.5 \\
Total N waste & 54.2 & 54.2 & 54.2 & 54.2 & 54.2 \\
Total P waste & 8.7 & 8.7 & 8.7 & 8.7 & 8.7 \\
& & & & & \\
2004 & & & & & \\
FW (\%) & 0 & 2 & 1 & 5 & 15 \\
TSW & 220 & 239 & 228 & 259 & 338 \\
SNW & 12.2 & 13.7 & 12.8 & 15.4 & 21.8 \\
SPW & 5.3 & 5.4 & 5.4 & 5.6 & 6.2 \\
DNW & 38.0 & 36.5 & 37.3 & 34.8 & 28.4 \\
DPW & 3.4 & 3.3 & 3.4 & 3.1 & 2.5 \\
Total N waste & 50.2 & 50.2 & 50.2 & 50.2 & 50.2 \\
Total P waste & 8.7 & 8.7 & 8.7 & 8.7 & 8.7 \\
\hline
\end{tabular}

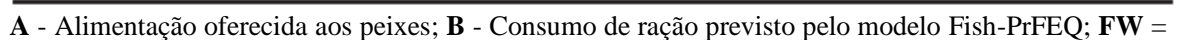
resíduos de ração (em\% total de consumo de ração seca); $\mathbf{1 \%} \mathbf{F W}=99 \%$ dos alimentos oferecidos como entrada do modelo; $\mathbf{5 \%} \mathbf{F W}=95 \%$ dos alimentos medido oferecido como entrada do modelo, $15 \%$ FW $=85 \%$ dos alimentos medido oferecido como entrada do modelo; TSW = resíduos sólidos total; SNW = resíduos sólidos N; SPW = P resíduos sólidos; DNW = resíduos de nitrogênio dissolvido; $\mathrm{DPW}=$ dissolvido resíduos $\mathrm{P}$. 
Estudos que determinam os resíduos aquícolas auxiliam na quantificação de carga gerada pela atividade aquícola, no entanto, o efluente lançado no reservatório deve ser avaliado de forma integrada com diversas variáveis bióticas e abióticas do ambiente que permitam determinar sua influência, e consequentemente, verificar a capacidade de suporte do ambiente aquático.

Neste contexto, um estudo de relevância na área de capacidade de suporte de reservatórios considerando as cargas de fósforo da aquicultura foi desenvolvido por Johansson e Nordvarg (2002), no qual foram comparados os modelos de Vollenweider e de Dillon e Rigler (1974), conforme apresentado na Figura 7.

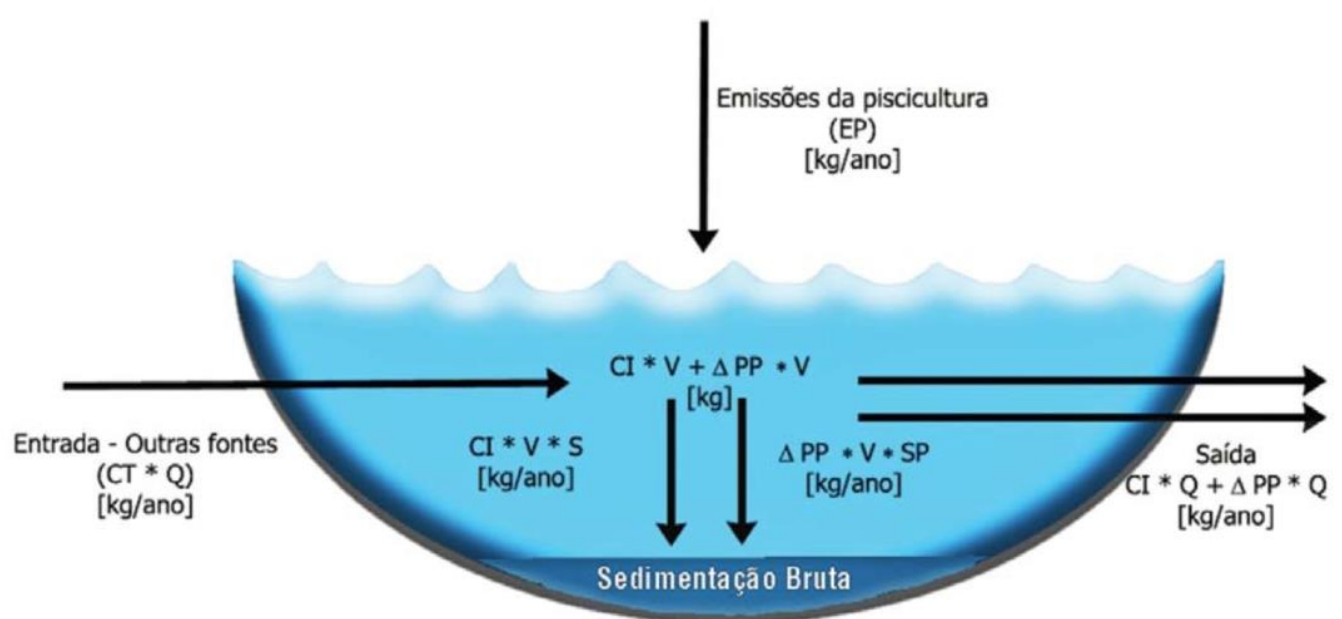

Figura 7. Ilustração do princípio básico de modelos de balanço de massa, baseado no modelo de Vollenweider e Dillon e Rigler. V é o volume do lago, $\mathbf{Q}$ é o fluxoanual de água $\left(\mathrm{m}^{3} / \mathrm{ano}\right), \mathbf{C T}$ é a concentração de fósforo nos tributários, $\mathbf{E P}$ as emissões anuais de fósforo ( $\mathrm{kg} / \mathrm{ano})$ geradas na piscicultura, $\Delta \mathbf{P P}$ é a contribuição das emissões originadas pela piscicultura em relação às concentrações totais de fósforo no reservatório $(\mu \mathrm{g} / 1), \mathbf{C I}$ relaciona-se às concentrações iniciais de fósforo no reservatório não relacionadas ao cultivo de peixes $\left(\mathrm{mg} / \mathrm{m}^{3}\right)$; SP são taxas anuais de sedimentação do fósforo originadas a partir da piscicultura; $\mathbf{S}$ são as taxas anuais de sedimentação anual de sedimentação do fósforo proveniente de outras fontes que não a piscicultura. Fonte: Johansson e Nordvarg (2002).

Neste estudo, utilizaram-se dados reais obtidos em dez lagos localizados na Suécia onde os autores observaram que os modelos utilizados superestimaram os efeitos das emissões de fósforo total a partir dos cultivos de peixes. Verificou-se que a biomassa produzida nesses ambientes pode ser maior do que a estimada pelos modelos testados, sem que isso cause alterações ambientais significativas.

Outro modelo hidrodinâmico trata-se do Lakeweb ("Rede Lacustre"), descrito em estudo realizado por Hakanson (2005), o qual é considerado uma ferramenta para avaliar como as emissões de nutrientes oriundas do sistema de tanques-rede podem influenciar o ecossistema lacustre. 
Portanto, o modelo considera as interações fundamentais da cadeia alimentar e suas relações bióticas e abióticas (Figura 8). O uso desse modelo envolve os cálculos de produção de biomassa e de predação, determinados por meio dos grupos funcionais de organismos, incluindo os produtores primários (fitoplâncton, algas bentônicas e macrófitas), produtores secundários (zooplâncton herbívoro, zooplâncton "predador", zoobentos, peixes "presas" e peixes predadores) e decompositores (organismos saprófitas, bacterioplâncton) (Figura 6).

No trabalho Hakanson (2005), as emissões do lago oriundas dos tanques-rede, foram calculadas com base nos seguintes aspectos: 1) Produção anual de pescado; 2) Taxa de conversão alimentar; 3) Fósforo total presente na ração $(0,9 \%)$; 4) Fósforo retido nos peixes (no caso de trutas, foi obtido o valor de 0,42\%); e 5) Moderador sazonal que considera que sempre há um período de maior emissão, geralmente no período que antecede a despesca (Figura 8).

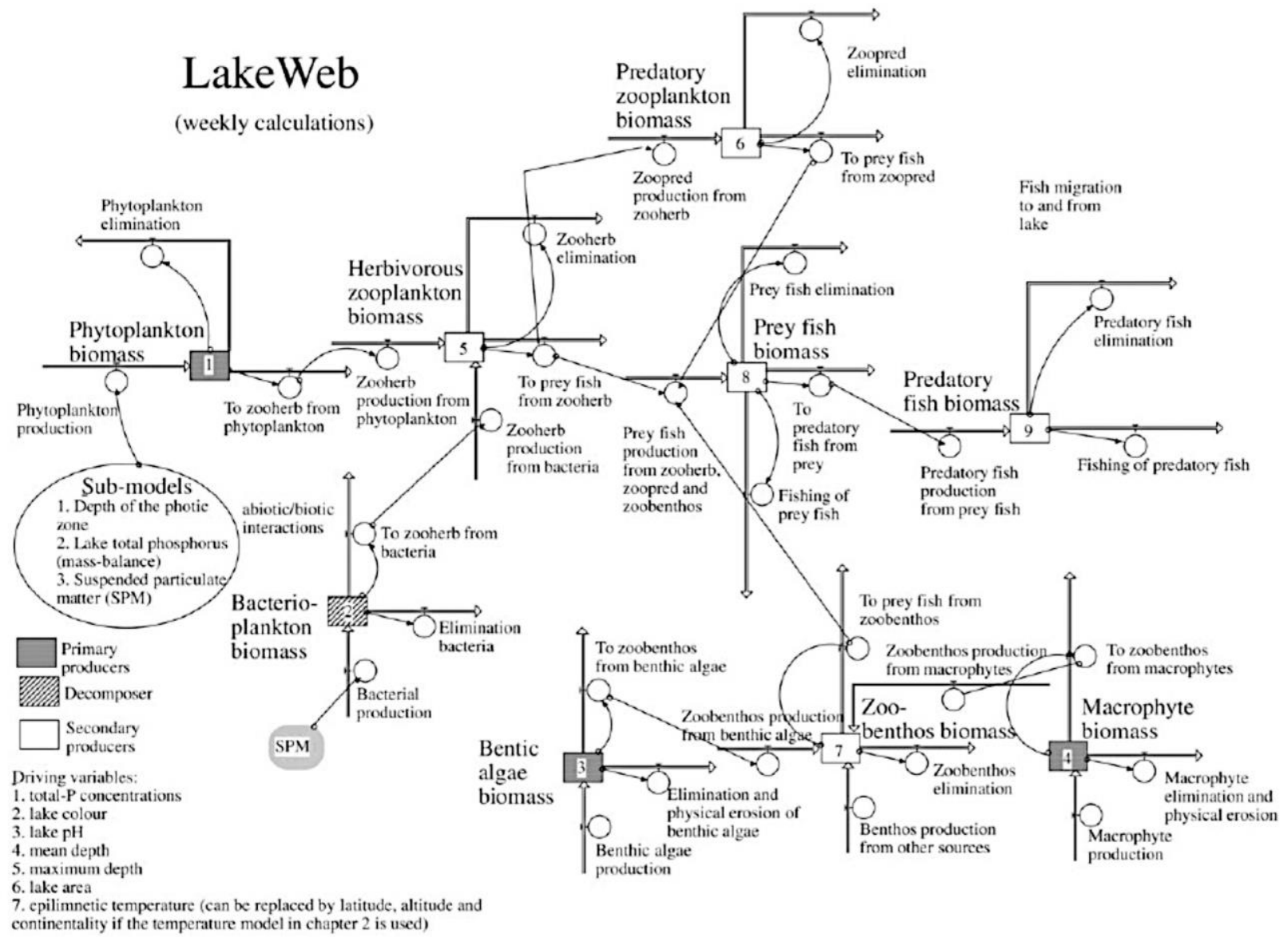

Figura 8. Representação do Modelo Lakeweb, ilustrando os nove grupos de organismos e as sete variáveis envolvidas (Concentração total de fósforo, cor da água, pH,profundidade média, profundidade máxima, a área do reservatório e temperatura). Fonte: Hakanson (2005).

Considerou também que $27 \%$ do total do fósforo lançado no ambiente encontram-se na forma dissolvida, e o restante na forma particulada. Para se avaliar quanto de ração não consumida 
foi absorvida pela ictiofauna presente no lago foram utilizados marcadores, com isso foi possível aferir o consumo pelos peixes do entorno.

Os resultados demonstraram que houve um significativo aumento na biomassa de peixes do lago, sem que ocorresse aumento na biomassa algal. Assim, mostrou-se que o cultivo de peixes em tanques-rede afetou mais diretamente a produtividade secundária do que a primária. Mesmo que essa afirmação seja um paradoxo, está relacionada ao fato de que a ictiofauna presente no lago consome diretamente os restos de ração e fezes liberadas pelos peixes do cultivo, reduzindo a eutrofização do sistema e o crescimento da biomassa algal.

Gyllenhammar et al. (2008) também avaliando a influência da aquicultura, utilizou um modelo dinâmico de balanço de massa para simular fluxos de fósforo e de nitrogênio em um mesocosmo representado por um cultivo de peixes em tanques-rede. A Figura 9 apresenta um esquema ilustrativo desse mesocosmo e a modelagem dos processos para o nitrogênio (a) e para o fósforo (b). Sendo: 1. Entrada de água; 2. Ração fornecida; 3. Absorção pelos peixes cultivados; 4. Fezes provenientes dos peixes cultivados; 5. Sedimentação; 6. Absorção pela ictiofauna associada; 7. Desnitrificação no sedimento (N); 8. Desnitrificação na água; 9. Saída de água (efluente).
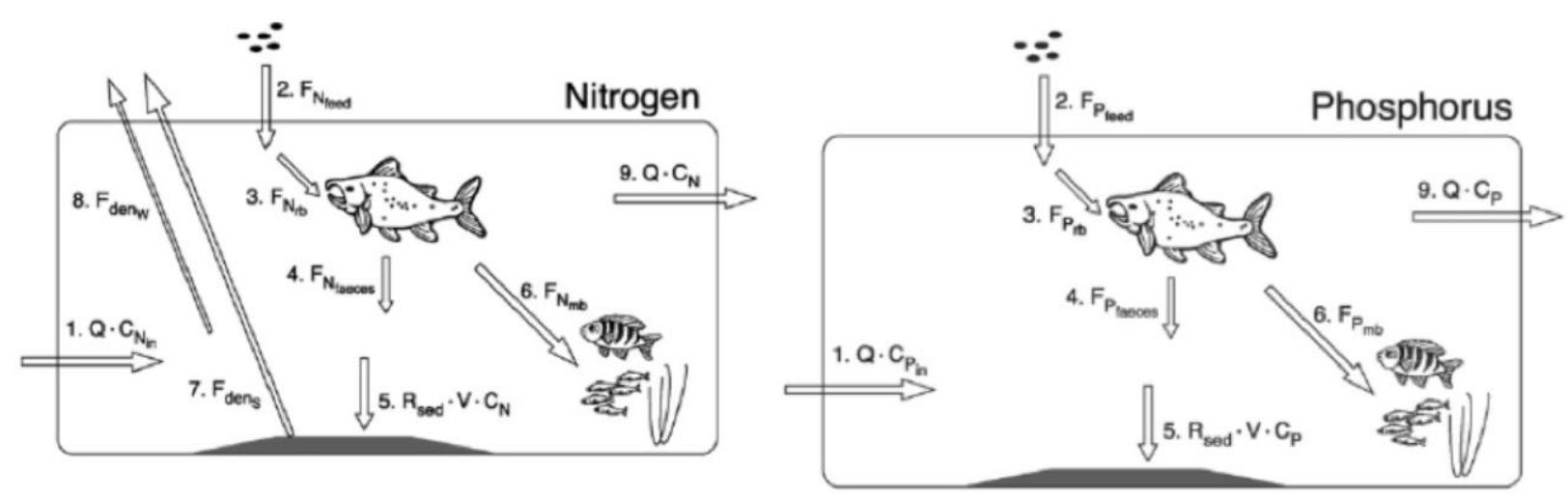

Figura 9. Desenho esquemático do mesocosmo com os balanços de massa de nitrogênio e de fósforo. Fonte: Gyllenhammar et al. (2008).

Os autores concluíram que com esse modelo de balanço de massa dinâmico é possível analisar a interação dos nutrientes em um mesocosmo baseado no cultivo de peixes em tanquesrede, contudo, a concentração de nutrientes na ração é um dos dados mais importantes, sendo a ausência desta informação pode acarretar na impressisão do modelo. Além desta variável, o padrão de crescimento (tamanho) dos peixes influência na concentração de nutrientes na água e a ictiofauna associada aos tanques contribui para a diminuição nas emissões dos dejetos nos tanques-rede. 
2.6 Estratégias para a estimativa e mitigação de efluentes aquícolas

Toda atividade aquícola gera resíduos, sejam eles, direto do cultivo como sacos de ração e de alevinos, tanques e materiais inutilizáveis, e principalmente os resíduos orgânicos como restos de rações, peixes mortos e excreções dos peixes.

Uma das principais estratégias utilizadas pelos órgãos gestores e fiscalizadores consiste no uso de modelos hidrodinâmicos que calculam a capacidade de suporte ou de carga de nutrientes que um determinado corpo hídrico possa receber e a influência que os cultivos de peixes possam exercer.

Com base nesses aspectos, alguns pesquisadores e empresas do ramo propõem modelos matemáticos como: Dillon e Rigler (1974), Vollenweider (1975), aplicativo MIKE, módulo ECO Lab. (DHI Water e Environment), VISQ (Variáveis que interagem de modo semiquantitativo), STELLA® (Structural Thinking Experimental Learning Laboratory with Animation), QUALRES, ECOPATH Modeling, Pegada Ecológica, DELPH 3D e MOHID (3D Water modelling system), que tratam-se de ferramentas que simulam a dinâmica das variáveis que ocorrem no ambiente aquático.

Geralmente, estes modelos são baseados na relação direta entre o incremento de fósforo e o crescimento de algas. Entretanto, a utilização destes modelos em ambientes tropicais para a determinação da capacidade de suporte para produção de pescados, nem sempre consideram fatores zootécnicos e limnológicos específicos e podem estar sub ou superestimando a real contribuição dos efluentes da produção de peixes.

Outras tecnologias para redução de resíduos, principalmente do fósforo, são apresentadas atualmente, as quais consistem no uso de biofiltros e argilas modificadas que atuam reduzindo a concentração de fósforo reativo dissolvido presente na coluna d'água, sedimento e camada intersticial de corpos da água.

Tem-se também o uso de tanques com estruturas rígidas e revestidas com fibras, geomembranas ou materiais sólidos que permitem a sucção dos resíduos depositados no fundo do tanque, além do manejo integrado com sistemas de biofiltro e consórcio com espécies filtradoras numa lógica de aplicação da aquicultura ecossistêmica (FAO, 2012).

Contudo, a utilização destas tecnologias requer alto investimento e manutenção, o que pode comprometer a viabilidade do empreendimento, principalmente ao tratar-se de extensos ambientes aquáticos como lagos e reservatórios. Neste cenário, as principais estratégias para a diminuição dos resíduos aquícolas consistem na formulação de dietas balanceadas, boas práticas de manejo e na 
utilização de ferramentas que proporcionem o ordenamento e planejamento da aquicultura, como por exemplo, os modelos matemáticos de predição de resíduos e ajuste da necessidade alimentar.

Portanto, a prática desordenada da atividade pode acarretar na degradação ambiental do ecossistema aquático. Como exemplos, têm-se os cultivos de salmão no Chile e Canadá, as fazendas de peixe na China e, mais recentemente, a carcinicultura no litoral brasileiro e os custivos de tilápia no reservatório do Castanhão no estado do Ceará que extrapolaram o limite de capacidade suporte do ambiente e ocasionaram a mortalidade de peixes e poluição do ambiente aquático.

\subsection{Modelos Matemáticos Aplicados à Produção Animal}

A modelagem fatorial tem sido utilizada com sucesso para estimar as exigências de aminoácidos e na melhoria do balanço energético e protéico das dietas para diversos animais, incluindo: galinhas poedeiras (Hurwitz e Bornstein, 1973, Hurwitz e Born-Stein, 1977), aves jovens, perus (Hurwitz et al., 1983) e suínos (Cook, 1991); e necessidades dietéticas para elementos essenciais para cavalos (Schryver et al., 1974), ratos (Weigand e Kirchgessner, 1977) e frangos (Hurwitz e Plavnik, 1986).

Em geral, um modelo fatorial dedutivo pode ser utilizado para examinar a relação entre a exigência líquida de um elemento essencial nos animais (a exigência para o crescimento e substituição da perda endógena) e a concentração na dieta necessária para atender essa exigência diminuindo perdas e excreções (Shearer, 1994; NRC, 2013). No entanto, cada modelo deverá considerar as características da espécie, ambiente, dieta, entre outros fatores que influênciam na resposta final a ser analisada.

\subsubsection{Modelos matemáticos aplicados à aquicultura}

O crescimento dos peixes é um processo complexo que representa resultados de uma série de processos fisiológicos e comportamentais começando com a ingestão de alimentos, a deposição de tecido animal e a excreção de metabólitos (Brett e Groves, 1979). Em cada situação da produção comercial aquícola, o conhecimento das taxas de crescimento em determinado período, sobre o consumo de ração são essenciais para a análise da viabilidade futura do empreendimento.

A maneira mais propícia para maximizar a eficiência e melhorar o crescimento animal pode ser realizada por meio do uso de modelos matemáticos que predizem as taxas de crescimento e os requisitos alimentares dos peixes. Estes modelos podem - se utilizados corretamente - tornarem-se uma ferramenta muito útil, tanto para o planejamento da produção, do ponto de vista da gestão, 
quanto no auxílio de estratégias futuras, ao compararmos o estado atual do cultivo com o que poderia ser obtido de forma viável biologicamente em um cenário posterior (Iwama e Tautz, 1981; Springborn et al., 1994; Cho e Bureau., 1998; Bureau et al., 2002).

Iwama e Tautz (1981) ressaltam que apesar de muitas tentativas de desenvolver expressões matemática para descrever o crescimento dos peixes, existe uma grande diversidade de abordagens e conceitos. Neste contexto, é comum encontrar o crescimento expresso em centímetro por mês, taxas de crescimento instantâneas, porcentagem de mudança de comprimento ou a porcentagem de mudança no peso, muitas vezes sem qualquer referência a temperaturas, alimentação ou condições de cultivo (NRC, 2013).

Portanto, um modelo de crescimento adequado permitirá estimativas dos requisitos (de alimentação) da energia do peixe e de suas taxas de crescimento. Esta informação permitirá ao produtor a resolução de vários problemas relacionados ao crescimento/taxa de alimentação que surgem na rotina de uma fazenda (Dumas et al., 2010).

Por exemplo, prever o peso médio final do peixe depois de um tempo definido de cultivo, estimar o tempo necessário para atingir um dado tamanho a ser comercializado pelo mercado, a uma temperatura definida, ou decidir qual a temperatura média necessária para produzir um determinado tamanho de peixe em um exato período de tempo. Além disto, um bom modelo matemático também pode fornecer informações sobre estoque de biomassa e sua exigência diárias de ração, energia, aminoácidos, etc (Iwama e Tautz, 1981; Bureau et al., 2002).

\subsubsection{Modelos de predição do crescimento corporal aplicados na piscicultura}

Para medir o crescimento dos peixes, geralmente utiliza-se a relação do comprimento ou peso (Wootton, 1998; Bureau et al., 2002). O método mais simples de relatar o crescimento é o aumento absoluto de peso ou crescimento.

Isso implica que a relação entre o tempo e peso é linear e que a taxa de crescimento absoluto é a mesma, independentemente do tamanho do peixe. No entanto, a taxa de crescimento do peixe varia com o tamanho do peixe e a taxa de crescimento relativo $\left(G_{R R}\right)$ irá permitir a comparação entre os tratamentos com peixes de diferentes tamanhos iniciais (Hopkins, 1992). Contudo, o crescimento relativo $\left(\mathrm{G}_{\mathrm{R}}\right)$ e a $\mathrm{G}_{\mathrm{RR}}$ são expressos matematicamente como:

$$
\begin{gathered}
G_{R}=\frac{W_{t}-W_{i}}{W_{i}} \\
G_{R R}=\frac{W_{t}-W_{i}}{W_{i}^{*} \Delta t}
\end{gathered}
$$


Eq. 01

Onde $W t$ é o peso no momento t, Wi é o peso inicial e $\Delta t$ é a duração da experiência (Ricker, 1979; Hopkins, 1992).

As taxas de crescimento relativo são tipicamente usadas em estudos de nutrição de peixes e estão apresentadas como percentagem de aumento de peso por unidade de tempo. No entanto, uma taxa de crescimento relativa é restrita para o período de tempo o qual foi calculado e não pode ser facilmente convertida para outro período de tempo (Hopkins, 1992). Diante disto, outros modelos e equações de crescimento podem ser empregados para obter melhores simulações e valores de crescimento.

\subsubsection{Taxa de crescimento específico (TCE)}

Dumas et al, (2010) citam que para eliminar o problema com o tempo das taxas de crescimento relativo, outro modelo de taxa de crescimento exponencial recomendado é o coeficiente de crescimento específico (CCE) ou taxa de crescimento relativo (Ricker, 1979; Hopkins, 1992). Este é normalmente reduzido para taxa instantânea de crescimento ou taxa específica, intrínseca, exponencial, logarítmica ou de juros compostos (Ricker, 1979).

Desta forma, utiliza-se o logarítimo do peso final $(\ln P f)$ e inicial $(\ln P i)$ a um dado tempo em dias $(d)$ conforme demonstra-se na Equação 2:

$$
C C E=\frac{\ln P f-\ln P i}{d} \times 100
$$

Eq. 2

\subsubsection{Coficiente de Crescimento Diário (CCD)}

Outra equação muito utilizada na aquicultura trata-se do cálculo do ganho de crescimento diário (Equação 3), dado pela:

$$
G C D=\frac{p f^{1 / 1 / s}-P i^{1 / d s}}{d} \times 100
$$

Observa-se na Equação 3 que o cálculo apenas considera os valores médios do peso no início $(P f)$ e fim $(P i)$ do crescimento do animal dividido pelo tempo em dias $(d)$ a um dado 
exponencial $\left({ }^{1 / 3}\right)$, este representa uma proporção de crescimento exponencial 0,333 o qual é aplicado para ajustar a curva de crescimento que não é considerado na equação do TCE:

\subsubsection{Crescimento Linear}

Diante dos modelos de crescimento apresentados anteriormente, a equação de crescimento linear, como as demais, não traduzem a trajetória real do ocorrido com o animal durante o cultivo, pois consideram apenas o peso final subtraído pelo peso inicial e dividido pelo número de dias de cultido, Assim, acreditava-se que isto seria um retrato da realidade ocorrida no cultivo, no entanto, tais equações desconsideram oscilações e diferenças de crescimento no período em relação à temperatura da água e condições metabólicas, exemplo descrito na Equação 4:

$$
\text { Linear }=\frac{P f-P_{i}}{d} \quad \text { Eq. } 4
$$

\subsubsection{Coeficiente de Crescimento Térmico (TGC)}

Diante da gama de modelos de predição e cálculo da trajetória de crescimento dos peixes existentes (TCE, CCD, Linear etc), surgiu a necessidade de considerar fatores como a temperatura da água na relação do metabolismo e crescimento dos peixes. Assim, Iwama e Tautz (1981) aplicaram o conceito de unidade térmica para estimar o crescimento em alevinos de truta, mas Cho em 1992, introduziu explicitamente o conceito de graus-dia em seu modelo e propôs uma derivação matemática fatorial (equação 5):

$$
T G C=\frac{P f^{(1-b)}-P i^{(1-b)}}{\sum t * d} \times 100
$$

Onde, $P I$ e $P f$ trata-se do peso inicial e final corporal, respectivamente, $d$ é dia, $t$ é a temperatura $\left({ }^{\circ} \mathrm{C}\right)$, e $(1-b)$ é expoente do peso corporal.

O modelo TGC desde então tem sido amplamente utilizado na aquicultura (Kaushik, 1998; Willoughby, 1999; Stead e Laird, 2002 e Hua e Bureau, 2006), permitindo um ajuste fino das curvas de crescimento dos peixes. 


\subsubsection{Integração entre modelos de crescimento e exigência energética para peixes}

Os modelos de predição surgiram para determinar o crescimento e o consumo alimentar dos animais como demonstram os estudos de Schryver et al. (1974); Pfeffer e Pieper (1979); Weigand e Kirchgessner, (1980) e nos trabalhos utilizando modelos para determinação da excreção metabólica e biodisponibilidade de nutrientes desenvolvidos por Phillips et al. (1957); O’Dell (1972); Lall (1991); Miller (1981); Suttle (1985); Cho e Bureau (1998); Booth et al. (2010); Bureau e Hua, (2010); Chowdhury et al.(2013); Bouwman et al. (2013).

Em geral, os primeiros modelos tratam de particionar a energia ingerida por meio do uso de equações de equilíbrio de energia onde vários modelos de complexidade variável têm sido construídos (Shearer, 1994). Uma forma simples utilizada seria: $\mathrm{C}=\mathrm{EM}+\mathrm{RC}+\mathrm{E}$, sendo a energia ingerida $(C)$, energia metabolizável (EM), retenção para o crescimento (RC) e excreção endógena (E) (Brett e Groves, 1979).

Usando esta equação equilibrada, um balanço de energia pode ser construído por qualquer período de tempo a partir de todo o ciclo de vida de um ponto instantâneo no tempo. Pfeffer e Pieper (1979) sugeriram um modelo dedutivo, contendo componentes empíricos, e este foi utilizado para determinar as necessidades dietéticas de elementos essenciais para os peixes. O modelo incluiu fatores para a exigência dietética (Edt), retenção para o crescimento $(\mathrm{RC})$, a excreção endógena $(\mathrm{E})$, e a disponibilidade do elemento na dieta (A). Estes fatores foram determinados empiricamente, mas sua relação foi construída dedutivamente como $\mathrm{Edt}=(\mathrm{RC}+\mathrm{E}) / \mathrm{A}$.

Os modelos fatoriais evoluíram e, atualmente, são construídos por meio da ligação de um grupo de parâmetros determinados a partir de estudos científicos e observações empíricas ao longo do cultivo, tais como: as necessidades metabólicas de energia para a manutenção, o potencial de crescimento dos peixes, a eficiência da utilização da energia e ingredientes disponíveis nas rações e a composição corporal dos animais. Assim, a determinação de cenários de crescimento, exigência energética e lançamentos de resíduos oriundos dos cultivos aquícolas passaram a ser mais precisos e aplicáveis.

\subsection{Bioenergética Nutricional}

A bioenergética descreve o fluxo de energia dos nutrientes dentro de um sistema biológico, por exemplo, em um peixe ou camarão. Esta abordagem descreve o processo biológico de utilização e transformação de nutrientes absorvidos para a energia, para a síntese do próprio corpo (NRC, 
2013). A alimentação, que é consumida, é transformada no corpo, compostos químicos complexos são divididos em componentes mais simples - proteínas em aminoácidos, carboidratos em glicose, lipídeos em ácidos graxos e essa energia é liberada dos processos metabólicos, a qual é utilizada para manutenção, produção e reprodução (Stränd, 2005).

Segundo Lehninger (1971), existem diferentes tipos de energia: energia química, energia elétrica, energia mecânica e calórica, as quais podem ser transformadas a um determinado custo, tendo como principal perda sob a forma de calor. O calor é a única forma de energia, em que todas as outras energias podem ser transformadas e medidas. A energia química armazenada no tecido, assim pode ser medida por meio de uma bomba calorimétria.

Stränd (2005) cita que a quantidade de calor produzida por oxidação completa da alimentação ou do tecido é conhecida como o calor de combustão ou energia bruta (EB). A energia térmica é normalmente expressa em quilocalorias (kcal) ou kilojoule $(\mathrm{kJ})$. Um kcal iguala-se a energia necessária para elevar a temperatura de um $\mathrm{kg}$ de água por um grau Celsius $\left({ }^{\circ} \mathrm{C}\right)$ - uma $\mathrm{kcal}$ equivale a $4.184 \mathrm{~kJ}$ (Lehninger, 1971).

Neste contexto, Jobling (2011) apresenta um exemplo sobre o conceito da bioenergética aplicado em peixes (Figura 10) onde a energia da alimentação (C) é a ingestão bruta de ração, geralmente expressa como uma taxa diária, mas nem toda quantidade ingerida está disponível para o peixe. A energia digestível é a disponibilidade de energia capaz de atender às demandas para o peixe manter-se vivo, crescer e se reproduzir.

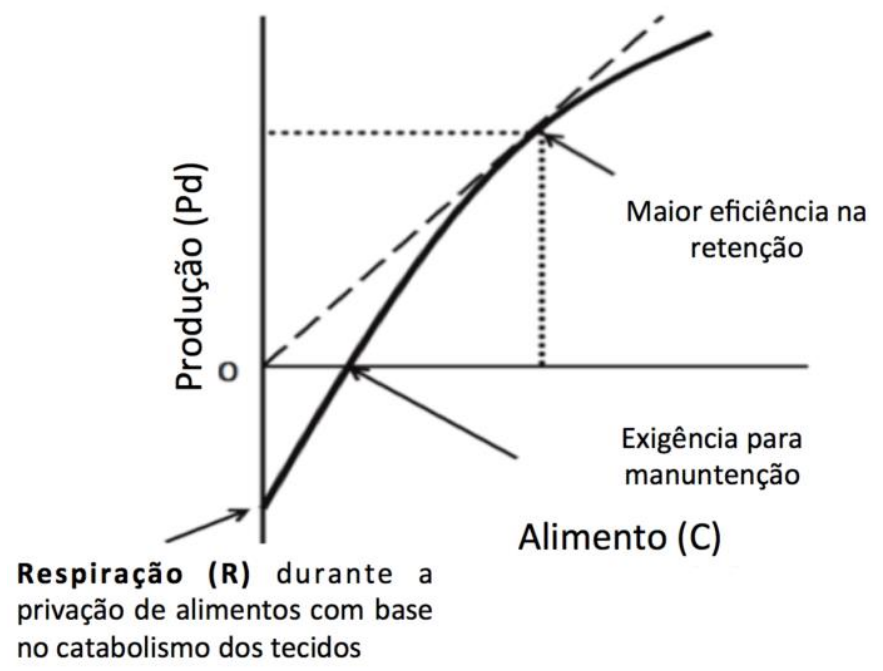

Figura 10. Relação entre a produção e o consumo de alimentos, ilustrando pontos-chave relacionados com a limitação de energia. Fonte: Jobling (2011) 
O gasto metabólico (GM) por um animal é frequentemente medido como a quantidade de calor produzido; isso geralmente é chamado de respiração (R). Ao analisarmos a diferença entre energia metabolizável (EM) e R, tem-se a energia retida, usualmente denominada de produção (Pd): $\mathrm{EM}-\mathrm{R}=\mathrm{Pd}$ (Figura 10).

Uma parte desta energia é perdida nas fezes (FE), e também há perdas como a excreção urinária (U) e pelas brânquias por meio da difusão da superfície do corpo. A partir destas, duas quantidades podem ser definidas: a energia digestível (ED) a qual é capaz de transformar-se em energia metabolizável (EM), processo demonstrado na Figura 11.

Jobling (2011) ressalta que quando um animal é privado de alimento $(C=0)$, os tecidos do corpo são catabolizados a fim de apoiar a R, o Pd é negativo, e o animal perde massa corporal. Por outro lado, se um animal ingere alguns alimentos, mas a energia retida é zero ao longo do tempo (isto é, Pd = 0), há um equilíbrio e o animal satisfaz a sua necessidade de manutenção (Figura 10).

Portanto, a determinação e o fornecimento de dietas que permitam o atendimento da exigência energética ideal aos peixes possibilitarão o atendimento de suas funções metabólicas basais e acréscimo na produção (crescimento, gordura e reprodução), bem como a minimização de perdas e resíduos oriundos do metabolismo.

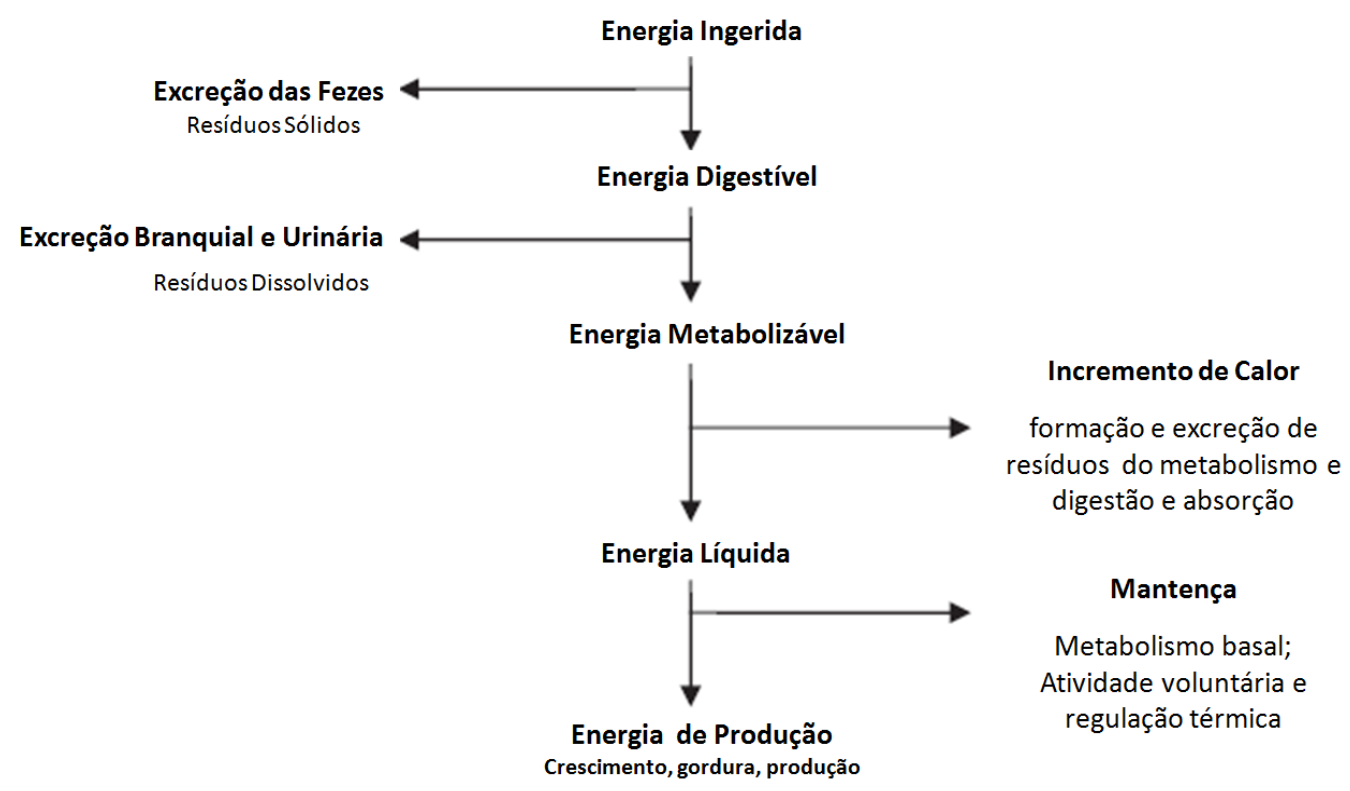

Figura 11. Fluxograma da estrutura de partição de energia no modelo bioenergético o qual destina-se a avaliar os requisitos para a alimentação animal e os resíduos. Fonte: Adaptado de Bureau et al. (2002) e NRC (2011). 


\subsubsection{Modelagem fatorial bioenergética aplicada na piscicultura}

De acordo com Cho (1982) citado por Stränd (2005), os princípios da modelagem fatorial bioenergética foram aplicados em peixes em 1914 por Ege e Krogh e vários anos depois por Ivlev (1939). Muitos estudos a respeito da utilização e do desperdícios de energia têm sido realizados desde então para várias espécies de peixes (Spoor, 1946; Brett, 1962; Warren e Davis, 1967; Niimi e Beamish, 1974; Cho et al., 1976; Cho e Kaushik, 1985; Kaushik e Medale, 1994).

Stränd (2005) relata que os modelos baseados em princípios semelhantes haviam sido propostos anteriormente por outros pesquisadores (Ursin, 1967; Kerr, 1971), mas o modelo desenvolvido pela Kitchell et al., (1974) usado para simular o crescimento do bluegill (Lepomis macrochirus), foi o mais influente e serviu posteriormente como um padrão em pesquisas para pecilotérmicos, o qual retratou a abordagem da modelagem bioenergética (Cui e Xie, 2000).

Tal modelo tem sido aplicado a várias espécies diferentes, por exemplo: o Gasterosteu saculeatus (Allen e Wootton, 1982), Sebastes melanops (Boehlert e Yoklavich, 1983), Perca fluviatilis (Solomon e Brafield, 1972) e para o Phoxinus phoxinus (Cui e Wootton, 1989; Cui e Xie, 2000).

$\mathrm{Na}$ ecologia de peixes, modelos bioenergéticos têm sido utilizados principalmente para calcular o consumo de alimentos a partir de dados de temperatura e crescimento (Kitchell e Breck, 1980; Rice et al, 1983; Raat, 1990), subsidiando o desenvolvimento de programas computacionais comerciais (Fish Bioenergetics 3.0 software for Windows®). No entanto, estes são muito generalistas por utilizarem sempre a mesma taxa metabólica, considerarem a alimentação natural (plâncton e peixes selvagens), desconsiderarem oscilações de temperatura e taxas de retenção de energia corporal entre as diferentes fases de vida e espécies. Isto gera valores grosseiros e pouco precisos para estimativa de resíduos do metabolismo animal.

No entanto, a aplicação dos modelos bioenergéticos para aquicultura consideram todos estes fatores e são precisos no desenvolvimento de estratégias ideais de alimentação e cálculo de resíduos (Cho e Bureau, 1998; Stränd, 2005), os quais se aprimoraram e tornaram-se eficientes ferramentas para aquicultores, órgãos de fomento e fiscalização da atividade.

\subsubsection{Uso da bioenergética para estimativa de resíduos aquícolas}

A produção de resíduos da aquicultura pode ser estimada utilizando princípios simples de nutrição e bioenergética aplicados por Cho et al.(1991, 1994 e 1998), que se trata de uma abordagem "biológica", ao invés de um produto químico. Alimentos ingeridos são digeridos e 
fornecem as proteínas, lipídios e carboidratos, os quais serão fontes de energia e nutrientes potencialmente disponíveis para manutenção, crescimento e reprodução do animal. O restante da alimentação (não digerido) é excretado nas fezes como resíduos sólidos (RS) (Figura 12).

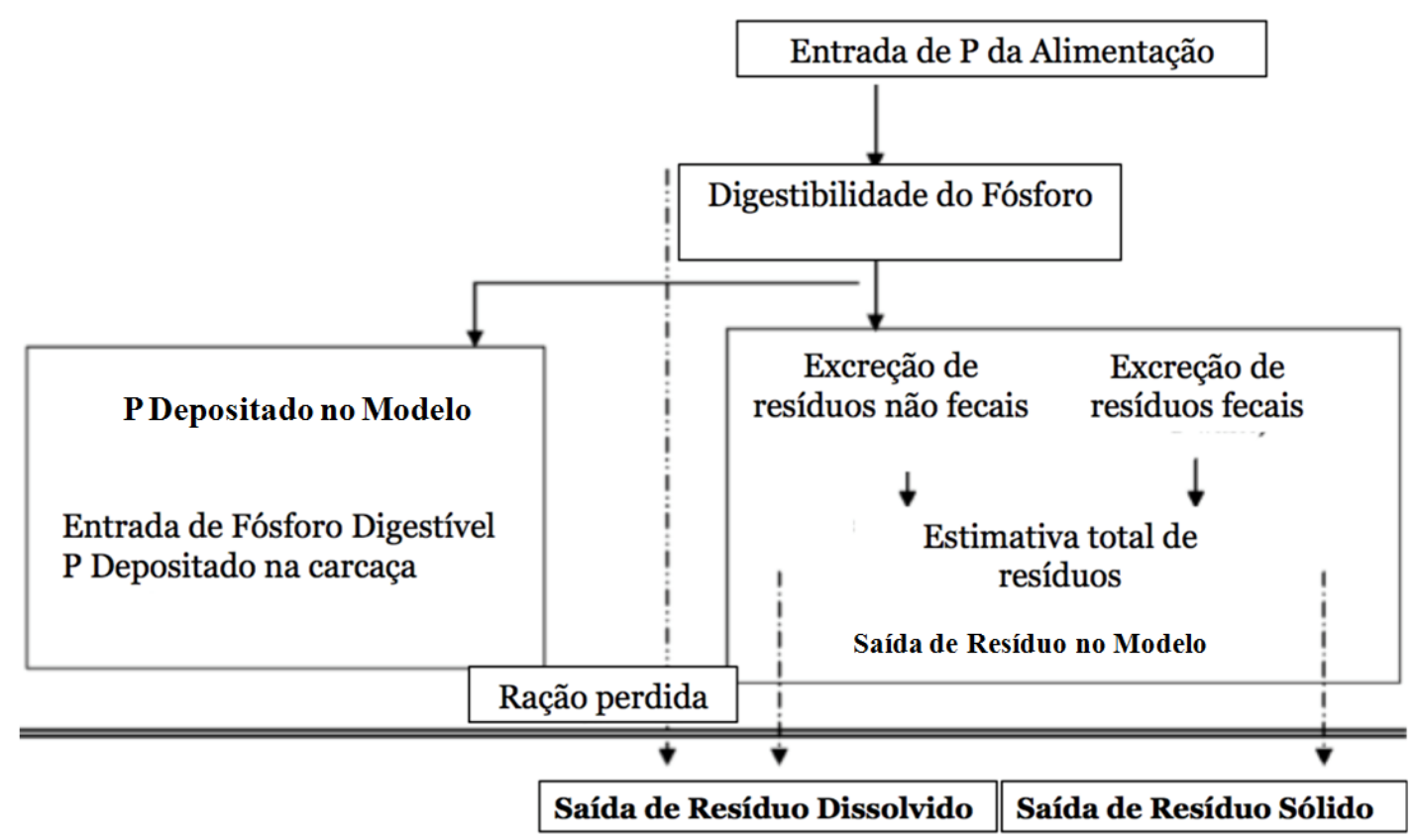

Figura 12. Fluxo do fósforo na produção de peixes. Fonte: Bureau et al. (2008).

Os subprodutos do metabolismo (amônia, uréia, fosfatos, dióxido de carbono, etc) são excretados como resíduos dissolvidos (RD), principalmente por meio dos rins (Figura 12). Sendo que o total dos resíduos oriundo da alimentação dos peixes em cultivo (TR) é composto pelos resíduos sólidos e dissolvidos, juntamente com os resíduos da perda de ração aparente durante a alimentação (PRA):

$$
\mathrm{TR}=\mathrm{RS}+\mathrm{RD}+\mathrm{PRA}
$$

Entretanto, as saídas RS, RD e PRA são biologicamente estimadas por: RS = [alimentação consumida x (1- Coeficiente de Digestibilidade Aparente, CDA)] e RD = (alimento consumido x CDA) - nutrientes retidos no peixe.

Portanto, os resíduos dissolvidos podem ser calculados pela diferença entre o nutriente digestível e o retido na carcaça. A estimativa precisa do total de resíduos sólidos (RS) e requer uma estimativa confiável dos resíduos da perda de ração aparente. Assim, a estimativa de PRA é quase impossível. Contudo, as melhores estimativas podem ser feitas com base nos requisitos de energia e 
no ganho esperado de acordo como descrito por Cho (1992), no qual a eficiência de energia (ganho de energia / consumo) indica o grau de PRA para uma determinada operação. Neste contexto, a exigência e quantidade de ração teórica (QRT) podem ser calculadas com base no balanço energético nutricional (QRT $=$ Ganho + Excretado (incluindo a perda de calor)).

A quantidade de entrada de alimentação acima da QRT é assumida como PRA e todos nutrientes que englobam a PRA devem ser incluídos na quantificação de resíduos sólidos. Cho (1992) ressalta que esta abordagem pode originar uma estimativa relativamente conservadora.

Contudo, procedimentos biológicos baseados no CDA para RS e análises comparativas de carcaça para RD fornecem estimativas confiáveis, sendo que os métodos biológicos são flexíveis e capazes de se adaptarem a uma variedade de condições e ambientes de cultivo (Cho et al., 1991; Cho e Bureau, 1997).

2.9 Vantagens e desvantagens do uso de modelos bioenergéticos

Diversos autores vêm apontando algumas fragilidades quanto ao uso de modelos bioenergéticos (Jobling, 1994; Brett, 1995; Cho e Bureau, 1998; Alanärä et al., 2001). Em geral, ressaltam que estes estudos para peixes têm sido em grande parte teóricos e realizados em laboratórios. Portanto esses fatores podem influenciar nos valores e informações que alimentam os modelos matemáticos, interferindo no resultado final da modelagem. Assim, ressalta-se que a aquisição de dados (volume, consistência e acurácea) é imprescindível para alimentar o modelo e torná-lo mais robusto, preciso e real.

Outro aspecto negativo trata-se da dificuldade em se determinar as diferentes quantidades e variações no metabolismo energético em condições comerciais, por exemplo, os métodos de medição do consumo de oxigênio, da determinação da digestibilidade dos animais durante a produção em condições de campo, situação muito diferente das encontras em laboratório.

Jobling (2011) ressalta que os experimentos, muitas vezes impõem regimes alimentares artificiais ou irrealistas sob as condições de vida do peixe. Isso expõe o peixe ao stress tanto agudo como crônico, que por sua vez produz uma gama de variações fisiológicas e metabólicas. Por fim, a variedade de métodos utilizados e as diversas maneiras de processamento e apresentação de dados do orçamento de energia fazem comparações entre os orçamentos e, portanto, estabelecem generalizações e princípios de confiança, extremamente difíceis (Brafield, 1985; Talbot, 1985).

Canale e Breck (2013) identificaram duas grandes "armadilhas" que devem ser evitadas quando se utilizam modelos bioenergéticos para simular o crescimento dos peixes ou consumo de energia. Eles observaram que erros matemáticos podem resultar da aplicação incorreta de modelos 
bioenergéticos convencionais e que as suposições de densidade de energia constantes para os peixes são biologicamente imprecisas, pois a densidade de energia pode mudar rapidamente com o aumento do tamanho do peixe. Os autores enfatizam que o aparente "sucesso" do modelo está na calibração das equações principalmente quando considera-se a conservação de energia e os processos biológicos fundamentais.

Isto enfatiza a importância do aprimoramento e desenvolvimento de estudos que considerem estes fatores e proporcionem o refino das informações e métodos a fim de aprimorar a aplicação da modelagem bioenergética fatorial para a indústria aquícola. 


\section{REFERÊNCIAS BIBLIOGRÁFICAS}

Agência Nacional de Energia Elétrica - ANNEL. 2011. Relatórios Anuais. Brasília. 536p.

Abery, N.W.; Sukadi, F.; Budhiman, A.A.; Kartamihardja, E.S.; Koeshendrajana, S. De Silva, S.S. 2005. Fisheries and cage culture of three reservoirs in west Java, Indonesia; a case study of ambitious development and resulting interactions. Fisheries Management and Ecology, 12, 315-330.

Association of Official Analytical Chemists - Official Methods of Analysis of the Association of Official Analytical Chemists. 2000. 16th ed., v. 1, Arlington: A.O.A.C., chapter 3. p. 4.

Agostinho, A.A.; Gomes, L.C.; Pelicice, F.M. 2007. Ecologia e manejo de recursos pesqueiros em reservatorios do Brasil, UEM/Nupelia, Maringa, Brazil.

Arthur, R.I.; Lorenzen, K.; Homekingkeo, P.; Sidavong, K.; Sengvilaikham, B.; Garaway, C.J. 2010. Assessing impacts of introduced aquaculture species on native fish communities: Nile tilapia and major carps in SE Asian freshwaters. Aquaculture, 299, 81-88.

Alanärä, A.; Kadri, S.; Paspatis, M. 2001. Feeding management. In: Feed intake in fish. Houlihan, D., Jobling, M. \& Boujard T. (Eds.), Blackwell Science, Oxford, UK: 332-353.

Allen, J. R. M.; Wootton, R. J. 1982. Age, growth and rate of food consumption in an upland population of the three-spined stickleback, Gasterosteus aculeatus (L.).Journal of Fish Biology, 21(1): 95-106.

Alves, R.C.P.; Baccarin, A.L., 2005. Efeitos da produção de peixes em tanques-rede sobre sedimentação de material em suspensão e de nutrientes no Córrego da Arribada (UHE Nova Avanhandava), baixo rio Tietê. In: NOGUEIRA, M.G. et al. (Org.). Ecologia de reservatórios: 
impactos potenciais, ações de manejo e sistemas em cascata.São Carlos: Rima, 2005, p. 329347.

Aquilar-Manjarrez, J. Kapetsky, J.M.; Soto, D. 2010. The potencial of spacial planning tools to support the ecosystem approach to aquaculture. FAO/Rome. Expert Workshop. Rome, Italy: FAO Fisheries and Aquaculture Proceedings. No.17. 2010. 176p.

Ayer, N.W.; Tyedmers, P.H. 2009. Assessing alternative aquaculture technologies: life cycle assessment of salmonid culture systems in Canada. Journal of Cleaner Production, 17, 362373.

Ayroza, L. M. S.; Romagosa, E.; Ayroza, D.M. M. R; Scorvo Filho, J, D.; Salles, F.A. 2011. Custos e rentabilidade da produção de juvenis de tilápia do nilo em tanques-rede utilizando-se diferentes densidades de estocagem. R. Bras. Zootec., v.40, n.2, p.231-239.

Azevedo, P. A.; Cho, C. Y.; Leeson, S.; Bureau, D. P. 1998. Effects of feeding leveland water temperature on growth, nutrient and energy utilization and waste outputs of rainbow trout (Oncorhynchus mykiss). Aquat. Living Resour. 11: 227- 238.

Azevedo, P.A.; Podemski, C.L.; Hesslein, R.H.; Kasian, S.E.M; Findlay, D.L, Bureau, D.P. 2011. Estimation of waste outputs by a rainbow trout cage farm using a nutritional approach and monitoring of lake water quality. Aquaculture, 311, 175-186.

Barton, J.R.; Fløysand, A. 2010. The political ecology of Chilean salmon aquaculture, 1982-2010: A trajectory from economic development to global sustainability. Global Environmental Change, 20, 739-752.

Béné, C.; Obirih-Opareh, N. 2009. Social and economic impacts of agricultural productivity intensification: The case of brush park fisheries in Lake Volta. Agricultural Systems, 102, 110.

Beveridge, M.C.M. 2004. Cage aquaculture, Blackwell Publishing, Oxford, UK.368p.

Booth, M.A.; Pirozzi, I.; Alan, G.A. 2010. Estimation of digestible protein and energy requirements of yellowtail kingfish Seriola lalanddi using a factorial approach. Aquaculture, 307, 247-259.

Boehlert, G. W.; Yoklavich, M. M. 1983. Effects of temperature, ration, and fish size on growth of juvenile black rockfish, Sebastes melanops. Environmental biology of fishes, 8(1): 17-28.

Brafield, A. E. 1985. Laboratory studies of energy budgets. In: Fish energetics: new perspectives. Tytler, P. \& Calow, P. (Eds.), Croom Helm Australia Pty Ltd., Sydney: 257-281. 
Brasil. Ministério da Pesca e Aquicultura (MPA). 2013. Balanço 2013 do Ministério da Pesca e Aquicultura. 14p.

Brasil. Mais Pesca e Aquicultura 2008: Plano de Desenvolvimento Sustentável: Uma rede de ações para o fortalecimento do setor. Ministério da Pesca e Aquicultura. 24p.

Brasil. Decreto $\mathrm{n}^{\circ}$ 4.895, de 25 de novembro de 2003. Dispõe sobre a autorização de uso de espaços físicos de corpos d'água de domínio da União para fins de aquicultura, e dá outras providências.

Brasil. Instrução Normativa Interministerial $n^{\circ}$ 06, de maio de 2004. República Federativa do Brasil, Brasília.

Brasil. Instrução Normativa Interministerial $n^{\circ}$ 07, de 28 de abril de 2005. República Federativa do Brasil, Brasília.

Brasil. Lei Federal n. 9.433, de 08 de janeiro de 1997, Institui a Politica e Sistema Nacional de Gerenciamente de Recursos Hídricos.

Brasil. Ministério do Planejamento, Orçamento e Gestão. Secretaria de Planejamento e Investimentos Estratégicos. Plano plurianual 2012-2015: projeto de lei/ Ministério do Planejamento, Orçamento e Gestão, Secretaria de Planejamento e Investimentos Estratégicos. - Brasília: MP, 2011.

Brett, J. R. 1962. Some considerations in the study of respiratory metabolism in fish, particularly salmon. Journal of Fisheries Research Board of Canada, 19: 1025-1038.

Brett, J. R.; Groves, T. D. D. 1979. Physiological energetics. In: Fish physiology. Hoar, W. S., Randall D. J. \& Brett, J. R. (Eds.) Academic Press Inc. Ltd., London, Vol. VIII.

Brister, D.J.; Kapuscinski, A.R. 2000. Environmental assessment tool for cage aquaculture in the Great Lakes Version 1.1. http://www.glfc.org/boardcomm/clc/envir1.pdf. Accesso em 10 jan 2015.

Brummett, R.; Lazard, J. Moehl, J. 2008. African aquaculture: Realizing the potential. Food Policy, $33,371-385$.

Boscolo, W.R.; Feiden, A.; Bombardelli, R.A.; et al. 2005. Exigências de fósforo para alevinos de tilápia do Nilo (Oreochromis niloticus). Acta Scientiarum Animal Sciences., v.27, n.1, p.8791, 2005. 
Bueno, G. W.; Ostrensky, A.; Canzi, C.; Matos, F.T.; Roubach, R. Implementation of aquaculture parks in Federal Government waters in Brazil. Reviews in Aquaculture, v. 7, p. 1-12. 2015.

Burridge, L.; Weis, J.S.; Cabello, F.; Pizarro, J.; Bostick, K. 2010. Chemical use in salmon aquaculture: A review of current practices and possible environmental effects. Aquaculture, $306,7-23$.

Buschmann, A.H.; Cabello, F.; Young, K.; Carvajal, J.; Varela, D.A.; Henríquez, L. 2009. Salmon aquaculture and coastal ecosystem health in Chile: Analysis of regulations, environmental impacts and bioremediation systems. Ocean \& Coastal Management, 52, 243-249.

Bureau, D.P.; Kaushik, S. J.; Cho, C. Y. 2002. Bioenergetics. Pages 1-59. In: J. E. Halver and R. W. Hardy (Eds). Fish Nutrition, Third Edition. Academic Press, San Diego, USA.

Bureau, D.P.; Gunther, S; Cho, C.Y. 2003. Chemical composition and preliminary theoretical estimates of waste outputs of rainbow trout reared on commercial cage culture operations in Ontario. North American Journal of Aquaculture, 65: 33-38.

Bureau, D.P.; Hua, K. 2010. Towards effective nutritional management of waste outputs in aquaculture, with particular reference to salmonid aquaculture operations. Aquaculture Research, 41: 777-792.

Butsic, V.; Lewis, D. J.; Radeloff, V. C. 2010. Lakeshore zoning has heterogeneous ecological effects: an application of a coupled economic-ecological model. Ecological Applications 20:867-879.

Canale, R.P.; Breck, J.E. 2013. Comments on proper (and improper) solutions of bioenergetic equations for modeling fish growth. Aquaculture, 404-405 (2013) 41-46.

Cardia, F.; Lovatelli, A. 2007. A review of cage aquaculture: Mediterranean Sea. In: Cage aquaculture. Regional reviews and global overview. (ed. by Matthias H, Doris S, Arthur JR). FAO, Rome, pp. 159-187.

Carvalho, E.D.; Silva, R.J.; David, G.S. 2012. Health and Enviromnment in Aquaculture. Rijeka: INTECH Open Acess Publisher, 428p.

Chen, J.; Guang, C.; Xu, H.; Chen, Z.; Xu, P.; Yan, X.; Wang, Y.; Liu, J. (2007). A review of cage and pen aquaculture: China. In: Cage aquaculture. Regional reviews and global overview. (ed. by Matthias H, Doris S, Arthur JR). FAO, Rome, pp. 53-72. 
Cho, C. Y.; Slinger, S. J.; Bayley, H. S. 1976. Influence of level and type of dietary protein, and of level of feeding on feed utilization by rainbow trout. J. Nutr. 106:1547-1556.

Cho, C.Y.; Slinger, S.J.; Bayley, H.S. Bioenergetics of salmonid fishes: energy intake, expenditure and productivity, Comp. Biochem. Physiol. 73B (1982) 25-41.

Cho, C. Y.; Kaushik, S. J. 1985. Effects of protein intake on metabolizable and net energy values of fish diets. Pp. 95-117 in Nutrition and Feeding in Fish, C.B. Cowey, A.M. Mackie; J.G. Bell, eds. London, UK: Academic Press.

Cho, C.Y.; Kaushik, S.J. Nutritional energetics in fish. Protein and energy utilization in rainbow trout, in: Boume J.H. (Ed.), Aspects of Food Production, Consumption and Energy Values, World Rev. Anim. Nutr. 61, 1990, pp. 132-172.

Cho, C. Y. 1992. Feeding systems for rainbow trout and other salmonids with reference to current estimates of energy and protein requirements. Aquaculture, 100: 107-123.

Cho, C.Y.; Bureau, D.P. 1997. Reduction of waste output from salmonid aquaculture through feeds and feeding. Progressive Fish Culturist, 59, 155 -160.

Cho, C. Y.; Bureau, D. P. 1998. Development of bioenergetic models and the Fish-PrFEQ software to estimate production, feeding ration and waste output in aquaculture. Aquatic Living Resources, 11(4): 199-210.

Cho, C.Y.; Bureau, D.P. 2001. A review of diet formulation strategies and feeding systems to reduce excretory and feed wastes in aquaculture. Aquaculture Research, 32: 349-360.

Chou, C.L.; Haya, K.; Paon, L.A.; Moffatt, J.D. 2004. A regression model using sediment chemistry for the evaluation of marine environmental impacts associated with salmon aquaculture cage wastes. Marine Pollution Bulletin, 49, 465-472.

Chowdhury, K.M.A.; Siddiqui, S.; Hua, K; Bureau, D.P. 2013. Bioenergetic-based Factorial Model to Determine Feed Requirement and Waste Output of Tilapia Produced under Commercial Conditions. Aquaculture, 410-411, 138-147.

CONAMA - BRASIL. Conselho Nacional de Meio Ambiente. Resolução Conama nº 357, de 17 de março de 2005. Disponível em: <http://www.mma.gov.br/port/conama/res/res05/res35705.pdf>. Acesso em: 19 fev. 2015.

CONAMA - BRASIL. Conselho Nacional de Meio Ambiente. Resolução Conama $n^{o}$ 428, de 17 de dezembro de 2010. Conselho Nacional de Meio Ambiente, Brasília. 
Cowey, C.B.; Cho, C.Y. 1991. Nutritional Strategies and Aquaculture Waste. Proceedings of the First International Symposium on Nutritional Strategies in Management of Aquaculture Waste. University of Guelph, Guelph, Ontario, Canada, 1990. 275p.

Cui, Y.; Wootton, R. J. 1989. Bioenergetics of growth of a cyprinid, Phoxinus phoxinus (L.): development and testing of a growth model. Journal of Fish Biology, 34: 47-64.

Cui, Y.;Xie, S. 2000. Modelling Growth in Fish. Feeding Systems and Feed Evaluation Models. Theodorou, M. K. \& France, J. (Eds.), CAB International: 413-434.

Csargo, I.J., Brown, M.L., Chipps, S.R., 2012. Application of a bioenergetics model for hatchery production: largemouth bass fed commercial feeds. North American Journal of Aquaculture, $74,352-359$.

De Silva, S.S. 2002. Reservoir fisheries: broad strategies for enhancing yields. In: Reservoir and Culture-based Fisheries: Biology and Management. (ed by De Silva SS). ACIAR, Canberra, pp. 7-16.

De Silva, S.S; Phillips, M.J. 2007. A review of cage aquaculture: Asia (excluding China). In: Cage aquaculture. Regional reviews and global overview. (ed. by Matthias H, Doris S, Arthur JR). FAO, Rome, pp. 21-48.

Dillon, P.J.; Rigler, F.H. 1974. A test of a simple nutrient budget model predicting the phosphorus concentration in lake water. J. Fish. Res. Board Can. 31:1771-1778.

Dumas, A.; France, J; Bureau, D.P. 2010. Modelling growth and body composition in fish nutrition: where have we been and where are we going? Aquaculture Research, 41, 161-181.

El-Gayar, O.F.; Leung, P. 2000. ADDSS: a tool for regional aquaculture development. Aquacultural Engineering, 23, 181-202.

Ege, R.; Krogh, A. 1914. On the relation between the temperature and the respiratory exchange in fishes. International Revue of Hydrobiology, 1: 48-55.

Faria, A. C. E. A.; Hayashi, C.; Soares, C. M., 2002. Farinha de Vísceras de Aves em Rações para Alevinos de Tilápia do Nilo, Oreochromis niloticus (L.). Revista Brasileira de Zootecnia, v.31, n.2, p.812-822, 2002 (supl).

Fitzsimmons, K. 2000. Future trends of tilapia aquaculture in the Americas. In: Tilapia aquaculture in the Americas (eds Costa-Pierce BA, Rackocy JE). The World Aquaculture Society, Baton Rouge, LA, USA, pp. 252-264. 
FAO (2013). Global aquaculture production statistics 2011. Fisheries and Aquaculture Department of the Food and Agriculture Organization of the United Nations, Rome.115p.

Furuya, W.M. 2010. Tabela Brasileira para a nutrição de tilápias. Toledo: GFM, 2010.100 p.

Garcia, F; Romera, D. M.; Gozi, K. S.; Onaka, E. M.; Fonseca, F. S.; Schalch, S. H. C.; Candeira, P. G.; Guerra, L. O. M.; Carmo, F. J.; Carneiro, D. J.; Martins, M. I. E. G.; Portella, M. C. 2013. Stocking density of Nile tilapia in cages placed in a hydroelectric reservoir. Aquaculture, v. 410, p. 51-56

Godinho, H.P. Estratégias reprodutivas de peixes aplicada à aquicultura: bases para o desenvolvimento de tecnologias de produção. Rev. Bras. Rep. Anim. 2007, 31, 351-360.

Gondwe, M.J.S.; Guildford, S.J.; Hecky, R.E. 2011. Carbon, nitrogen and phosphorus loadings from tilapia fish cages in Lake Malawi and factors influencing their magnitude. Journal of Great Lakes Research, 37, 93-101.

Grøttum, J.A.; Beveridge, M. 2007. A review of cage aquaculture: northern Europe. In: Cage aquaculture. Regional reviews and global overview. (ed. by Matthias H, Doris S, Arthur JR). FAO, Rome, pp. 129-154.

Guo, L. 2003. Effects of nitrogen and phosphorus from fish cage-culture on the communities of a shallow lake in middle Yangtze River basin of China. Aquaculture, 226, 201-212.

Gowen, R.J.; Weston, D.P.; Ervik, A. 1991. Aquaculture and the benthic environment: a review. In:

Nutritional Strategies and Aquaculture Waste (ed. by C.B. Cowey; C.Y. Cho), 187-205. Proceedings of the First International Symposium on Nutritional Strategies in Management of Aquaculture Waste, University of Guelph, Ontario, Canada. Fish Nutrition Research Laboratory, University of Guelph, Canada.

Hargreaves, J.A. 1998. Nitrogen biogeochemistry of aquaculture ponds. (Review). Aquaculture, Amsterdam, 166:181-212.

Halide, H.; Stigebrandt, A.; Rehbein, M.; Mckinnon, A.D. 2009. Developing a decision support system for sustentaible cage aquaculture. Enrironmental Modelling Software, 24: 694-702.

Hamblin, P.F.; Gale, P. 2002. Water Quality Modeling of Caged Aquaculture Impacts in Lake Wolsey, North Channel of Lake Huron. Journal of Great Lakes Research, 28, 32-43.

Hambrey, J.; Edwards, P.; Belton, B. 2008. An ecosystem approach to freshwater aquaculture: a global review. In: Building an ecosystem approach to aquaculture (ed. by Soto D, Aguilar- 
Manjarrez J, Hishamunda N). FAO/Universitat de les Illes Balears Expert Workshop, Palma de Mallorca, Spain, pp. 117-221.

Hopkins, K. D. 1992. Reporting Fish Growth: a Review of the Basics. Journal of the World Aquaculture Society, 23(3): 173-179.

Hua, K.; Bureau, D.P. 2006. Modelling digestible phosphorus content of salmonid fish feeds. Aquaculture, vol. 254, p. 455-465.

Hua, K.; D.P. Bureau. 2010. Quantification of differences in digestibility of phosphorus among cyprinids, cichlids, and salmonids through a mathematical modelling approach. Aquaculture, 308: $152-158$

Hurwitz S., Sklan D., Bartov I. 1978: New formal approaches to the determination of energy and amino acid requirements of chickens. Poultry Science, 57, 197-205.

Instituto Brasileiro de Geografia e Estatística - IBGE. Produção da Pecuária Municipal. Prod. Pec. munic., Rio de Janeiro, v. 41, p.1-108, 2013.

Iwama, G. K.; Tautz, A. F. 1981. A Simple Growth Model for Salmonids in Hatcheries. Canadian Journal of Fisheries and Aquatic Sciences, 38: 649-656.

Ivlev, V. S. 1939. Energy balance in the carp. Zool. Zh. 18: 303-318.

Israel, D.C. 2007. The current state of aquaculture in Laguna de Bay. In: Discussion Paper Series No. 2007-20. Philippine Institute for Development Studies, Makati City, Philippines, pp. 1-65.

Jobling, M. 2003. The thermal growth coefficient (TGC) model of fish growth: a cautionary note. Aquae. Res. 34: 581-584.

Jobling, M. 2011. Bioenergetics in aquaculture settings. In: Farrell, A.P. (Ed.), Encyclopedia of Fish Physiology: From Genome to Environment. Elsevier, Oxford, pp. 1664-1674.

Kaushik, S. J. 1998. Nutritional bioenergetics and estimation of waste production in non-salmonids. Aquatic Living Resources, 11(4): 211- 217.

Kaushik, S. J.; Médale, F. 1994. Energy-requirements, utilization and dietary supply to salmonids. Aquaculture, 124(1-4).

Kerr, S. R. 1971. A simulation model of lake trout growth. Journal of Fisheries Research Board of Canada, 28(6): 815-819. 
Kitchell, J. F., Koonge, J. F., O'Neill, R. V., Shugart, H. H., Magnuson, J. J.; Booth, R. S. 1974. Model of fish biomass dynamics. Transactions of the American Fisheries Society, 103(4): 786-798.

Kitchell, J. F.; Stewart, D. J.; Weininger, D. 1977. Applications of bioenergetics model to yellow perch (Perca flavescens) and walleye (Stizostedion vitreum vitreum). J. Fish. Res. Board Can, 34: 1922-1935.

Kubitza, F. 1999. Tanques-rede, rações e impacto ambiental. Revista Panorama da Aquicultura, v. 51, n. 9, p. 44-50, 1999.

Lall S.P. 1991. Digestibility, metabolism and excretion of dietary phosphorus in Fish. In: Nutritional Strategies and Aquaculture Waste (ed. by C.B. Cowey \& C.Y. Cho), 21-36. Proceedings of the 1st International Symposium on Nutritional Strategies in Management of Aquaculture Waste, Guelph, Ontario, Canada. Fish Nutrition Research Laboratory, University of Guelph, Canada.

Lazzeri, R.; Baldisseroto, B. 2008. Nitrogen and phosphorus waste in fish farming. B. Inst. Pesca, São Paulo, 34(4): 591 - 600.

Lehninguer, A. L. 1971. Bioenergetics: The Molecular Basis of Biological Energy Transformations. Binding: Soft cover Book Condition: Fine Edition: 2nd Edition. 245p.

Macedo, C. F.; Sipaúba-Tavares, L. H. 2010. Eutrophication and water quality in pisciculture: consequences and recommendations. Bol. Inst. Pesca, 36 (2): 149-163.

Masser, M.P.: Bridger, C.J. 2007. A review of cage aquaculture: North America. In: Cage aquaculture. Regional reviews and global overview. (ed. by Matthias H, Doris S, Arthur JR). FAO, Rome, pp. 105-125.

Montanhini Neto, R.; Ostrensky, A. 2013. Nutriente load estimation in the waste of Nile tilápia Oreochromis niloticus (L.) reared in cages in tropical climate conditions. Aquaculture Research, 114.

National Research Council - NRC. 2011. Nutrient Requirements of Fish and Shrimp. National Academy Press, Washington, DC.392p.

Nepomuceno, D. 2004. Addressing freshwater conflicts: The LLDA experience in Laguna de Bay. In: Workshop on Natural Resource-Based Conflicts in the Philippines Sponsored by the 
United States Agency for International Development (USAID) and the Department of Environment and Natural Resources (DENR, Westin Philippine Plaza, Psay City, Philippines.

Neves, P.R.; Natali, M.R.M.; Ribeiro, R.P; et al., 2009. Morphological characteristics of ovarian development Of two Nile tilapia (Oreochromis niloticus) strains in mixed-culture systems. Arq. Bras. Med. Vet. Zootec.,v.61, n.5, p.1173-1182, 2009.

Nilsson, C. 2009. Reservoirs. In: Encyclopedia of Inland Waters (ed by Gene EL). Academic Press, Oxford, pp. 625-633.

Niimi, A.; Beamish, F. W. H. 1974. Bioenergetics and growth of largemouth bass (Micropterus salmoides) in relation to body weight and temperature. Canadian Journal of Zoology, 52(4): 447- 456.

Petrere, M. 1996. Fisheries in large tropical reservoirs in South America. Lakes \& Reservoirs: Research \& Management, 2, 111-133.

Petts, G.E. 1984. Impouded rivers: perspectives for ecological management., Wiley \& Sons, 326 p.

Persson G. 1991. Eutrophication resulting from salmonid fish culture in fresh and salt waters: Scandinavian experience. In: Nutritional Strategies and Aquaculture Waste (ed. by C.B. Cowey \& C.Y. Cho), 163-185. Proceedings of the 1st International Symposium on Nutritional Strategies in Management of Aquaculture Waste, Guelph, Ontario, Canada. Fish Nutrition Research Laboratory, University of Guelph, Canada.

Penczak T., Galicka W., Molinski M., Kusto E. \& Zalewski M. (1982) The enrichment of a mesotrophic lake by carbon, phosphorus and nitrogen from the cage aqua- culture of rainbow trout, Salmo gairdneri. Journal of Applied Ecology 19, 371-393.

Phouthavongs, K. 2006. Employing geographical information systems in fisheries management in the Mekong River: a case study of Lao PDR. In: School of Geosciences. University of Sydney, Sydney, pp. 210.

Ramos, I.P.; Franceschini, L.; Zica, É.O.P.; Carvalho, E.D.; Silva, R.J. 2014. The influence of cage farming on infection of the corvine fish Plagioscion squamosissimus (Perciformes: Sciaenidae) with metacercariae of Austrodiplostomum compactum (Digenea: Diplostomidae) from the Chavantes reservoir, São Paulo State, Brazil. Journal of Helminthology, v. 88, p. 342-348, 2014. 
Rojas A, Wadsworth S (2007) A review of cage aquaculture: Latin America and the Caribbean. In: Cage aquaculture. Regional reviews and global overview. (ed. by Matthias H, Doris S, Arthur JR). FAO, Rome, pp. 73-100.

Rice, J. A., Breck, J. E., Bartell, S. M.; Kitchell, J. F. 1983. Evaluating the constraints of temperature, activty and consumption on growth of largemouth bass. Environmental biology of fishes 9(3-4): 263-275.

Ricker, W. E. 1979. Growth rates and models. In: Fish physiology. Hoar, W. S. Randall, D. J. \& Brett, J. R. (Eds.), Academic Press Inc. Ltd., London, Vol. VIII.

Sang, J.S. 2006. Lawmaking for Management and Protection of Wetlands in China. Wetland Science \& Management, 2, 50-53.

Solomon, D. J.; Brafield, A. E. 1972. The energetics of feeding, metabolism and growth of perch (Perca fluviatilis L.). Journal of Animal Ecology 41(3): 699-718.

Strand, Å., Alanärä, A.;Magnhagen, C. 2005. The effect of group size on feed intake, growth and energy expenditures of juvenile perch (Perca fluviatilis). In prep.

Skonhoft, A. 2005. National Aquaculture Legislation Overview - Denamark. http://www.fao.org/fishery/legalframework/nalo_denmark/en. Accessad on 10 november 2012.

Sowles, J. 2009. Aquaculture task force discussion paper on bio-physical carrying capacity. http://www.maine.gov/dmr/aquaculture/reports/carryingcapacity.pdf. Accessad on 11 march 2013.

Spoor, W. A. 1946. A quantitative study of the relationship between activity and oxygen consumption of the goldfish and its application to the measurement of respiratory metabolism in fishes. Biology Bulletin 91: 312-325.

Stickney, R.R. Tilapia nutrition feeds and feeding. In: Costa-Pierce, B.A.; Rakocy, J.E. (Eds.) Tilapia Aquaculture in the Americas.Baton Rouge: The World Aquaculture Society \& The American Tilapia Association, 1997. v.1, p.34-54.

Shearer, K.D. 1994. Factors affecting the proximate composition of cultured fshes with emphasis on salmonids. Aquaculture 11, 63-88. 
SINAU/MPA - Sistema de Informação das Autorizações de Uso das Águas de Domínio da União para fins de Aquicultura - SINAU. 2014. Apresentações de infromações técnicas do plano safra 2013/2014. 123p.

Su, L. Liu, J. Christensen, P. 2010. Comparative study of water resource management policies between China and Denmark. Procedia Environmental Sciences, 2, 1775-1798.

Sugiura, S.H. Marchant, D.D. Kelsey, K.; Wiggins, T; Ferraris, R.P. 2006. Effluent profile of commercially used low-phosphorus fish feeds. Environmental Pollution, 140, 95-101.

Tacon, A.G.J. Salmon aquaculture dialogue: Status of information on salmon aquaculture feed and the environment. Aquafeed International, v.8, p.22-37, 2005.

Tacon, A.G.J.; Halwart M (2007) Cage aquaculture: a global overview. In: Cage aquaculture. Regional reviews and global overview. (ed. by Matthias H, Doris S, Arthur JR). FAO, Rome, pp. 3-16.

Talbot, C. 1985. Laboratory methods in fish feeding and nutritional studies. In: Fish energetics: new perspectives. Tytler, P. \& Calow, P. (Eds.), Croom Helm Australia Pty Ltd., Sydney: 125154.

Tundisi, T.M.J.G, Tundisi TM. (2008) Limnologia. Oficina de textos, São Paulo.

Ursin, E. 1967.Amathematical model of some aspects of fish growth, respiration and mortality. Journal of Fisheries Research Board of Canada 24: 2355-2453.

Wang, X.; Olsen, L.M.; Reitan, K.I.; Olsen, Y. 2012. Discharge of nutrient wastes from salmon farms: environmental effects, and potential for integrated multi-trophic aqua- culture. Aquacult Environ. Interact., 2:267-283.

Warren, C. E. \& Davis, G. E. 1967. Laboratory studies on the feeding, bioenergetics, and growth of fish. In: The Biological Basis of Freshwater Fish Production. Gerking, S. D. (Ed.): 175-214.

Wootton, R. J. 1998. Ecology of Teleost Fish. Kluwer Academic Publishers, Dordrecht.

Yi, Y. 1999. A bioenergetics growth model for Nile tilapia (Oreochromis niloticus) based on limiting nutrients and fish standing crop in fertilized ponds. Aquacultural Engineering, 18: $157-173$.

Zhou, Z.; Xie, S.; Lei, W.; Zhu, X.; Yang, Y. 2005. A bioenergetic model to estimate feed requirement of gibel carp, Carassius auratusgibelio. Aquaculture, 248: 287- 297. 


\section{CAPÍTULO 2}

\section{BIOENERGÉTICA NUTRICIONAL PARA A ESTIMATIVA DA EXIGÊNCIA ALIMENTAR E EFLUENTES DA PRODUÇÃO COMERCIAL DE TILÁPIA DO NILO (Oreochromis niloticus) EM RESERVATÓRIO NA REGIÃO SUDESTE DO BRASIL}

Guilherme Wolff Bueno ${ }^{1}$, Francisco Ernesto Moreno Bernal ${ }^{2}$, Rodrigo Roubach ${ }^{3}$, James Owen Skipper-Horton ${ }^{4}$, Dominique P. Bureau ${ }^{4}$

${ }^{1}$ Zootecnista, Doutorando da UnB, Brasília, DF - Brasil

${ }^{2}$ Médico Veterinário, Doutor, Professor da UnB, Brasília, DF - Brasil

${ }^{3}$ Biólogo, Doutor, Ministério da Pesca e Aquicultura, Brasília, DF - Brasil

${ }^{4}$ Cientista Animal, Doutor, Universidade de Guelph, Guelph, Ontário - Canadá 


\section{RESUMO}

O estudo consistiu na determinação do requisito alimentar (Dreq.) e na estimativa de resíduos sólidos (RS) e dissolvidos (RD) com as respectivas frações de resíduos dissolvidos fosfatados (P) e nitrogenados $(\mathrm{N})$ da produção comercial de tilápia (Oreochromis niloticus) cultivada em tanquesrede utilizando a abordagem da modelagem bioenergética nutricional e o cálculo do balanço de massas. Utilizaram-se informações de 30 tanques-rede de uma fazenda comercial localizada no reservatório de Chavantes, SP. No mesmo período, implantou-se um cultivo experimental com 10.700 tilápias com peso inicial de $36 \pm 2,70 \mathrm{~g}$ e peso médio final de $789 \pm 5,12 \mathrm{~g}$, distribuídas igualmente em quatro tanques-rede. Mensalmente, durante os 210 dias de cultivo, mediram-se o desempenho zootécnico e a composição centesimal corporal dos peixes em cultivo. Paralelamente, realizaram-se ensaios de digestibilidade das rações comerciais utilizadas para as fases de juvenil I (JVI: 30 a 100g), juvenil II (JVII: 100 a 500g) e peso de mercado (PM: >500g). Relações isométricas e alométricas de peso vivo com a água, proteína bruta, lipídios, cinza, energia bruta, fósforo e nitrogênio corporal foram avaliados por meio de análise de regressão. A Dreq., o RS e RD para cada fase de cultivo foram estimadas usando o modelo fatorial bioenergético Fish-PrFEQ ${ }^{\circledR}$ e adaptadas para as condições de cultivo em reservatório tropical localizado no estado de São Paulo, na região sudeste do Brasil. As rações apresentaram 32, 29 e 29\% de proteína digestível; 15; 14 e 13 $\mathrm{MJ} \mathrm{kg}^{-1}$ de energia digestível e 0,85;0,67;0,62\% de fósforo digestível para as respectivas fases JVI, JVII, PM. O RE médio foi de 6,13 $\mathrm{MJ} \mathrm{kg}^{-1}$. Obtiveram-se valores médios de 282,4 de RS, sendo 9,8 $\mathrm{kg} / \mathrm{t}$ de nitrogênio sólido e 5,1 kg/t de fósforo sólido, além de 44,8 e 2,9 quilos de $\mathrm{N}$ e P dissolvidos para cada tonelada de peixe produzido.

Palavras-chave: aquicultura sustentável, bioenergética; capacidade de suporte, resíduos aquícolas, modelo fatorial; tilápia do Nilo. 


\begin{abstract}
The study consisted in determining the feed requirement (Dreq.) and the estimation of solid waste (RS) and dissolved (RD) - phosphate (P) and nitrogen (N) - from the commercial production of tilapia (Oreochromis niloticus) rared in cages using the approach of nutritional bioenergetics modeling and calculating the mass balance. It was used information of 30 cages of a commercial farm located in Chavantes reservoir, São Paulo, Brasil. In the same period, it was implemented an experimental cultivation of 10,700 tilapia equally distributed in four cages with initial weight of 36 $\pm 2.70 \mathrm{~g}$ and $789 \pm 5.12 \mathrm{~g}$ final weight. Monthly, during 210 days of cultivation, fish growth performance was monitored and the body composition analysed. At the same time, the digestibility trials of commercial diets used for juvenile stages (JVI: 30 to 100g), juvenile II (JVII: 100 to 500g) and market weight (PM: >500g) were performed. Isometric and allometric relationships of body weight with water, protein, fat, ash, gross energy, phosphorus and nitrogen body were evaluated by regression analysis. The Dreq., and estimation of charged residues of the fish production were estimated using the factorial bienergetic model Fish-PrFEQ ${ }^{\circledR}$ and adapted these growing conditions for tropical reservoir. The diets have 32, 29 and $29 \%$ of digestible protein; $15 ; 14$ and $13 \mathrm{MJ} \mathrm{kg}^{-1}$ of digestible energy and $0.85 ; 0.67 ; 0.62 \%$ of digestible phosphorus for the respective phases JVI, JVII, PM. The average RE was $6.13 \mathrm{MJ} \mathrm{kg}^{-1}$. Mean values observed were $282.4 ; 9.8 ; 5.1 ; 44.8 ; 2.9$ $\mathrm{kg}$ per ton of fish produced for TRS, TNS, TFS, TND, TFD, respectively.
\end{abstract}

Keywords: aquaculture waste, bioenergetic, carrying capacity, sustainable aquaculture, factorial model, tilapia. 


\section{INTRODUÇÃO}

A aquicultura passou por um intenso processo de desenvolvimento nos últimos dez anos, sendo que seu crescimento médio mundial na última década foi cinco vezes maior, quando comparada as outras atividades do setor, tais como a bovinocultura, a suinocultura e a avicultura (FAO, 2013).

No Brasil, a atividade tem se consolidado cada vez mais, em decorrência dos recursos hídricos disponíveis, clima favorável, mão de obra relativamente pouco onerosa e crescente mercado interno (Garcia et al. 2013). Nesta década, o país chegou ao sexto lugar como produtor de tilápia cultivada no mundo, isto representou aproximadamente $43 \%$ da produção total de pescados no país com valores em torno de 169 mil toneladas/ano (MPA/IBGE, 2013).

Segundo o relatório “Fish to 2030: Prospects for Fisheries and Aquaculture”, cerca de 62\% dos peixes para o consumo humano virá da aquicultura até 2030, sendo que a produção de tilápia, carpa e bagre serão as principais espécies cultivadas. A produção global de tilápia esperada será quase o dobro, de 4,3 milhões de toneladas para 7,3 milhões de toneladas por ano.

Neste cenário, Montanhini Neto e Ostrensky (2015) citam que para produzir uma tonelada de tilápias são lançados no ambiente aproximadamente $1.040 \mathrm{~kg}$ de matéria orgânica, $45 \mathrm{~kg}$ de nitrogênio e $14 \mathrm{~kg}$ de fósforo. Alves e Baccarin (2005) relatam que 66\% do fósforo aportado pelo arraçoamento intensivo em fazendas de peixes vão para o sedimento, $11 \%$ ficam dissolvidos na água e $23 \%$ são incorporados no peixe em cultivo.

Portanto, os resíduos lançados pela aquicultura tornam-se uma preocupação e um limitante para o desenvolvimento sustentável da atividade. Assim, vários pesquisadores (Cho e Bureau, 1998; Lupatsch e Kissil, 1998; Yi, 1999; Bureau e Hua, 2010; Azevedo et al., 2011; Csargo et al., 2012) têm demonstrado que os produtos residuais e taxas de alimentação requerida pelos peixes podem ser estimadas por meio de modelos matemáticos fatoriais. 
Dentres estes modelos, detaca-se a bioenergética nutricional que descreve o fluxo de energia dos nutrientes dentro de um sistema biológico, considerando o processo de utilização e transformação dos nutrientes absorvidos para a síntese corporal (Jobling, 2011). Este permite considerar fatores como: peso corporal, taxa de crescimento, sexo, atividade, estado fisiológico, meio ambiente e composição da alimentação fornecida para o ajuste do manejo nutricional e simulação de resíduos excretados pelos peixes (NRC, 2013).

Diante disto, o objetivo deste estudo consistiu em determinar a exigência alimentar e os efluentes sólidos e dissolvidos (fósforo e nitrogênio) de uma produção comercial de tilápia do Nilo (Oreochromis niloticus) cultivada em tanques-rede em reservatório tropical localizado no estado de São Paulo - Brasil, por meio do cálculo do balanço de massas e do modelo bioenergético nutricional Fish-PrFEQ ${ }^{\circledR}$. 


\section{MATERIAL E MÉTODOS}

\subsection{Local experimental e coleta de dados}

Utilizou-se o histórico do desempenho zootécnico de trinta tanques-rede (ciclo completo) de uma fazenda comercial de tilápia do Nilo (Oreochromis niloticus) instalada no reservatório de Chavantes (trecho lêntico, ambiente oligotrófico segundo Perbiche-Neves et al. (2011), localizado no rio Paranapanema entre os estados de São Paulo e Paraná, no município de Fartura, Brasil com as coordenadas geográficas em UTM - SAD69: 1 (644.481 E, 7.413.975 N); 2 (644.500 E, 7.413.928 N); 3 (644.781 E, 7.414.038 N) (Figura 13).
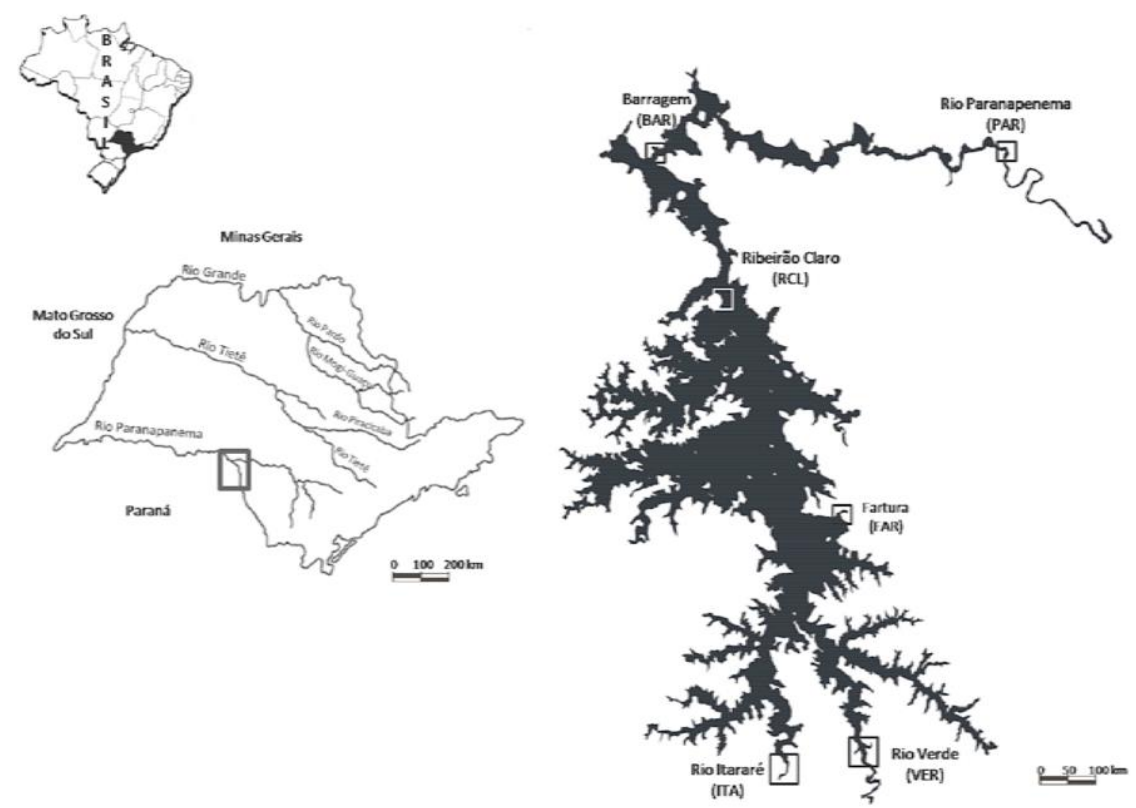

Figura 13. Mapa identificando o estado de São Paulo, os trechos lóticos: rio Itararé (ITA) e verde (VER), intermediários: rio Paranapanema (PAR) e Fartura (local do 
experimento) e lênticos: Barragem (BAR) e Ribeirão Claro (RCL). Fonte: Mangoni (2009)

De acordo com Köppen, o clima dominante desta região é classificado como Cwa e abrange toda a parte central do estado de São Paulo, sendo caracterizado pelo clima tropical de terra alta, com chuvas no verão e seca no inverno, com temperatura média no mês mais quente acima de $22^{\circ} \mathrm{C}$ (Köppen, 1948).

Além dos dados históricos, implantou-se neste reservatório um cultivo experimental com 10.700 machos revertidos de tilápia do Nilo (Oreochromis niloticus) linhagem Gift, oriundas de uma piscicultura comercial com peso médio de $36 \pm 2.73 \mathrm{~g}$ distribuídos igualmente em quatro tanques-rede de $16,2 \mathrm{~m}^{3}$ (3,0 x 3,0 x 1,8 m), com a densidade média de $40 \mathrm{~kg}_{\text {por }} \mathrm{m}^{3}$. Os peixes foram cultivados até o peso médio de $130 \mathrm{~g}$ e posteriormente, transferidos para tanques-rede de 43 $\mathrm{m}^{3}(6,0 \times 6,0 \times 1,2 \mathrm{~m})$, mantendo-se a densidade de $75 \mathrm{~kg}$ por $\mathrm{m}^{3}$ até atingirem o peso médio de mercado (PM) de aproximadamente 800g (Figura 14).

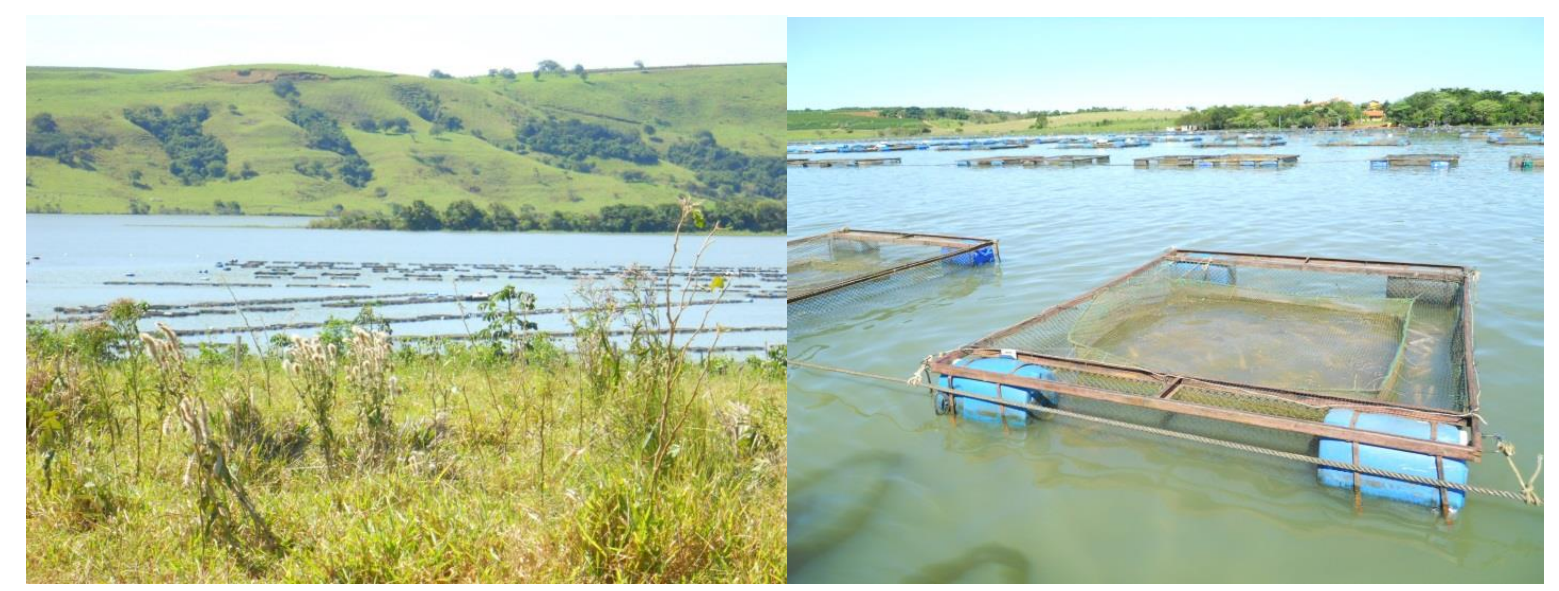

Figura 14. Tanques-rede comerciais utilizados durante o experimento.

\subsection{Dieta e alimentação}

Utilizaram-se rações comerciais extrusadas contendo níveis de garantia de 32\% de proteína bruta, $92 \%$ de matéria seca, $6 \%$ de lipídio, $13 \%$ de cinzas, $17.50 \mathrm{MJ} \mathrm{kg}^{-1}$ de energia bruta e $1,5 \%$ de fósforo total, recomendadas comercialmente para as fases de juvenil I (JVI: 30 a $100 \mathrm{~g}$ ), com granulometria de 4 a 6 mm, fase de juvenil II (JVII: 100 a 500 g), com granulometria de 6 a 8 mm e fase de terminação ou peso de mercado (PM: >500 g), com granulometria de 8 a $10 \mathrm{~mm}$.

Deste lote de ração utilizado durante o experimento, coletaram-se seis amostras de $300 \mathrm{~g}$ de cada ração das três fases de cultivo (JVI, JVII e PM), estas foram identificadas e preservadas em 
sacos térmicos na câmara fria $\mathrm{a}-10^{\circ} \mathrm{C}$ para posterior análise centesimal e comparação com os valores fornecidos no rótulo das rações comerciais.

Os peixes foram alimentados quatro vezes ao dia, a cada três horas, até a saciedade aparente. Os valores de arraçoamento diário de cada tanque-rede foram quantificados individualmente e registrados por meio do aplicativo Aquability ${ }^{\circledR}$.

\subsection{Composição corporal e analises químicas}

Mensalmente, 5\% dos indivíduos de cada tanque-rede foram retirados para pesagem individual e durante o manejo de transição das fases, todos os indivíduos foram pesados (ajuste de densidade de acordo com o manejo adotado na fazenda: início 30g, classificação com $100 \mathrm{~g}$ e $500 \mathrm{~g}$ ). Dentre estes exemplares, retiraram-se 50 animais de cada tanque-rede durante sete meses de cultivo totalizando 1.400 amostras para a caracterização química corporal das fases de JVI, JVII e PM. Para a captura dos peixes, utilizou-se um puçá e em seguida os peixes foram acondicionados em um recipiente de 20 litros de água diluído com $50 \mathrm{mg} \mathrm{L}^{-1}$ de óleo de cravo como anestésico (INOUE et al., 2003).

Os procedimentos de manejo dos animais seguiram os protocolos de manejo racional e BemEstar Animal de acordo com o preconizado pela World Society for the Protection of Animals WSPA e foi aprovado pela Comissão de Ética no Uso Animal (CEUA) do Instituto de Ciências Biológicas da Universidade de Brasília - UnB sob o protocolo UnB Doc n ${ }^{52708 / 2013 .}$

No Laboratório de Análises Avançadas e Biotecnologia da Universidade Federal de Lavras UFLA, seguiu-se o protocolo do Laboratório de Nutrição de Peixes (FNRL) da Universidade de Guelph, Ontário, Canadá onde as amostras de cada período de coleta (total de peixes por tanquerede por mês/período) foram inseridas em sacos térmicos e processadas na autoclave de 20 litros a temperatura de $121^{\circ} \mathrm{C}$ sob pressão de $1 \mathrm{kgf} / \mathrm{cm}^{3}$ por 90 minutos, estas foram processadas em triplicata. Posteriormente adicionou-se $0.6 \mathrm{ml}$ de antioxidante (Etoxiquin ${ }^{\circledR}$ ) para evitar a degradação.

As amostras foram homegenizadas no processador de alimentos, formando uma massa única de peixe, a qual foi congelada a $-90^{\circ} \mathrm{C}$ por 48 horas para posterior redução do teor de umidade pelo processo de liofilização e determinação da matéria seca (MS) para posteriores análises centesimais (AOAC, 2000).

Para a quantificação do teor de proteína bruta $(\% \mathrm{~PB}=\% \mathrm{~N} \times 6,25)$, utilizou-se o método de Kjeldahl, com o auxílio do Kjeltech 1030 autoanalyser (Tecator, Hoganas, Sweden) e do lipídeo, 
pelo método de ácido hidrólise, ambos seguindo o proposto pela AOAC (2000). As cinzas foram determinadas por incineração a $550^{\circ} \mathrm{C}$. Os teores de fósforo total foram obtidos pelo método colorimétrico segundo Nakamura (1957) e o extrativo não nitrogenado (ENN) pela fórmula (ENN= matéria seca - proteína bruta - lipídios - cinzas). A energia bruta (EB) foi determinada pela bomba calorimétrica (Parr Instruments, Moline, IL, USA). Um coeficiente de variação de repetições inferiores a $5 \%$ foi considerado como aceitável, caso contrário, as amostras foram novamente analisadas.

\subsection{Desempenho zootécnico e qualidade da água}

Semanalmente às $11 \mathrm{~h}$ a.m. na superfície do reservatório $(3 \mathrm{~m})$ foram analisados in loco os parâmetros da qualidade de água como: temperatura da água $\left({ }^{\circ} \mathrm{C}\right)$, transparência (disco de Secchi), o potencial hidrogeniônico $(\mathrm{pH})$, o oxigênio dissolvido $\left(\mathrm{O}_{2} \mathrm{D}\right)$ e a saturação $\left(\mu \mathrm{S} . \mathrm{cm}^{-1}\right)$ por meio de uma sonda multiparâmetro YSI. Mensalmente, utilizou-se a garrafa de Von Dorn para coleta de água e posterior análise do fósforo e nitrogênio totais seguindo a metodologia proposta por APHA (1998). Durante o cultivo, avaliraram-se os índices de desempenho zootécnico e quantificou-se a mortalidade (\%) para posterior cálculo dos seguintes parâmetros:

i) Consumo de ração seca (Consumo = ração seca total $/ \Sigma$ (número de peixes $\times$ número de dias);

ii) Ganho de peso vivo $\left(\mathrm{GP}=\right.$ (peso corporal final $\left(\mathrm{g}\right.$ peixe $\left.\mathrm{e}^{-1}\right) /$ número final de peixe) - (peso Corporal inicial (g peixe $\left.\mathrm{g}^{-1}\right) /$ número inicial de peixe);

iii) Taxa de Conversão alimentar (TCA = consumo de ração/ganho de peso vivo seco);

iv) Biomassa total $(\mathrm{BT}=$ número de peixes $\times$ peso individual);

v) Eficiência alimentar (EA = ganho de peso vivo seco/ consumo de ração);

vi) Taxa de eficiência protéica (TEP = ganho em peso úmido/proteína consumida);

vii) Retenção de proteína $(\mathrm{RP}=[$ (peso corporal final $\times$ proteína corporal final - peso corporal inicial $\times$ proteína corporal inicial)/(consumo de ração/ proteína digestível)];

viii) Retenção de fósforo $(\mathrm{RF}=[$ (peso corporal final $\times$ fósforo corporal final - peso corporal inicial $\times$ fósforo corporal inicial)/(consumo de ração/ fósforo digestível)] e

ix) Retenção de energia bruta $(\mathrm{REB}=[$ (peso corporal final $\times$ energia corporal final - peso corporal inicial $\times$ energia corporal inicial)/(consumo de ração/ energia digestível)]. 


\subsection{Aplicação dos diferentes modelos de crescimento corporal}

Para comparação de vários modelos de crescimento corporal, utilizaram-se os dados de crescimento da tilápia obtidos neste estudo e os dados históricos de 30 lotes do cultivo comercial da tilápia na fazenda comercial em questão, que caracteriza-se pelo crescimento obido em cada tanque-rede durante a safra/ciclo completo, estes foram separados de acordo com sua fase de produção (JVI, JVII e PM).

Aplicaram-se as equações da taxa de crescimento específico (TCE) (Eq. 1), coeficiente de crescimento diário (CCD) (Eq. 2), linear (Eq. 3) e o coeficiente de crescimento térmico (TGC) mantendo o expoente do peso corporal fixo $(1-b=0,3333)$ (Eq. 4). Posteriormente, este foi calibrado por interação de acordo com o preconizado por Dumas et al. (2010).

Obtidos os valores de crescimento nestes modelos, aplicou-se a técnica de mínimos quadrados para minimizar a soma dos quadrados dos resíduos (RSS). Desta forma, o desempenho dos modelos de avaliação do crescimento corporal foram comparados pelos valores de RSS como um fator determinante para identificar o melhor modelo de crescimento e realizar o ajuste adequado para as condições de temperatura da água e metabolismo da tilápia nas fases de peso estudadas sob tais condições de cultivo.

$T C E=\frac{\ln P f-\ln I P i}{d} \times 100$

Eq. 1

$\mathrm{CCD}=\left[\left(\mathrm{Pf}^{1 / 3}-\mathrm{Pi}^{1 / 3}\right) \times 100\right] / \mathrm{d}$

Eq. 2

Linear $=\frac{p f-p i}{d}$

Eq. 3

$T G C=\frac{p f^{(1-b)}-P i^{(1-b)}}{\sum t \& d} \times 100$

Eq. 4

Onde: $P i$ e $P f$ é o peso inicial e final corporal, respectivamente, $d$ é dia, $t$ é temperatura $\left({ }^{\circ} \mathrm{C}\right)$, e $(1-\mathrm{b})$ é o expoente do peso corporal (Dumas et al., 2010). O Pf foi calculado por meio da reorganização das equações de 1 a 4 para os respectivos modelos (Equações 5 a 8) permitindo o ajuste das equações. 
Para TCE, $P f(g)=\operatorname{Exp}[\ln (P i)]+\left[\frac{T C E}{100} * d\right]$

Para CCD, $P f(g)=P i^{1 / 3}+\left[\frac{C C D}{100} * d\right]^{3}$

Para Linear, $P f(g)=$ Intercepto $+[$ vértice * $P i]$

Para TGC, $P f(g)=\left[P i^{(1-\mathrm{b})}+\frac{T G C}{100} \sum t * d\right]^{\frac{1}{(1-\mathrm{b})}}$
Eq. 5

Eq. 6

Eq. 7

Eq. 8

\subsection{Ensaios de digestibilidade aparente (CDA) in vivo das rações comerciais}

A análise da ração comercial utilizada durante o cultivo foi realizada por meio do experimento de digestibilidade in vivo no laboratório de aquicultura do Núcleo de Tecnologia em Piscicultura e Pecuária na Secretaria de Agricultura do Distrito Federal-SEAGRO/DF com tilápia do Nilo (Oreochromis niloticus) linhagem Gift oriundas da mesma fazenda comercial utilizadas no experimento em tanques-rede na Fazenda Cristalina, Fartura - SP.

Anteriormente ao início do experimento, os animais foram submetidos a um período de adaptação de 15 dias às instalações e ao manejo. Posteriormente, foram adaptados às dietas experimentais por mais sete dias. Os períodos de coletas de fezes foram de sete dias, formando desta maneira uma amostra composta (pool) para cada unidade experimental.

Utilizou-se um lote de 180 exemplares de tilápias do Nilo separados de acordo com seu peso médio 30 g. Os peixes foram alojados em seis cubas cônicas de 200 litros, onde realizou-se o ensaio de digestibilidade das rações empregando o Sistema Guelph adaptado (Cho, 1982), o qual utiliza um copo coletor na parte inferior das cubas onde as fezes depositam-se. Um termostato (200W) foi acoplado para a manutenção da temperatura, que manteve-se em $26^{\circ} \mathrm{C}$, a mesma média registrada no reservatório de Chavantes durante o experimento.

O sistema possuía aeração individual, realizada por meio de uma pedra porosa acoplada a dispersores de ar para conservação de aproximadamente $5,0 \mathrm{mg} \mathrm{L}^{-1}$ de oxigênio dissolvido em cada cuba.

As fezes de cada dia de coleta foram congeladas para futuras análises de composição químico-bromatológica. $\mathrm{O}$ arraçoamento foi realizado durante o período de adaptação e coleta até aparente diminuição do consumo, indicando o momento em que os peixes atingiram a saciedade 
aparente. Ao final do dia, realizou-se a limpeza das cubas e a troca de 50\% do volume de água.

A ração comercial oriunda do cultivo foi triturada para a incorporação do óxido crômico $\left(\mathrm{Cr}_{2} \mathrm{O}_{3}\right)$ como indicador inerte segundo Cho et al. (1982), na proporção de $0,1 \%$ da dieta e, em seguida, foi novamente peletizada para fornecimento aos animais.

O Coeficiente de digestibilidade aparente (CDA) foi calculado de acordo com a equação 9 (Cho et al., 1982):

$$
C D A=1-\left(\frac{F}{D} x \frac{D i}{F i}\right)
$$

Onde: $D=\%$ nutriente (ou $\mathrm{kJ} \mathrm{g}^{-1}$, energia bruta) da dieta; $F=\%$ nutriente (ou $\mathrm{kJ} \mathrm{g}^{-1}$, energia bruta) das fezes; $D i=$ indicador inerte (óxido de cromo) concentração (ppm) da dieta; $F i=$ indicador inerte (óxido de cromo) concentração (ppm) nas fezes.

\subsection{Metabolismo Basal (HeE) e Incremento de Calor da Alimentação (HiE)}

O metabolismo basal (HeE, $\mathrm{kJ}$ peixe $\mathrm{e}^{-1}$ ) foi calculado em função da temperatura metabólica e peso corporal (potência de 0,8 do peso vivo do peixe) de acordo com o recomendado por Cho e Bureau (1998) (Eq. 10).

$$
\text { HeE }=(a+b T) * \text { Peso Corporal }{ }^{0.8} \quad \text { Eq. } 10
$$

Em que, $(\mathrm{a}+\mathrm{bT})$ é a relação da temperatura $(\mathrm{T})$ com HeE e do peso corporal metabólico $\left(\mathrm{BW}^{0.8}\right)$ seguido o preconizado por Cho e Bureau (1998) e Dumas et al.(2010).

$\mathrm{O}$ incremento calórico da alimentação ( $\mathrm{HiE}, \mathrm{kJ}$ peixe ${ }^{-1}$ ) foi estimado utilizando 70 observações de 40 estudos publicados entre 1989 e 2013, de acordo com o apresentado por Chowdhury et al. (2013). A diferença entre a ingestão energética (IE, kJ peixe ${ }^{-1}$ ) e a soma da energia para o metabolismo basal $\left(\mathrm{HeE}, \mathrm{kJ}\right.$ peixe $\left.{ }^{-1}\right)$, fezes $\left(\mathrm{FE}, \mathrm{kJ}\right.$ peixe $\left.\mathrm{e}^{-1}\right)$, fezes não-fecal (UE + $\mathrm{ZE}, \mathrm{kJ}$ peixe $\mathrm{e}^{-1}$ ), perda de energia e energia retida (RE) foram utilizadas para estimar HiE (Eq. 11).

O RE foi calculado a partir da diferença entre a energia bruta do peso final e inicial. O custo de energia da urina (UE) e brânquias (ZE) foi calculado como $24,9 *(\mathrm{UN}+\mathrm{ZN}) \mathrm{kJ}$ peixe ${ }^{-1}$ onde, $\mathrm{UN}$ e ZN são as perdas de nitrogênio urinário e branquial, respectivamente de acordo com o proposto por Kaushik (1998). 


$$
H i E=I E-F E-R E-(U E+Z E)-H e E \quad \text { Eq.11 }
$$

\subsection{Estimativa dos resíduos da piscicultura}

O total de resíduos liberados pela piscicultura refere-se aos resíduos sólidos (RS) gerados pela alimentação durante a produção, pelos resíduos da ração e os resíduos dissolvidos (RD). Desta forma, a saída de resíduos sólidos e dissolvidos foram estimados utilizando as equações 12 e 13, respectivamente.

$$
R S=M S \text { ingerido } x(1-C D A M S)
$$

Onde RS é o total de resíduos sólidos, o CDA é o coeficiente de digestibilidade aparente, e MS é matéria seca. Equação semelhante foi utilizada para estimar a saída de resíduos sólidos de $\mathrm{N}$ e P. Os resíduos dissolvidos de $\mathrm{N}$ e $\mathrm{P}$ foram estimados a partir da diferença entre os valores digestíveis e retidos nos peixes (Eq. 13).

$R D N$ ou $R D P=($ ingerido $N$ ou $P$ X CDA do $N$ ou $P)-$ Nou $P$ retido $\quad$ Eq. 13

Onde RDN e RDP são os resíduos dissolvidos nitrogenados e fosfatados, respectivamente.

Posteriormente, realizou-se uma simulação considerando 5 e $10 \%$ de perda de ração durante

o arraçoamento, estes valores foram incorporados aos valores totais de $\mathrm{RS}$ expressos em $\mathrm{kg} \mathrm{t}^{-1 \mathrm{de}}$ peixe produzido.

\subsection{Análises estatísticas}

Relações isométricas e alométricas do peso vivo corporal com o conteúdo de água, proteína bruta, lipídios, cinzas, energia bruta, fósforo e nitrogênio corporal dos peixes foram avaliados por meio de análise de regressão para obtenção dos coeficientes da composição corporal de acordo com o recomendado por Dumas et al. (2010). 
Os valores médios obtidos para os parâmetros de qualidade da água, de desempenho zootécnico e dos coeficientes de digestibilidade aparente foram submetidos à análise de variância e quando observadas diferenças significativas entre as médias, aplicou-se o teste de Tukey a $5 \%$ de significância utilizando o programa Statistical Analysis System $\left(\mathrm{SAS}^{\circledR}\right.$ v.9.3 Cary, North Carolina). 


\section{RESULTADOS}

Verificam-se na Tabela 3 as variáveis da qualidade da água coletadas na superfície da área aquícola $(3 \mathrm{~m})$ onde estavam instalados os tanques-rede no reservatório de Chavantes, São Paulo, Brasil.

Tabela 3. Média das variáveis da água coletadas na piscicultura Cristalina durante o experimento.

\begin{tabular}{|c|c|c|c|c|c|c|c|}
\hline \multirow{2}{*}{ Var. } & \multicolumn{6}{|c|}{ Período/Mês } & \multirow[b]{2}{*}{7} \\
\hline & 1 & 2 & 3 & 4 & 5 & 6 & \\
\hline $\mathrm{TA}$ & $26,0 \pm 0.05^{\mathrm{a}}$ & $28,3 \pm 0.08^{\mathrm{a}}$ & $29,0 \pm 0.08^{\mathrm{a}}$ & $25,6 \pm 0.00^{\mathrm{a}}$ & $24,6 \pm 0.05^{\mathrm{a}}$ & $22,8 \pm 0.02^{b}$ & $21,6 \pm 0.3^{b}$ \\
\hline TAR & $27,7 \pm 0.14^{\mathrm{a}}$ & $32,5 \pm 0.01^{\mathrm{a}}$ & $36,6 \pm 0.00^{\mathrm{a}}$ & $29,8 \pm 0.00^{\mathrm{a}}$ & $28,5 \pm 0.02^{\mathrm{a}}$ & $26,1 \pm 0.01^{\mathrm{b}}$ & $25,4 \pm 0.01^{\mathrm{b}}$ \\
\hline $\mathrm{pH}$ & $7,4 \pm 0.23^{\mathrm{a}}$ & $7,2 \pm 0.12^{\mathrm{a}}$ & $7,8 \pm 0.19^{\mathrm{a}}$ & $6,5 \pm 0.08^{\mathrm{a}}$ & $6,9 \pm 0.10^{\mathrm{a}}$ & $8,2 \pm 0.21^{\mathrm{a}}$ & $7,6 \pm 0.10^{\mathrm{a}}$ \\
\hline $\mathrm{CE}$ & $46.1 \pm 1.44^{\mathrm{a}}$ & $38.3 \pm 2.53^{\mathrm{a}}$ & $50.0 \pm 0.95^{\mathrm{a}}$ & $44.2 \pm 1.50^{\mathrm{a}}$ & $51.0 \pm 2.12^{\mathrm{a}}$ & $35.1 \pm 1.12^{\mathrm{a}}$ & $35.0 \pm 1.0^{\mathrm{a}}$ \\
\hline SA & $0,02 \pm 3.12^{\mathrm{a}}$ & $0,07 \pm 2.75^{\mathrm{a}}$ & $0,02 \pm 1.88^{\mathrm{a}}$ & $0,04 \pm 1.15^{\mathrm{a}}$ & $0,02 \pm 1.45^{\mathrm{a}}$ & $0,02 \pm 1.45^{\mathrm{a}}$ & $0,02 \pm 2.17^{\mathrm{a}}$ \\
\hline $\mathrm{O}_{2} \mathrm{D}$ & $9,0 \pm 0.67^{\mathrm{a}}$ & $9,0 \pm 0.88^{a}$ & $8,5 \pm 0.10^{\mathrm{a}}$ & $8,3 \pm 0.51^{\mathrm{a}}$ & $8,4 \pm 0.49^{\mathrm{a}}$ & $9,1 \pm 0.83^{\mathrm{a}}$ & $9,2 \pm 0.17^{\mathrm{a}}$ \\
\hline $\mathrm{TR}$ & $3,8 \pm 0.25^{\mathrm{a}}$ & $3,5 \pm 0.02^{\mathrm{a}}$ & $4,0 \pm 0.01^{\mathrm{a}}$ & $2,8 \pm 0.00^{\mathrm{a}}$ & $3,1 \pm 0.02^{\mathrm{a}}$ & $3,5 \pm 0.01^{\mathrm{a}}$ & $4,0 \pm 0.01^{\mathrm{a}}$ \\
\hline NT & $0,06 \pm 4.60^{\mathrm{a}}$ & $0,05 \pm 6.74^{\mathrm{a}}$ & $0,03 \pm 3.89^{\mathrm{a}}$ & $0,01 \pm 4.80^{\mathrm{a}}$ & $0,01 \pm 6.10^{\mathrm{a}}$ & $0,03 \pm 5.75^{\mathrm{a}}$ & $0,02 \pm 7.10^{\mathrm{a}}$ \\
\hline PT & $0,06 \pm 13 \cdot 10^{\mathrm{a}}$ & $0,07 \pm 14 \cdot 12^{\mathrm{a}}$ & $0,05 \pm 8.11^{\mathrm{a}}$ & $0,01 \pm 7.41^{\mathrm{a}}$ & $0,02 \pm 6.56^{\mathrm{a}}$ & $0,04 \pm 9.01^{\mathrm{a}}$ & $0,03 \pm 8.80^{\mathrm{a}}$ \\
\hline
\end{tabular}

$\mathbf{T A}=$ Temperatura da água, ${ }^{\circ} \mathrm{C} ; \mathbf{T A R}=$ Temperatura do ar, ${ }^{\circ} \mathrm{C} ; \mathbf{p H}=$ Potencial hidrogênionico; $\mathbf{C E}=$ Condutividade elétrica, $\mu \mathrm{S} . \mathrm{cm}^{-1} ; \boldsymbol{S A}=$ Salinidade $-\mu \mathrm{S} . \mathrm{cm}^{-1} ; \mathbf{O}_{2} \mathbf{D}=$ Oxigênio dissolvido, $\mathrm{mg} \mathrm{L}^{-1}$; $\mathbf{T R}=$ Tranparência, $\mathrm{m} ; \mathbf{N T}=$ Nitrogênio total, $\mathrm{mg} \mathrm{L}^{-1} ; \mathbf{P T}=$ Fósforo total, $\mathrm{mg} \mathrm{L}^{-1} \mathrm{P}$.

Os valores da composição centesimal da dieta comercial apresentados pelo fabricante para todo o ciclo de produção foram de $32 \%$ de proteína bruta, $92 \%$ de matéria seca, $6 \%$ de lipídio, $13 \%$ de cinzas, 17,50 $\mathrm{MJ} \mathrm{kg}^{-1}$ de energia bruta e 1,5\% de fósforo total. No entanto, foram realizados testes da composição centesimal e digestibilidade das dietas (Tabela 4). 
Tabela 4. Composição centesimal (\%), nutrientes digestíveis e energia das dietas comerciais utilizadas em três fases de produção na fazenda Cristalina (juvenil I (JVI), juvenil II (JVII) e peso de mercado (PM)).

\begin{tabular}{lrrr}
\hline Composição & JVI & JVII & PM \\
\hline Matéria seca, \% (MS) & 92.7 & 92.6 & 92.0 \\
Matéria seca digestível, \% (MSD) & 77.2 & 72.5 & 68.7 \\
\hline Proteína bruta, \% (PB) & 35.6 & 32.1 & 34.7 \\
Proteína bruta digestível, \% (PD) & 31.7 & 28.7 & 28.9 \\
\hline Lipídio, \% (L) & 6.2 & 6.4 & 5.6 \\
Lipídio digestível, (LD) \% & 4.5 & 4.5 & 3.6 \\
\hline Cinza, \% & 13.1 & 14.4 & 11.9 \\
Cinza digestível, \% & 8.6 & 8.0 & 6.2 \\
\hline Extrativo não nitrogenado ${ }^{*}$ & 37.8 & 39.9 & 40.3 \\
\hline Fósforo, \% (P) & 1.2 & 1.0 & 1.0 \\
Fósforo digestível, \% (PDi) & 0.8 & 0.7 & 0.6 \\
\hline Energia bruta, MJ/kg (EB) & 17.5 & 17.4 & 17.3 \\
Energia digestível, Mj/kg (ED) & 15.1 & 13.7 & 13.1 \\
\hline Relação PD/ED & 21 & 21 & 22 \\
\hline
\end{tabular}

"Extrato não nitrogenado foi obtido pela diferença (matéria seca- proteina bruta - lipídio - cinza).

Na Tabela 5, encontram-se os parâmetros de desempenho dos peixes durante todo o ciclo produtivo demonstrando a biomassa final de 37,79 e $90 \mathrm{~kg} / \mathrm{m}^{3}$; a taxa de conversão alimentar de $1.38,1.80$ e 1.90 e a eficiência alimentar de $0,79,0,63$ e 0,56 com os demais fatores de desempenho para as respectivas fases de JVI, JVII e PM.

Tabela 5. Parâmetros zootécnicos da tilápia em tanques-rede no reservatório de Chavantes SP para as fases de juvenil I (JVI), juvenil II (JVII) e peso de mercado (PM) durante o ciclo de produção na fazenda Cristalina.

\begin{tabular}{lccc}
\hline Parâmetros- Parameters & JVI & JVII & PM \\
\hline PI (g) & $36 \pm 2.73$ & $135 \pm 1.83$ & $480 \pm 2.11$ \\
PF $(\mathrm{g})$ & $135 \pm 4.05$ & $480 \pm 2.66$ & $789 \pm 5.12$ \\
GPD (g/peixe/dia) & $1.6 \pm 3.12$ & $3.0 \pm 5.78$ & $5.0 \pm 2.12$ \\
MO $(\%)$ & $4.0 \pm 10.14$ & $2.1 \pm 6.54$ & $1.0 \pm 4.10$ \\
BF $\left(\mathrm{kg} / \mathrm{m}^{3}\right)$ & $37 \pm 9.77$ & $79 \pm 5.13$ & $90 \pm 3.12$ \\
TCA (ração: ganho de peso) & $1.4 \pm 0.89$ & $1.8 \pm 1.00$ & $1.9 \pm 1.20$ \\
EA (ganho de peso: ração) & $0.8 \pm 0.89$ & $0.6 \pm 1.00$ & $0.5 \pm 1.20$ \\
TEP & $2.4 \pm 1.11$ & $2.2 \pm 2.56$ & $1.9 \pm 1.73$ \\
\hline
\end{tabular}

$\overline{\mathbf{P I}}=$ Peso inicial; $\mathbf{P F}=$ Peso final; $\mathbf{G P D}=$ Ganho de peso dia $(\mathrm{g} /$ peixe/dia $) ; \mathbf{M O}=\overline{\text { Mortalidade; } \mathbf{B F}=\text { Biomassa final; } \mathbf{T C A}=}$ Taxa de conversão alimentar (ração:ganho de peso); EA= Eficiência alimentar (ganho de peso:ração); TEP= Taxa de eficiência protéica. 
Além dos dados observados no experimento, verificam-se na Tabela 6 a série histórica do desempenho zootécnico de trinta lotes de cultivo (ciclo completo) da produção comercial de tilápia do Nilo (Oreochromis niloticus) instalada no reservatório de Chavantes, permitindo a comparação entre os dados obtidos no experimento (Tabela 05) e os simulados pelo modelo bioenergético (Tabela 9).

Tabela 6. Média do histórico dos parâmetros zootécnicos da tilápia produzida em tanques-rede no reservatório de Chavantes, $\mathrm{SP}(n=30)$.

\begin{tabular}{cccccccccc}
\hline Tempo & TA & Peso & Biomassa & Qtd. & MO & GPD & Ração & TCA & TGC \\
\hline Dias & ${ }^{\circ} \mathbf{C}$ & g/peixe & $\mathbf{~ k g / m ~}^{\mathbf{3}}$ & peixes & \% & g/dia & tipo & ração: GP & \\
\hline 0 & 25.0 & 35 & 11 & 2750 & 0.0 & 0.0 & A $4 / 6 \mathrm{~mm}$ & 0.00 & - \\
15 & 26.0 & 58 & 17 & 2666 & 3.1 & 1.4 & A $4 / 6 \mathrm{~mm}$ & 1.44 & 0.139 \\
45 & 26.0 & 118 & 34 & 2572 & 3.5 & 1.3 & $\mathrm{~A} 4 / 6 \mathrm{~mm}$ & 1.41 & 0.089 \\
75 & 28.0 & 188 & 32 & 7430 & 2.2 & 2.4 & B $6 / 8 \mathrm{~mm}$ & 1.44 & 0.039 \\
105 & 29.0 & 283 & 48 & 7311 & 1.6 & 3.2 & B $6 / 8 \mathrm{~mm}$ & 1.68 & 0.027 \\
135 & 28.0 & 412 & 69 & 7277 & 0.5 & 4.3 & B $6 / 8 \mathrm{~mm}$ & 1.55 & 0.023 \\
165 & 27.0 & 578 & 67 & 4995 & 0.7 & 5.5 & B 6/8 mm & 1.75 & 0.020 \\
195 & 25.0 & 810 & 91 & 4982 & 0.3 & 7.0 & C $8 / 10 \mathrm{~mm}$ & 1.77 & 0.019
\end{tabular}

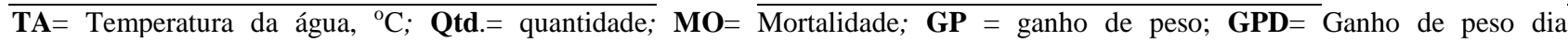
(g/peixe/dia); $\mathbf{T C A}=$ Taxa de conversão alimentar (alimentação: ganho de peso); TGC=Coeficiente de crescimento térmico.

Apresenta-se na Tabela 7, a aplicação das equações de predição do crescimento corporal e o ajuste da relação de crescimento, por meio da análise da soma residual com os valores reais encontrados no experimento em campo. Estes valores foram utilizados para compor o modelo bioenergético nutricional e determinar as taxas de retenção de nutrientes e excreção para cada categoria de peso da $O$. niloticus cultivada em tanques-rede.

Tabela 7. Coeficientes e soma residual (RSS) dos modelos: taxa de crescimento específico (TCE), coeficiente de crescimento diário (CCD), linear e coeficiente de crescimento térmico (TGC) ajustado para $O$. niloticus produzidas em tanques-rede com temperatura média de $26^{\circ} \mathrm{C}$.

\begin{tabular}{|c|c|c|c|c|c|c|c|}
\hline \multirow{2}{*}{ Fase de Cultivo } & \multirow{2}{*}{$\begin{array}{c}\text { Categoria de } \\
\text { Peso }(\mathrm{g})\end{array}$} & \multicolumn{4}{|c|}{ Coeficientes $^{1}$} & \multicolumn{2}{|c|}{ Revisado $^{3}$} \\
\hline & & TCE & $\mathrm{CCD}$ & Linear & TGC & TGC & $\begin{array}{l}\text { TGC } \\
\text { Exp. }\end{array}$ \\
\hline Juvenil I & $36-133$ & 2.19 & 3.02 & 1.63 & 0.12 & 0.90 & 0.65 \\
\hline $\mathrm{RSS}^{2}$ & - & 26 & 0 & 109 & 88 & 12 & - \\
\hline Juvenil II & $133-496$ & 1.11 & 2.38 & 3.07 & 0.09 & 0.28 & 0.48 \\
\hline $\mathrm{RSS}^{2}$ & - & 1937 & 810 & 3751 & 1554 & 25 & - \\
\hline Peso de Mercado & $496-797$ & 0.79 & 2.26 & 5.02 & 0.10 & 22.82 & 1.00 \\
\hline $\operatorname{RSS}^{2}$ & - & 1457 & 1040 & 415 & 1039 & 45 & - \\
\hline
\end{tabular}

Coeficientes e expoentes de peso corporal revistos foram determinados utilizando o método dos mínimos quadrados.

${ }^{2}$ Valores da soma dos quadrados residuais indicam diferenças significativas $(\mathrm{P}<0,05)$ entre os modelos 
determinados pelo teste de Tukey em ANOVA.

${ }^{3}$ Representa o coeficiente de crescimento térmico revisado de acordo com o proposto (Eq.8) aplicado para $O$. niloticus sob condições tropicais.

Os coeficientes dos modelos TCE, CCD e linear (Tabela 7) foram utilizados para simular a curva de crescimento da tilápia em diferentes fases de peso ao longo do cultivo e comparar com o crescimento observado no experimento (Figura 15).
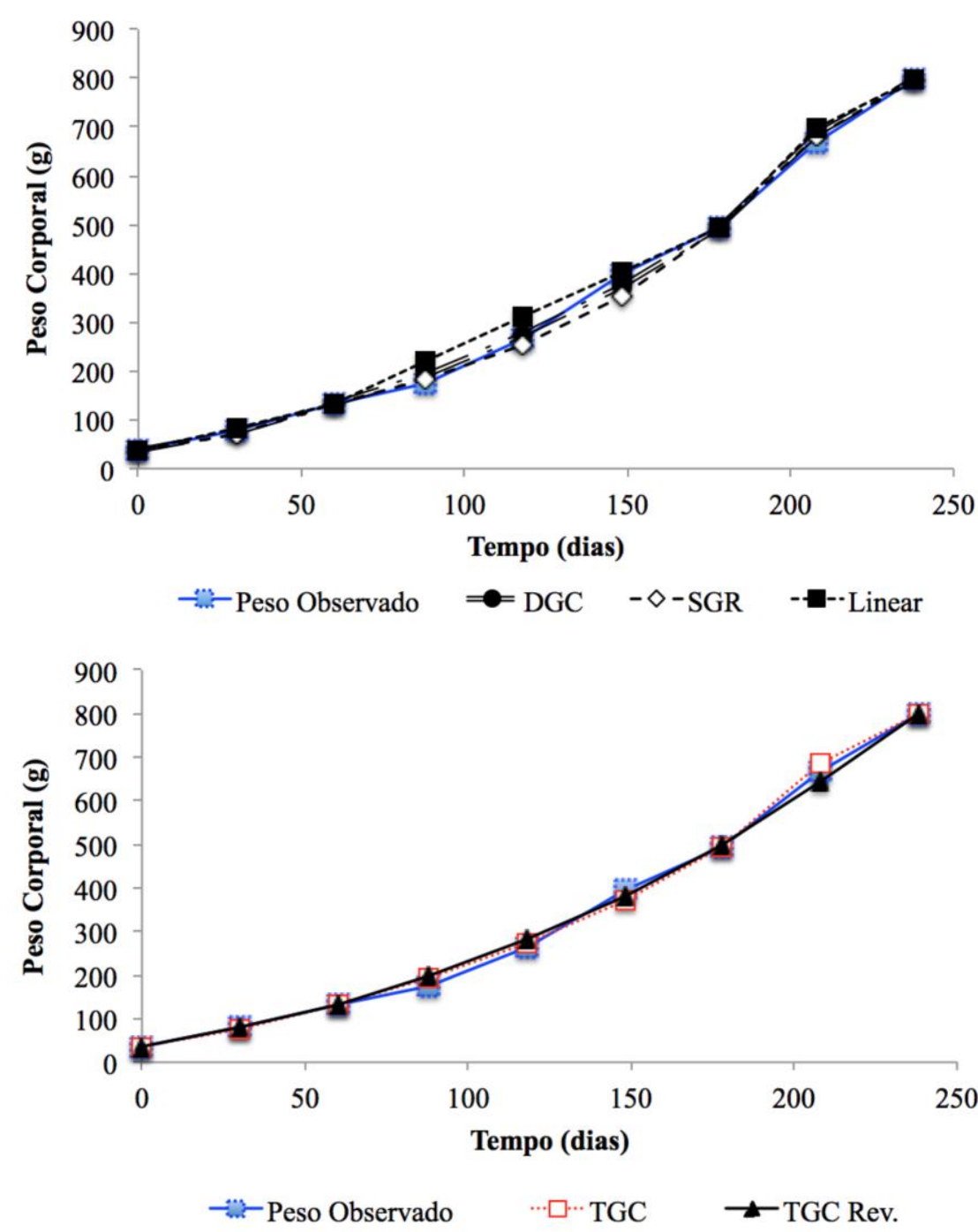

Figura 15. A) Curva de crescimento corporal da $O$. niloticus observada e predita pelos modelos: taxa de crescimento específico (TCE), coeficiente de crescimento diário (CCD) e crescimento linear. B) Curva de crescimento corporal predita pelos modelos de coeficiente de crescimento térmico (TGC - tradicional) e (TGC revisado).

A partir do cálculo do TGC para cada categoria de peso (JVI=0,900; JVII=0,280 e PM= 22,82) obtiveram-se os novos coeficientes do TGC (JVI=0,65; JVII =0,48 e PM=1,00) para a $O$. niloticus e desta forma, definiu-se a curva de crescimento estimada pelo modelo (Figura 15). Posteriormente, realizou-se a simulação de curvas de crescimento para diferentes faixas de 
temperatura da água com o intuito de observar o crescimento corporal da tilápia em diferentes regiões no Brasil ou em situações que podem ocorrer em fazendas com tilápias em reservatórios tropicais (Figura 16).

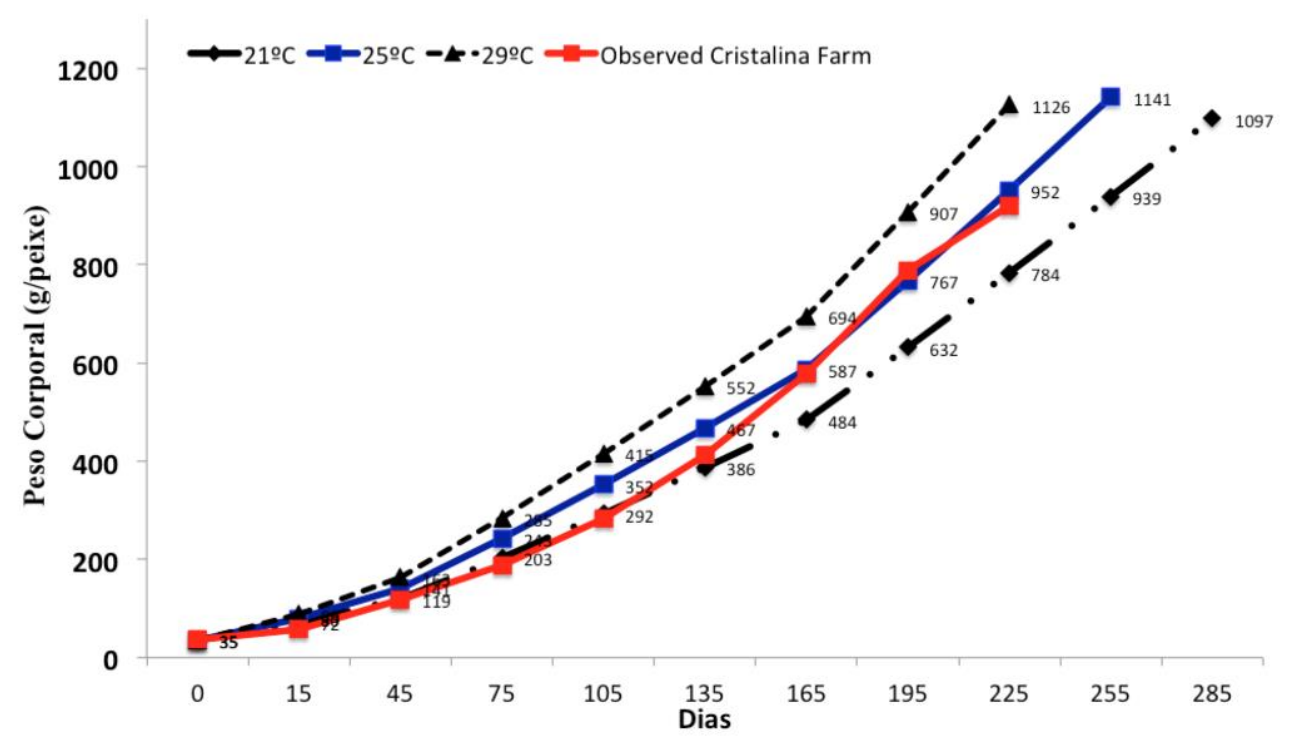

Figura 16. Simulação de curvas de crescimento corporal para diferentes condições de temperatura da água por meio do modelo bioenergético FishPrFEQ® (Cho e Bureau, 1998).

Na Tabela 8, observa-se a média da composição corporal dos peixes em relação à deposição de proteína, lipídios, cinzas e energia bruta da tilápia (Figura 17).

Tabela 8. Composição química da carcaça da tilápia do Nilo (Oreochromis niloticus).

\begin{tabular}{ccccccc}
\hline Peso (g) & Umidade (\%) & Lipídio (\%) & $\begin{array}{c}\text { PB } \\
(\boldsymbol{\%})\end{array}$ & $\begin{array}{c}\text { Cinzas } \\
(\boldsymbol{\%})\end{array}$ & $\mathbf{P}(\boldsymbol{\%})$ & EB (kg/g) \\
\hline 35 & $70.5 \pm 0.24$ & $7.3 \pm 0.43$ & $16.6 \pm 1.71$ & $3.6 \pm 0.88$ & $0.2 \pm 0.23$ & $5.3 \pm 0.43$ \\
80 & $75.0 \pm 0.32$ & $6.4 \pm 0.50$ & $12.4 \pm 1.03$ & $3.9 \pm 0.75$ & $0.5 \pm 0.43$ & $5.6 \pm 0.45$ \\
135 & $76.3 \pm 0.51$ & $6.8 \pm 0.52$ & $12.4 \pm 1.11$ & $4.0 \pm 1.73$ & $0.4 \pm 0.73$ & $5.6 \pm 0.33$ \\
156 & $78.5 \pm 0.44$ & $6.4 \pm 0.83$ & $11.0 \pm 1.32$ & $4.5 \pm 1.08$ & $0.4 \pm 0.67$ & $5.5 \pm 0.30$ \\
240 & $72.5 \pm 0.41$ & $8.2 \pm 1.43$ & $14.0 \pm 1.72$ & $3.8 \pm 1.13$ & $0.2 \pm 0.74$ & $5.4 \pm 0.33$ \\
380 & $75.9 \pm 0.45$ & $6.9 \pm 1.70$ & $13.1 \pm 1.63$ & $4.3 \pm 2.11$ & $0.5 \pm 0.90$ & $5.6 \pm 0.52$ \\
480 & $74.5 \pm 0.45$ & $8.1 \pm 1.73$ & $13.4 \pm 1.12$ & $4.3 \pm 2.13$ & $0.5 \pm 1.73$ & $6.0 \pm 0.77$ \\
660 & $74.7 \pm 0.31$ & $8.3 \pm 1.23$ & $13.1 \pm 1.56$ & $4.5 \pm 2.02$ & $0.5 \pm 1.88$ & $6.0 \pm 0.45$ \\
789 & $74.3 \pm 0.46$ & $8.5 \pm 1.79$ & $15.9 \pm 1.73$ & $4.2 \pm 2.17$ & $0.5 \pm 1.13$ & $6.1 \pm 0.50$ \\
\hline
\end{tabular}

Diante desta análise centesimal, aplicaram-se regressões para definir a incorporações destes nutrientes e a deposição ao longo do cultivo as quais permitiram a análise das relações alométricas e isométricas da massa corporal da $O$. niloticus de acordo com o demonstrado na Figura 17. 

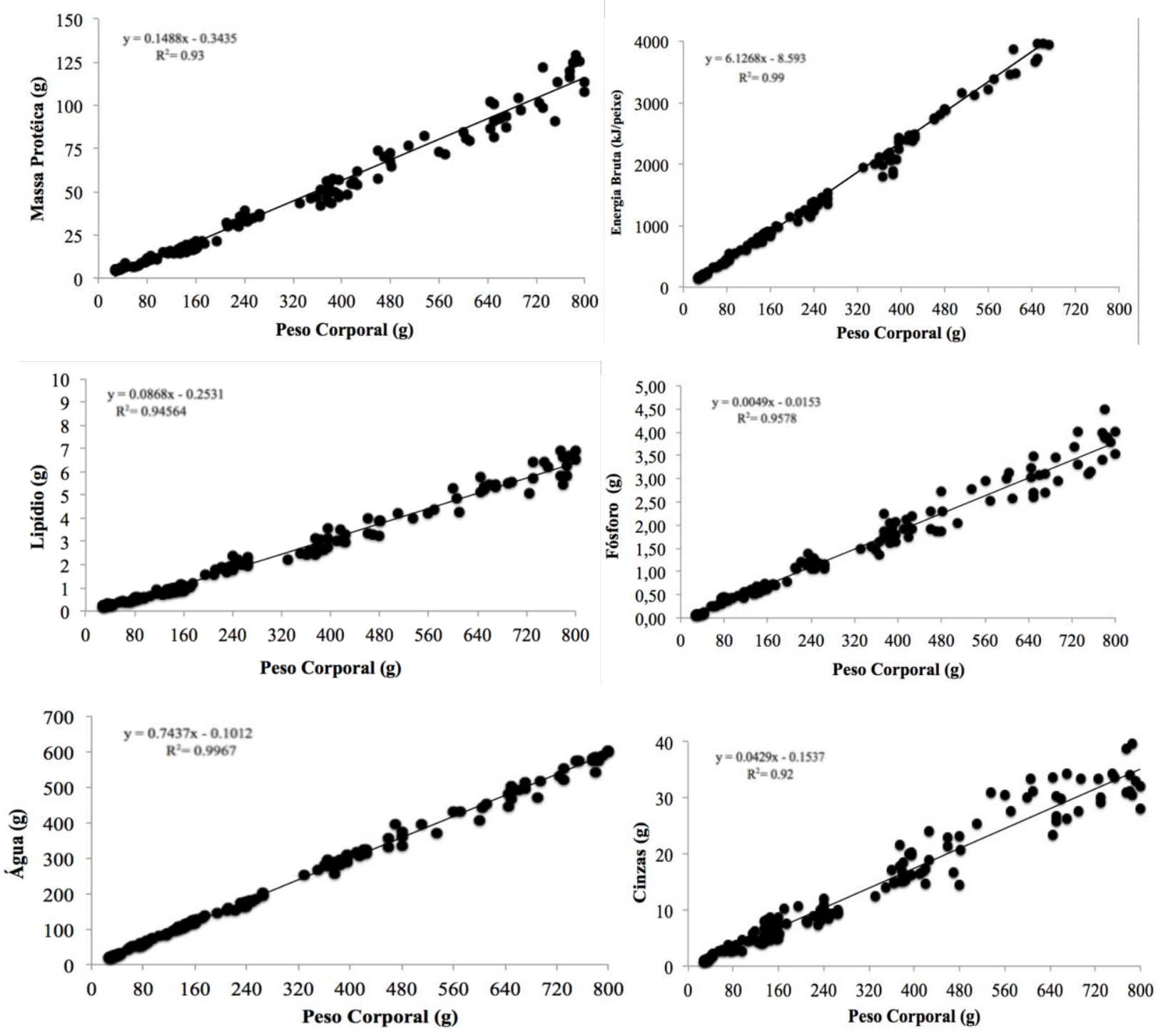

Figura 17. Relações alométricas e isométricas da massa corporal da $O$. niloticus em relação a deposição de proteína, lipídios, cinzas e energia bruta cultivada em condições tropicais.

Na Figura 18, apresentam-se os percentuais dos nutrientes em relação à composição corporal total (carcaça) com base no peso vivo para diferentes categorias de peso, os quais permitiram a utilização destes valores (Figura 17 e 18), para análise das equações de regressão para cada elemento avaliado nas diferentes fases de peso (Tabela 9), estas possibilitaram a determinação das taxas de retenção e composição estimada para cada peso corporal da O.niloticus. 


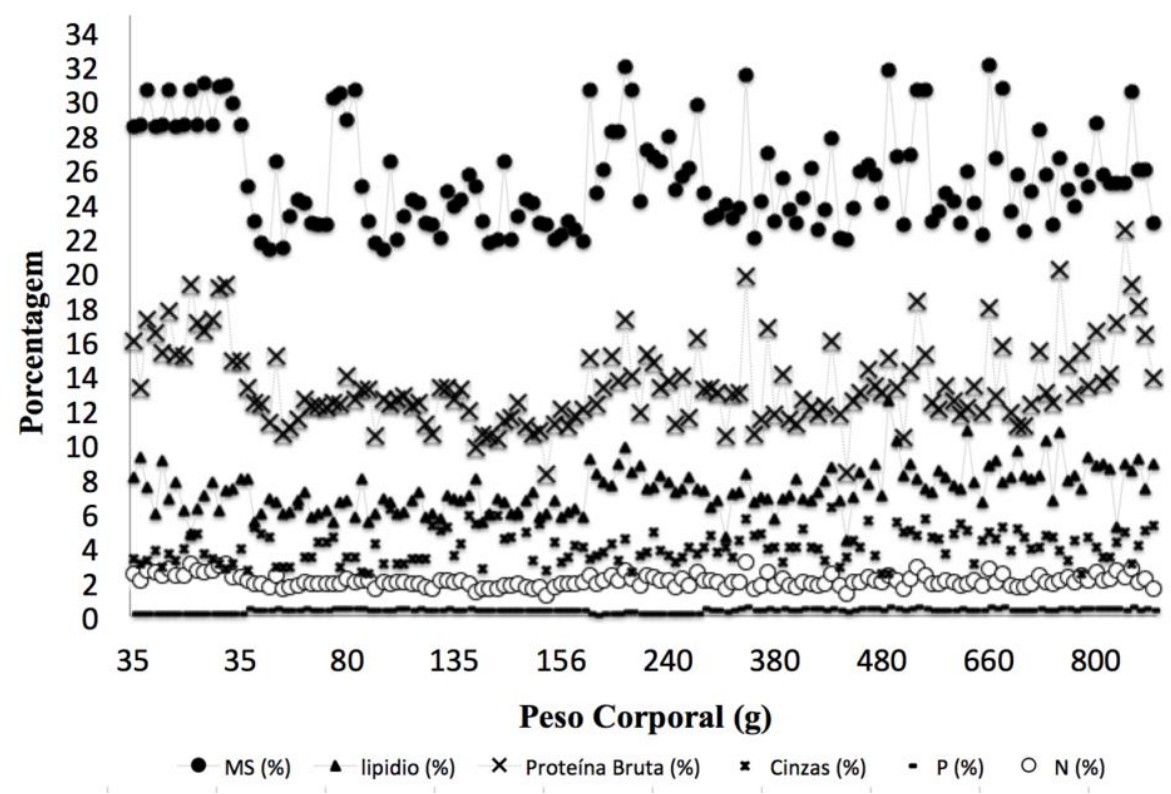

Figura 18. Composição corporal da O. niloticus (MS - matéria seca, lipídio, proteína bruta, $\mathrm{P}$ - fósforo total, $\mathrm{N}$ - nitrogênio) para diferentes categorias de peso.

Posteriormente, aplicou-se o modelo bioenergético Fish-PrFEQ ${ }^{\circledR}$ (Cho e Bureau, 1998) para estimar as taxas de conversão alimentar e eficiência alimentar durante o cultivo considerando a temperatura da água obtida neste experimento (Tabela 10), tal projeção possibilitou a comparação com valores observados no experimento e ajuste da diferença com os estimados no modelo bioenergético.

Tabela 9. Coeficientes das equações para a estimativa da composição química corporal da tilápia cultivada em tanques-rede em condições tropicais.

\begin{tabular}{lll}
\hline Composição Corporal & Coeficientesobtidos & $\boldsymbol{R}^{2}$ \\
\hline Proteína (Eq. 9) & $0.148( \pm 0.343) * B W$ & 0.93 \\
Lipídio (Eq. 10) & $0.086( \pm 0.253) * B W$ & 0.94 \\
Cinzas (Eq. 11) & $0.043( \pm 0.153) * B W$ & 0.91 \\
Energia Bruta (Eq. 12) & $6.128( \pm 8.593) * B W$ & 0.99 \\
Fósforo (Eq. 13) & $0.005( \pm 0.015) * B W$ & 0.95 \\
\hline
\end{tabular}

Após a determinação dos parâmetros de desempenho, curvas de crescimento e equações de estimativa da composição química corporal da tilápia, determinou-se os resíduos sólidos e dissolvidos ( $\mathrm{P}$ e N), além da simulação de perdas de ração durante a alimentação dos animais. Para tanto, definiu-se o metabolismo basal (HeE), as perdas de calor na alimentação (HiE), o requisito 
energético (Dreq.), a retenção de energia (RE) e a expectativa da eficiência alimentar (EA) e a taxa de conversão alimentar esperada (TCE) dos peixes para tais condições de cultivo (Tabela 9).

Tabela 10. Energia, oxigênio e modelagem da expectativa da eficiência e da conversão alimentar da tilápia do Nilo cultivada em tanques-rede sob condições comerciais no Brasil.

\begin{tabular}{|c|c|c|c|c|c|c|c|c|c|}
\hline Fase de cultivo, g/peixe & 36 & 80 & 140 & 238 & 353 & 475 & 581 & 738 & 900 \\
\hline Crescimento, g/peixe/dia & 1,32 & 1,47 & 2,00 & 3,27 & 3,83 & 4,07 & 3,53 & 5,23 & 5,40 \\
\hline Ração ingerida, \%peso (RI) & 5,70 & 4,00 & 3,70 & 3,20 & 2,50 & 1,60 & 1,80 & 1,60 & 1,40 \\
\hline Energia diges.Fornecida, $\mathrm{MJ} \mathrm{kg}^{-1}$ (EDF) & 15,12 & 15,12 & 15,12 & 13,70 & 13,70 & 13,70 & 13,70 & 13,70 & 13,10 \\
\hline Requisito de ED, $\mathrm{MJ} \mathrm{kg}^{-1}$ (EDreq.) & 10,41 & 12,25 & 11,98 & 13,48 & 14,72 & 14,65 & 13,52 & 14,26 & 14,98 \\
\hline Metabolismo basal, $\mathrm{MJ} \mathrm{kg}^{-1}$ (HeE) & 0,66 & 1,86 & 1,69 & 2,66 & 3,47 & 3,43 & 2,69 & 3,17 & 3,64 \\
\hline Incremento calórico, $\mathrm{MJ} \mathrm{kg}^{-1}(\mathrm{HiE})$ & 3,05 & 3,60 & 3,52 & 3,95 & 4,32 & 4,30 & 3,97 & 4,19 & 4,40 \\
\hline Perdas não fecais, $\mathrm{MJ} \mathrm{kg}^{-1}$ (UE+ZE) & 0,57 & 0,67 & 0,65 & 0,73 & 0,80 & 0,80 & 0,74 & 0,78 & 0,82 \\
\hline Energia retida, $\mathrm{MJ} \mathrm{kg}^{-1}(\mathrm{RE})$ & 6,13 & 6,13 & 6,13 & 6,13 & 6,13 & 6,13 & 6,13 & 6,13 & 6,13 \\
\hline Eficiência alimentar esperada (EAE) & 1,46 & 1,24 & 1,26 & 1,02 & 0,93 & 0,94 & 1,01 & 0,92 & 0,87 \\
\hline Taxa de conv. alimentar esperada (TCE) & 0,69 & 0,81 & 0,79 & 0,98 & 1,07 & 1,07 & 0,99 & 1,09 & 1,14 \\
\hline Req. de $\mathrm{O}_{2}, \mathrm{~g} \mathrm{~kg}^{-1}$ ganho de peso (RO) & 273 & 401 & 382 & 486 & 573 & 568 & 489 & 541 & 591 \\
\hline
\end{tabular}

Analisaram-se a taxa de arraçoamento observada durante o cultivo, a taxa prevista pelo modelo bioenergético e a taxa recomendada por tabelas comerciais de arraçoamento, comumente utilizada pela indústria brasileira para o cultivo comercial de tilápia em tanques-rede, além da taxa calculada no modelo bioenergético a qual considerou perdas no arraçoamento de 5 e $10 \%$ (Figura 20).

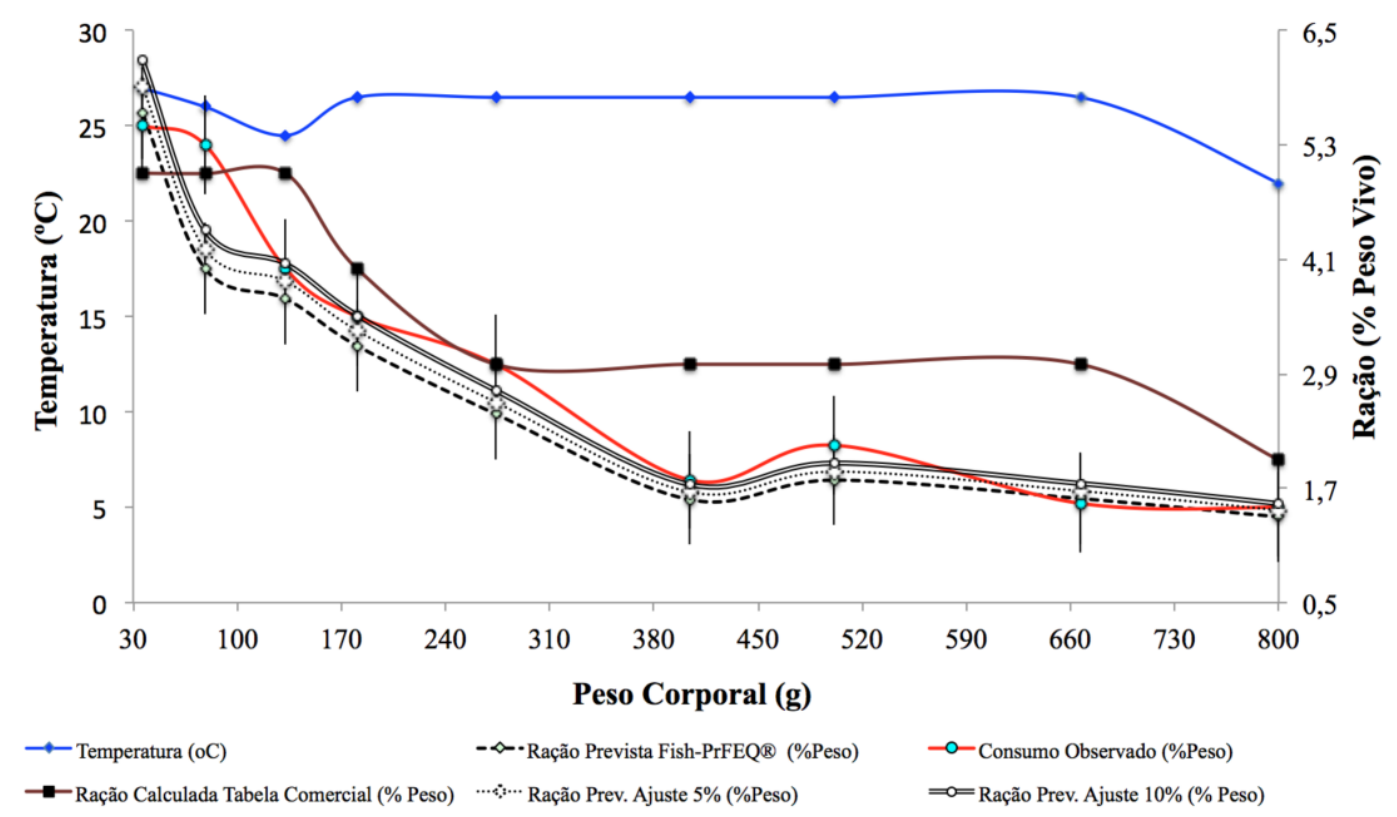

Figura 19. Taxa de arraçoamento observada, estimada pelo modelo bioenergético, calculada por tabelas comerciais e modelada considerando perdas no arraçoamento de 5 e $10 \%$ na alimentação. 
Na Tabela 11, apresentam-se a estimativa dos resíduos da produção de $O$. niloticus com as respectivas frações sólidas, dissolvidas e o percentual obtido em cada fase de cultivo (categoria de peso) da tilápia calculada por meio do Fish-PrFEQ ${ }^{\circledR}$ (Cho e Bureau, 1998).

Tabela 11. Estimativa de efluentes da produção comercial de tilápia (Oreochromis niloticus) em tanques-rede simulados para diferentes categorias de peso durante o ciclo de produção.

\begin{tabular}{ccccc}
\hline $\begin{array}{c}\text { Kg de Resíduos por tonelada } \\
\text { de peixe produzido }\end{array}$ & Juvenil I & Juvenil II & $\begin{array}{c}\text { Peso de } \\
\text { Mercado }\end{array}$ & $\begin{array}{c}\text { Média do } \\
\text { Ciclo }\end{array}$ \\
\hline Resíduo Sólido (RS) & 199,0 & 287,2 & 360,9 & 282,4 \\
Perda de 5\% de ração & 216,0 & 365,5 & 458,4 & 346,6 \\
Perda de 10\% de ração & 236,9 & 463,1 & 576,1 & 425,4 \\
Nitrogênio Sólido (RSN) & 8,1 & 8,7 & 12,7 & 9,8 \\
Perda de 5\% de ração & 8,8 & 11,1 & 16,1 & 12,0 \\
Perda de 10\% de ração & 9,6 & 14,0 & 20,3 & 14,6 \\
Fósforo Sólido (RSF) & 4,5 & 5,0 & 5,9 & 5,1 \\
Perda de 5\% de ração & 4,9 & 6,4 & 7,5 & 6,2 \\
Perda de 10\% de ração & 5,4 & 8,1 & 9,4 & 7,6 \\
Nitrogênio Dissolvido (RDN) & 39,4 & 44,8 & 50,2 & 44,8 \\
Fósforo Dissolvido (RDF) & 3,2 & 2,9 & 2,5 & 2,9 \\
\hline
\end{tabular}




\section{DISCUSSÕES}

Durante os 210 dias de cultivo, a média da transparência e a da condutividade elétrica foram de 3,5 metros e $36,5 \mu \mathrm{S} \mathrm{cm}^{-1}$, respectivamente. $\mathrm{O} \mathrm{pH}$ manteve-se entre 6,5 a 8,2 (Tabela 3), valores dentro da faixa recomendável para esta espécie cultivada em tanques-rede (Ono e Kubitza, 2003). Merola e Souza (1988) e Mallasen et al. (2012) cultivando tilápias com pH variando de 4,9 a 8,3 e condutividade entre 30 a $50 \mu \mathrm{S} \mathrm{cm} \mathrm{cm}^{-1}$, também observaram que estes parâmetros não foram limitantes ao desempenho dos peixes, conforme verificado neste estudo (Tabela 5).

A temperatura da água oscilou entre $22^{\circ} \mathrm{C}$ a $28^{\circ} \mathrm{C}$ com média de $25,7^{\circ} \mathrm{C}$, aproximando-se dos limites adequados para o conforto térmico de peixes tropicais (entre 26 e $30^{\circ} \mathrm{C}$ ) segundo Galli et al. (1999). Corroborando com esta afirmativa, Ayroza et al. (2013) demonstram não haver correlação do desempenho da $O$. niloticus cultivadas em tanques-rede sob temperatura média de $28^{\circ} \mathrm{C}$, também no reservatório de Chavantes. Garcia et al. (2013) avaliando diferentes densidades de estocagem da O.niloticus em tanques-rede com temperaturas de 27,0 a $29,8^{\circ} \mathrm{C}$, no reservatório de Ilha Solteira, ressaltaram a adaptação desta espécie às condições térmicas dos reservatórios tropicais.

Perbiche-Neves et al. (2011) e Ayroza et al. (2013) salientam que os reservatórios possuem uma heterogeneidade temporal, a qual relaciona-se as diferenças sazonais de temperatura e precipitação, isto deve-se principalmente às mudanças nas condições climáticas de entradas e saídas de água, além dos ventos e lixiviação que ocorrem no reservatório, ocasionando a entrada de matéria orgânica e mudança no gradiente de calor, agravando-se em casos da ocorrência de estratificação térmica da água.

Houlihan et al. (2001) citam que o aumento da temperatura da água pode influenciar no aumento da ingestão alimentar e no crescimento dos peixes. Portanto, frequentemente assume-se que a temperatura da água promove maior excreção de resíduos e metabólicos ao ambiente aquático. Fato que enfatiza a importância de avaliar o consumo e a excreção durante o ciclo 
produtivo de forma fragmentada para obtenção de valores mais precisos na taxa de conversão alimentar e de excreção dos peixes (Lupatcsh et al., 1998), conforme verificado na Tabela 11 a diferença de excreção de RS, N e P entre as fases de peso.

Em relação aos níveis de oxigênio, Tran-Duy et al. (2008) relatam que estes podem influenciar no equilíbrio dinâmico do organismo, ou homeostase e, consequentemente, alterar o consumo de ração e a saciedade dos peixes devido à interferência nas condições fisiológicas e de bem estar dos animais. Milstein et al. (1992) cita que para produção de Oreochromis sp deve-se manter níveis acima de $4,0 \mathrm{mg} \mathrm{L}^{-1}$ de $\mathrm{O}_{2} \mathrm{D}$. Contudo, o oxigênio dissolvido $\left(\mathrm{O}_{2} \mathrm{D}\right)$ na água oscilou entre 8,3 a 9,2 $\mathrm{mg} \mathrm{L}^{-1}$, valores próximos aos obtidos por Jorcin e Nogueira (2005) e por Pomari (2010) (8,8 $\mathrm{mg} \mathrm{L}^{-1}$ de $\left.\mathrm{O}_{2} \mathrm{D}\right)$ em piscicultura também no reservatório de Chavantes.

Joblin (1981) relatou que os processos que demandam oxigênio têm um nível de saturação, o qual é determinado pelo nível de metabolismo celular, ao invés da disponibilidade de oxigênio ou da capacidade de obter-se oxigênio, uma vez que a taxa de consumo de $\mathrm{O}_{2}$ em peixes mais ativos pode ser muito maior do que as taxa de peixes em condições de descanso ou baixa rotina de natação (Beamish, 1970; Brett, 1972).

Desta forma, a avaliação deste parâmetro em sistemas intensivos com condições ambientais de alta recirculação da água demandam dietas concentradas e apresentam influência direta no metabolismo dos peixes. Neste contexto, Chowdbury et al. (2013) ao avaliarem 84 observações a partir de 15 estudos publicados entre 1969 e 2002 referentes ao consumo de $\mathrm{O}_{2} \mathrm{D}$ da tilápia em jejum, concluíram que peixes pesando entre 4 e $400 \mathrm{~g}$ criados em temperaturas de $16^{\circ} \mathrm{C}$ a $38^{\circ} \mathrm{C}$ têm um coeficiente oxicalorífico do metabolismo de $13,6 \mathrm{~kJ} \mathrm{~g}^{-1}$ de $\mathrm{O}_{2}$ consumido. Aplicando-se esta abordagem obteve-se a média de $478 \mathrm{~g} \mathrm{~kg}^{-1}$ para um ganho acumulado de peso em 52, 110, $159 \mathrm{~g}$ nas respectivas fases de JVI, JVII e PM (Tabela 6).

Quanto aos valores da composição das rações comerciais (Tabela 2), verificaram-se diferenças em relação aos os níveis de garantia indicados no rótulo (32\% de PB, $92 \%$ de MS, 6\% de LP, $13 \%$ Cinzas, $17,50 \mathrm{MJ} \mathrm{kg}^{-1}$ de EB e 1,5\% de PT), isto enfatiza a importância de haver controle e análise de cada lote de produção, além de ações integradas entre produtores, indústria e órgãos legisladores que permitam maior segurança e qualidade nas informações sobre as dietas. Neste contexto, Tacon (2005) ressalta a mudança na composição das rações utilizadas em salmonicultura no Chile, que apresentavam 60\% PB e em 1985 passaram a conter em média 35\% de PB em 2005.

Situação semelhante ocorreu com a indústria do salmão na Noruega e no Canadá, onde foram adotadas uma série de medidas para reduzir a liberação de nutrientes, como a otimização da composição alimentar, melhorias na digestibilidade do alimento e tecnologias de processamento, 
que permitiram a diminuição de custos e a redução da carga de nutrientes na água (Cheshuk et al., 2003).

Islam (2005) cita que a taxa média de conversão alimentar da indústria de salmão norueguês passou de 2,08 em 1974, para 1,00 em 2005. No Canadá, a conversão alimentar média da indústria na década de 80 estava em 1,50, e, vinte anos depois se apresentou em 1,10. Como consequência, houve a diminuição de $14 \mathrm{~kg}$ de fósforo sólido por tonelada de peixe produzido (Bureau, 2010).

Contudo, estas estratégias devem ser seguidas pela indústria brasileira, principalmente no processamento das dietas e no manejo alimentar aplicado às fazendas, fato evidenciado neste estudo, quando avaliadas as diferenças de digestibilidade, retenção e eficiência alimentar entre as fases de peso (Tabela 5 e 8). Xie et al. (1997) enfatizam que a eficiência alimentar associada à utilização de nutrientes de alta qualidade minimizam o potencial poluidor, além de permitir um aumento na produção por unidade de área que, em geral, é maior do que o aumento dos custos de produção associados, conforme demonstram Bechara et al. (2005).

Os valores de fósforo digestível foram de 1,0\% para a fase JVI e 0,89\% para as fases JVII e PM, os quais atenderam a exigência da espécie, que está em torno de 0,80 a 1,1\% (Miranda et al., 2000; Furuya et al., 2008). Os níveis de proteína digestível (PD) foram de 32, 29 e 29\% e energia digestível (ED) de 15; 14 e $13 \mathrm{MJ} \mathrm{kg}^{-1}$ (Tabela 4), valores comumente obtidos em rações comerciais para O. niloticus no Brasil (Mondriani e Ostrensky, 2015). Segundo o NRC (2011), dietas para peixes contêm quantidades elevadas de proteína (28 a 50\%) e uma grande quantidade de energia na dieta é fornecida como compostos nitrogenados, que levam ao aumento da produção de catabolitos nitrogenados na água.

Entretanto, não houve influência do teor de nitrogênio total na água $(\mathrm{p}>0,05)$ durante o experimento $\left(0,01\right.$ a $\left.0,06 \mathrm{mg} \mathrm{L}^{-1}\right)$. Cho e Kaushik (1985) ressaltam que poupar a proteína inserindo energia digestível pode reduzir consideravelmente a poluição devido ao acréscimo de produtos finais nitrogenados, destacando a importância da PD e ED na dieta para aumentar a retenção de nitrogênio.

Trung et al. (2011) aplicando um modelo nutricional bioenergético para definir a exigência de ED e PD para $O$. niloticus verificaram que a espécie tem uma capacidade de derivar níveis significativos de energia a partir do amido digestível e, consequentemente pode utilizar dietas de baixo custo e densidade energética sem comprometer suas exigências nutricionais. Botaro et al. (2007) demonstraram que é possível reduzir o teor de PB digestível de 27 para 24,3\% em dietas para tilápia do Nilo criadas em tanques-rede. Isto pode ser obtido com a suplementação de 
aminoácidos, formulação de dietas baseado no conceito de proteína ideal e uso de modelagem bioenergética para o cálculo exato dos requisitos de ED, conforme demostrado na Tabela 10.

Quanto o requisito energético, NRC (2011) ressalta que normalmente estudos de bioenergética apresentam a exigência de energia expressa em quantidade absoluta de DE por kg de peso corporal por dia para uma determinada produção máxima, o qual é apresentado como proporção do consumo de ração máxima $\left(\mathrm{C}_{\max }\right)$.

No entanto, $\mathrm{C}_{\max }$ dos animais são fatores que são altamente dependentes da genética, composição da dieta, condições ambientais (ex.: temperatura), práticas de criação, estado de saúde, dentre outras variáveis. Consequentemente, a necessidade de energia para a produção máxima calculada em alguns estudos (ex. necessidade de energia expressa em termos absolutos como kcal por peixe por dia) só pode ser válida em condições extremamente específicas (Cho e Bureau, 2001).

Corroborando com esta afirmativa, verificou-se um requisito de 10,4 $\mathrm{MJ} \mathrm{kg}^{-1}$ de ED para peixes com o peso médio de $36 \mathrm{~g}$ e valores crescentes (15 $\mathrm{MJ} \mathrm{kg}^{-1}$ de ED) até o peso de $900 \mathrm{~g}$. Porém, Chowdhury et al. (2013) também avaliando a exigência energética e alimentar da $O$. niloticus em sistema de recirculação sob temperaturas de 27 a $30^{\circ} \mathrm{C}$, verificaram valores distintos de

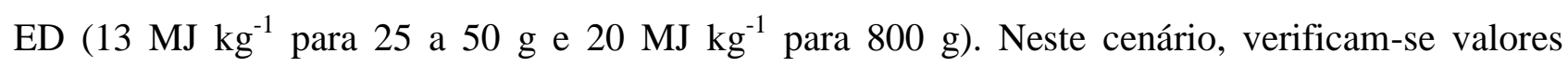
próximos ao recomendado por Furuya et al. (2010) (12,88 $\mathrm{MJ} \mathrm{kg}^{-1}$ para O. niloticus de $100 \mathrm{~g}$ ) e NRC (2011) de aproximadamente $14,3 \mathrm{MJ} \mathrm{kg}^{-1}$ para esta espécie.

A diferença da necessidade energética também foi observada para outras espécies de peixes, segundo o NRC (2011) em estudo com truta arco-íris (Oncorhynchus myskiss) a $12^{\circ} \mathrm{C}$, alimentados com $44 \%$ de proteína digestível e $19 \mathrm{MJ} \mathrm{kg}^{-1}$ de ED, o requisito de ED para produzir $1 \mathrm{~g}$ de biomassa é de 10,5 $\mathrm{MJ} \mathrm{kg}^{-1}$ e de 26,8 $\mathrm{MJ} \mathrm{kg}^{-1}$ para produzir $1 \mathrm{~kg}$. Lupatcsh et al. (1998), empregando a mesma abordagem da bioenergética nutricional para o Sea Bass europeu (Dicentrarchus labrax) obtiveram 9,8 $\mathrm{MJ} \mathrm{kg}^{-1}$ em peixe de $1 \mathrm{~g}$ e valores crescente de até 26,2 $\mathrm{MJ}$ $\mathrm{kg}^{-1}$ para 400g. Glengross (2008) avaliando o Sea Bass asiático (Lates calcarifer) de 10 a $3.000 \mathrm{~g}$ obtiveram ED de 8,9 a $27,8 \mathrm{MJ} \mathrm{kg}^{-1}$, respectivamente.

Portanto, Cho e Bureau (2010) ressaltam que peixe crescendo a taxas diferentes irão depositar nutrientes em ritmos diferentes e, consequentemente, têm requisitos distintos de energia e alimentos. Assim, a exigência de energia deve ser calculada para níveis explicitamente expressos pelo desempenho (ex. o esperado ou nível possível de desempenho), composição da alimentação, estágio de vida, entre outros fatores.

Trung et al. (2011) citam que a tilápia tem demonstrado requisitos energéticos semelhantes à maioria das outras espécies de peixes. A relação entre o metabolismo energético desta espécie e 
do seu peso corporal (PC) também está de acordo com a equação alométrica especificada por Cho e Bureau (1998) e com o observado por Chowdhury et al. (2013), onde o expoente do peso corporal (EPC) para o metabolismo de energia da tilápia, a $32^{\circ} \mathrm{C}$, mostrou-se $\mathrm{PC}^{0,849}$. Glencross et al. (2008) e Glencross et al, (2011) citam que a comparação do EPC do metabolismo energético da tilápia com pangasius, garoupa (filé) e roubalo é de $\mathrm{PC}^{0,800}$.

Contudo, as constantes energéticas apresentadas nos EPC são semelhantes entre as demais espécies de peixes, tanto onívoros e carnívoros (Lupatsch et al, 2003), assim, geralmente assume-se um valor padrão de EPC de 0,800. Diante disto, Shearer (1994) e Bureau e Cho (1998) citam que o conhecimento da composição centesimal dos peixes é um dos principais fatores que afetam a composição e permitem a avaliação da saúde, eficiência alimentar e retenção de nutrientes, fato observado na Figura 17, quando avaliadas as relações alométricas e isométricas da massa corporal da $O$. niloticus com as respectivas equações de regreção e coeficientes da composição corporal (Tabela 7).

Neste contexto, o cálculo do requisito alimentar previsto no modelo bioenergético (Tabela 8) ocassionou uma diferença média de $14 \%$ na taxa de arraçoamento em função do peso corporal quando comparado às taxa propostas por tabelas comerciais de arraçoamento. $\mathrm{O}$ cenário estimado no modelo bioenergético, que considerou $10 \%$ de perda durante o arraçoamento, esteve próximo ao consumo observado na fazenda (Figura 19), taxas de disperdício semelhantes às observadas por Azevedo et al. (2011) e Montanhini Neto e Ostrensky (2015) para o manejo alimentar em fazendas de peixe.

Bureau e Hua (2010) ressaltam que a previsão exata da composição centesimal para um peixe cultivado comercialmente para um determinado peso corporal auxilia na redução do desperdício global de alimentação, na melhoria da eficiência alimentar e no aumento da rentabilidade da operação, conforme observado neste estudo, a diferença no TFS de 5,1 para 7,6 kg ton- ${ }^{1}$ de peixe produzido (Tabela 11 ).

Além dos resíduos oriundos do arraçoamento, Wang et al. (2012) enfatizam que do total da alimentação, $70 \% \mathrm{C}, 62 \% \mathrm{~N}$ e $70 \% \mathrm{P}$ foram libertados no ambiente oriundos da produção de salmão. Azevedo et al. (2011) citam que a produção comercial de Oncorhynchus mykiss em tanques-rede, sob temperatura média de $14^{\circ} \mathrm{C}$, aportou em média 12,5 e 5,3 $\mathrm{kg}^{-1}{ }^{-1}$ de $\mathrm{N}$ e $\mathrm{P}$ sólidos e 37,3 e $3.3 \mathrm{~kg} \mathrm{ton}^{-1}$ de $\mathrm{N}$ e P dissolvidos, respectivamente.

Chowdbury et al. (2013) ao avaliarem a $O$. niloticus alimentadas sob diferentes níveis de proteína na dieta $\left(40,38\right.$ e 35\%), demonstraram haver aumento na excreção de 4,2 para 5,0 kg ton- ${ }^{1}$ de $\mathrm{P}$ e decréscimo nos valores de $\mathrm{N}$ de 46,2 para 40,9 $\mathrm{kg}$ por tonelada de tilápia produzida. 
Montanhini Neto e Ostrensky (2015) também avaliando a carga potencial de resíduos da produção comercial de $O$. niloticus estimaram uma carga de 1.040,63 $\mathrm{kg}$ de matéria orgânica, 44,95 $\mathrm{kg}$ de nitrogênio e 14,26 kg de fósforo, o que representa 78\%, 65\% e 72\%, respectivamente, em relação às quantidades de nutrientes fornecidos pela alimentação, valores inferiores ao obtidos para estas condições de cultivo (Tabela 9).

Contudo, Penczak et al. (1982) afirmam que somente 32\% do fósforo são utilizados para o metabolismo do peixe e os $68 \%$ restantes são transferidos para o meio. Reforçando esta idéia, Alves e Baccarin (2005) informam que 66\% do fósforo aportado pelo arraçoamento intensivo vão para o sedimento, $11 \%$ ficam dissolvidos na água e $23 \%$ são incorporados no peixe em cultivo, valores que enfatizam a necessidade de programas de manejo e controle dos resíduos aquícolas. 


\section{CONCLUSÕES}

O requisito alimentar médio de ração em relação ao peso corporal para a fase de juvenil I foi de $4,85 \%$, juvenil II de $2,75 \%$ e peso final de mercado de $1,6 \%$ sob temperatura média de $26^{\circ} \mathrm{C}$. As rações apresentaram 32, 29 e 29\% de proteína digestível; 15; 14 e $13 \mathrm{MJ} \mathrm{kg}^{-1}$ de energia digestível e 0,$85 ; 0,67 ; 0,62 \%$ de fósforo digestível para as respectivas fases com RE médio de $6,13 \mathrm{MJ} \mathrm{kg}^{-1}$.

Os valores médios de efluentes sólidos e dissolvidos gerados para cada tonelada de tilápia produzida em tanques-rede foram de $284 \mathrm{~kg}$ de resíduos sólidos, sendo $9,8 \mathrm{~kg} \mathrm{t}^{-1}$ de nitrogênio sólido e 5,1 $\mathrm{kg} \mathrm{t}^{-1}$ de fósforo sólido, além de 44,8 e 2,9 quilos de $\mathrm{N}$ e $\mathrm{P}$ dissolvidos, respectivamente.

A aplicação do cálculo do balanço de massas e do modelo bioenergético nutricional FishPrFEQ $^{\circledR}$ sintetizam de forma prática e objetiva novas abordagens e procedimentos a serem incorporados pela indústria aquícola brasileira visando à melhoria na eficiência nutricional e ambiental, a qual irá proporcionar ganho econômico e minimizar resíduos oriundos das operações aquícolas. 


\section{AGRADECIMENTOS}

Ao Conselho Nacional de Desenvolvimento Científico e Tecnológico - CNPq, a International Science and Technology Partnerships Canada (ISTP Canadá) pelos recursos financeiros e a Coordenação de Aperfeiçoamento de Pessoal de Nível Superior - Capes pelo apoio com bolsas de pesquisa. À piscicultura Cristalina Ltda e aos Laboratórios de Análises Avançadas e Biotecnologia da Universidade Federal de Lavras - UFLA e de Nutrição de Peixes (FNRL) da Universidade de Guelph, Ontário, Canadá pela disponibilização das estruturas e apoio para o desenvolvimento desta pesquisa. 


\section{REFÊRENCIAS BIBLIOGRÁFICAS}

Alves R.C.P.; Baccarin A.L. (2005) Efeitos da produção de peixes em tanques-rede sobre sedimentação de material em suspensão e de nutrientes no Córrego da Arribada (UHE Nova Avanhandava), baixo Rio Tietê. In: Ecologia de Reservatórios: Impactos Potenciais, Ações de Manejo e Sistemas em Cascata (ed. by M.G. Nogueira, R. Henry \& A. Jorcin), pp 329-348. São Carlos, Rima.

American Public Health Association - APHA. Standard methods for the examination of water and wastewater. 20th ed. Washington, D.C.: American Public Health Association, American Water Works Association, and Water Pollution Control Federation, 1998.

ASSOCIATION OF OFFICIAL ANALYTICAL CHEMISTS - AOAC. Official Methods of Analysis of the Association of Official Analytical Chemists, 16th ed., v. 1, Arlington: A.O.A.C., 2000, chapter 3. p. 4. (method 985.01).

Ayroza, D.M.M.R.; Nogueira, M.G.; Carvalho, E.D.; Ferraudo, A.S.; Camargo, A.F.M. 2013. Temporal and Spatial Variability of Limnological Characteristics in Areas under the Influence of Tilapia Cages in the Chavantes Reservoir, Paranapanema River, Brazil. Journal of the world aquaculture society, v.44, n. 06: 814-825.

Azevedo, P.A.; Podemski, C.L.; Hesslein, R.H.; Kasian, S.E.M; Findlay, D.L, Bureau, D.P. 2011. Estimation of waste outputs by a rainbow trout cage farm using a nutritional approach and monitoring of lake water quality. Aquaculture, 311, 175-186.

Beamish, F. W. H. 1970. Oxygen consumption of largemouth bass, Micropterus salmoides, in relation to swimming speed and temperature. Can. J. 2001. 48, 1221-1228. 
Bechara J.A., Roux J.P., Diaz F.J.R., Quintana C.I.F. \& De Meabe C.A.L. (2005) The effect of dietary protein level on pond water quality and feed utilization efficiency of pacu, Piaractus mesopotamicus (Holmberg, 1887). Aqua- culture Research 36, 546-553.

Brett, J. R. 1972. The metabolic demand for oxygen in fish, particularly salmonids, and a comparison with other vertebrates. Respir. Physiol. 14, I5 1-1.

Bureau, D.P.; Hua, K. 2010. Towards effective nutritional management of waste outputs in aquaculture, with particular reference to salmonid aquaculture operations. Aquaculture Research, 41: 777-792.

Cheshuk, B.W.; Purser, G.J.; Quintana, R. 2003. Integrated open-water mussel (Mytilus planulatus) and Atlantic salmon (Salmo salar) culture in Tasmania, Australia. Aquaculture 218:357-378.

Cho, C. Y.; Bureau, D. P. 1998. Development of bioenergetic models and the Fish-PrFEQ software to estimate production, feeding ration and waste output in aquaculture. Aquatic Living Resources, 11(4): 199-210.

Cho, C. Y.; Bureau, D. P. 1998. Development of bioenergetic models and the Fish-PrFEQ software to estimate production, feeding ration and waste output in aquaculture. Aquatic Living Resources, 11(4): 199-210.

Cho, C. Y.; Kaushik, S. J. 1985. Effects of protein intake on metabolizable and net energy values of fish diets. Pp. 95-117 in Nutrition and Feeding in Fish, C.B. Cowey, A.M. Mackie; J.G. Bell, eds. London, UK: Academic Press.

Cho, C.Y.; Bureau, D.P. 2001. A review of diet formulation strategies and feeding systems to reduce excretory and feed wastes in aquaculture. Aquaculture Research, 32: 349-360.

Cho, C.Y.; Slinger, S.J.; Bayley, H.S. Bioenergetics of salmonid fishes: energy intake, expenditure and productivity, Comp. Biochem. Physiol. 73B (1982) 25-41.

Chowdhury, K.M.A.; Siddiqui, S.; Hua, K; Bureau, D.P. 2013. Bioenergetic-based Factorial Model to Determine Feed Requirement and Waste Output of Tilapia Produced under Commercial Conditions. Aquaculture, 410-411, 138-147.

Csargo, I.J., Brown, M.L., Chipps, S.R., 2012. Application of a bioenergetics model for hatchery production: largemouth bass fed commercial feeds. North American Journal of Aquaculture, $74,352-359$. 
Dumas, A.; France, J; Bureau, D.P. 2010. Modelling growth and body composition in fish nutrition: where have we been and where are we going? Aquaculture Research, 41, 161-181.

FAO (2012) The State of World Fisheries and Aquaculture 2012. pp. 24-46. Food and Agriculture Organization of the United Nations, Rome.

FAO (2013). Global aquaculture production statistics 2011. Fisheries and Aquaculture Department of the Food and Agriculture Organization of the United Nations, Rome.115p.

Furuya et al. 2010. Tabelas brasileiras para a nutrição de tilápias. Toledo: GFM, 100p.

Furuya, W.M.; Fujii, K.M.; Dos Santos, L.D. et al. 2008. Exigência de fósforo disponível para tilápia-do-nilo (35 a 100g). Rev. Bras. Zootec., v.37, p.961-966.

Garcia, F; Romera, D. M.; Gozi, K. S.; Onaka, E. M.; Fonseca, F. S.; Schalch, S. H. C.; Candeira, P. G.; Guerra, L. O. M.; Carmo, F. J.; Carneiro, D. J.; Martins, M. I. E. G.; Portella, M. C. 2013. Stocking density of Nile tilapia in cages placed in a hydroelectric reservoir. Aquaculture, v. 419, p.51-56.

Glencross, B.D. 2008. A fatorial growth and feed utilization model for barramundi, lates calcarifer, based on Australian production condictions. Aquaculture Nutrition, 14: 360-373.

Glencross, B.D.; Bermudes, M 2011. Effect of high water temperatures on energetic allometric scalling in barramundi (Lates calcarifer). Comp. Biochem. Physiol. - Part A 159, 167-174.

Houlihan, D.; Boujard, T.; Jobling, M. 2001. Food Intake in Fish. Blackwell Science, Oxford, 440p.

Hua, K.; D.P. Bureau. 2010. Quantification of differences in digestibility of phosphorus among cyprinids, cichlids, and salmonids through a mathematical modelling approach. Aquaculture, 308: $152-158$

Inoue, L. A. K. A.; Santos Neto, C.; Moraes, G. 2003. Óleo de cravo como anestésico para juvenis de matrinxãBryconcephalus (Gunther, 1869). Ciência Rural, Santa Maria, v. 33, 5: 943-947.

Instituto Brasileiro de Geografia e Estatística - IBGE. Produção da Pecuária Municipal. Prod. Pec. munic., Rio de Janeiro, v. 41, p.1-108, 2013.

Instituto Brasileiro de Geografia e Estatística - IBGE. Produção da Pecuária Municipal. Prod. Pec. munic., Rio de Janeiro, v. 41, p.1-108, 2013.

Islam M.S. (2005) Nitrogen and phosphorus budget in coastal and marine cage aquaculture and impacts of effluent loading on ecosystem: review and analysis towards model development. Marine Pollution Bulletin 50, 48-61. 
Iwama, G. K.; Tautz, A. F. 1981. A Simple Growth Model for Salmonids in Hatcheries. Canadian Journal of Fisheries and Aquatic Sciences, 38: 649-656.

Jobling, M. (1981), The influences of feeding on the metabolic rate of fishes: a short review. Journal of Fish Biology, 18: 385-400.

Jorcin, A.; Nogueira, M. G. 2005. Temporal and spatial patterns based on sement and sedimentwater interface characteristics along a cascade of reservoirs (Paranapanema River, south-east Brazil). Lakes \& Reservoirs: Research and Management, 10: 1-12.

Kaushik, S. J. 1998. Nutritional bioenergetics and estimation of waste production in non-salmonids. Aquatic Living Resources, 11(4): 211- 217.

Köppen, W. 1948. Climatologia: con un estudio de los climas de la tierra. Fondo de Cultura Econômica, Ciudad de México, 478p.

Lupatcsh, I.; Kissil, G.W. 1998. Predicting aquaculture waste from gilthead seabream (Sparus aurata)culture ising a nutritional approach. Aquat. Living Resour. 11:265-268.

Lupatcsh, I.; Kissil, G.W.; Slan, D.; Pfeffer, E. 1998. Energy and protein requirements for maintenance and growth in gilthead seabream (Sparus aurata L.) Aquaculture Nutr. 4: 165173.

Lupatsch, I.; Kissil, G.W.; Sklan, D. 2003. Comparison of energy and protein efficiency among three fish species, gilthead sea bream (Sparus aurata), European sea bass (Dicentrarchus labrax) and white grouper (Epinephelus aeneus): Energy expediture for protein and lipid deposition. Aquaculture, 225:175-189.

Macedo, C. F.; Sipaúba-Tavares, L. H. 2010. Eutrophication and water quality in pisciculture: consequences and recommendations. Bol. Inst. Pesca, 36 (2): 149-163.

Mallasen, M., H. P. Barros, D. P. Traficante, and A. L. S. Camargo. 2012. Influence of a net cage tilapia culture on the water quality of the Nova Avanhandava reservoir, São Paulo State, Brazil. Acta Scientiarum. Biological Sciences 34:289-296.

Merola N, Souza JH (1988) Cage Culture of the Amazon Fish Tambaqui, ColossomaMacropomum, at 2 Stocking Densities. Aquaculture, 71, 15-21.

Milstein A, Zoran M, Krambeck HJ (1992) Fish performance and oxygen dynamics in a dual purpose reservoir (fish farming and field irrigation) in the Israeli coastal area. . Limnologica, 22, 7. 
Miranda, E.C.; Pezatto, C.A.; Pezzato, L.E. et al. 2000. Disponibilidade aparente de fósforo em ingredientes pela tilápia-do-nilo (Oreochromis niloticus). Acta Scient., v.22, p.669-675.

Montanhini Neto, R. ; Ostrensky, A. 2014 Evaluation of commercial feeds intended for the Brazilian production of Nile tilapia (L.): nutritional and environmental implications. Aquaculture Nutrition (Print), v. I, 1-9.

Montanhini Neto, R.; Ostrensky, A. 2013. Nutriente load estimation in the waste of Nile tilápia Oreochromis niloticus (L.) reared in cages in tropical climate conditions. Aquaculture Research, 1-14.

National Research Council - NRC. 2011. Nutrient Requirements of Fish and Shrimp. National Academy Press, Washington, DC.392p.

Ono, E. A.; Kubtiza, F. Cultivo de peixes em tanque-rede. 3ed. Jundiaí: E.A.Ono, 2003. 112p.

Penczak T., Galicka W., Molinski M., Kusto E. \& Zalewski M. (1982) The enrichment of a mesotrophic lake by carbon, phosphorus and nitrogen from the cage aqua- culture of rainbow trout, Salmo gairdneri. Journal of Applied Ecology 19, 371-393.

Perbiche-Neves, G.; Ferreira, R.A.R; Nogueira, M.G. 2011.Phytoplankton structure in two contrasting cascade reservoirs (Paranapanema River, Southeast Brazil). Rev. Biologia. (66) 6, p. 967-976.

Pomari, J. 2010. Efeitos da tilapicultura em tanques-rede sobre as assembléias zooplanctônicas do reservatório de Chavantes, rio Paranapanema (SP/PR) Dissertação (mestrado) - Universidade Estadual Paulista, Instituto de Biociências, Botucatu, 2010, 205p.

SAS. SAS/STAT software: changes and enhancements through release 6.12. Cary: Statistical Analysis System Institute, 1997. 1167p.

Shearer K.D. (1994) Factors affecting the proximate composition of cultured fshes with emphasis on salmonids. Aquaculture 11, 63-88.

Tacon, A.G.J. Salmon aquaculture dialogue: Status of information on salmon aquaculture feed and the environment. Aquafeed International, v.8, p.22-37, 2005.

Tran-Duy, A.; Schrama, J. W.; Van Dam, A. A.; Verreth, J.A. J. 2008 Effects of oxygen concentration and body weight on maximum feed intake, growth and hematological parameters of Nile tilapia, Oreochromis niloticus, Aquaculture, v. 275, Issues 1-4, p.152-162. 
Trung, D.V.; Diu, N. T.; Hao, N.T.; Glencross, B. 2011. Development of nutritional model to define the energy and protein requirements of tilápia, Oreochromis niloticus. Aquaculture, 320: 69-75.

Wang, X.; Olsen, L.M.; Reitan, K.I.; Olsen, Y. 2012. Discharge of nutrient wastes from salmon farms: environmental effects, and potential for integrated multi-trophic aqua- culture. Aquacult Environ. Interact., 2:267-283.

Xie S., Cui Y., Yang Y. \& Liu J. (1997a) Energy budget of Nile tilapia, Oreochromis niloticus, in relation to ration size. Aquaculture 154, 57-68.

Yi, Y. 1999. A bioenergetics growth model for Nile tilapia (Oreochromis niloticus) based on limiting nutrients and fish standing crop in fertilized ponds. Aquacultural Engineering, 18: $157-173$. 


\section{CAPÍTULO 3}

\section{INTEGRAÇÃO DA MODELAGEM HIDRODINÂMICA COM O MODELO BIOENERGÉTICO NUTRICIONAL FISH-PRFEQ® PARA DETERMINAÇÃO DA CAPACIDADE DE SUPORTE PARA PRODUÇÃO DE TILÁPIA NO RESERVATÓRIO DE CHAVANTES, SP, BRASIL}

Guilherme Wolff Bueno ${ }^{1}$, Francisco Ernesto Moreno Bernal ${ }^{2}$, Rodrigo Roubach ${ }^{3}$, James Owen Skipper-Horton ${ }^{4}$, Dominique P. Bureau ${ }^{4}$

${ }^{1}$ Zootecnista, Doutorando da UnB, Brasília, DF - Brasil

${ }^{2}$ Médico Veterinário, Doutor, Professor da UnB, Brasília, DF - Brasil

${ }^{3}$ Biólogo, Doutor, Ministério da Pesca e Aquicultura, Brasília, DF - Brasil

${ }^{4}$ Cientista Animal, Doutor, Universidade de Guelph, Guelph, Ontário - Canadá 


\section{RESUMO}

Devido ao crescente uso de lagos e reservatórios para a prática da aquicultura, torna-se necessária à utilização de ferramentas de monitoramento, observação e simulação do real impacto desta atividade no ambiente aquático. Neste contexto, o presente estudo tem como objetivo a estimativa de cenários de lançamento de efluentes (fósforo e nitrogênio) da produção comercial de tilápia do Nilo (Oreochromis niloticus) em reservatório tropical por meio da integração do modelo bioenergético nutricional Fish-PrFEQ ${ }^{\circledR}$ com o modelo hidrodinâmico Dillon e Riegler (1974). Serão consideradas rações comerciais brasileiras com diferentes percentuais de fósforo total (PT) de 0,8; 1,2 e 2,1\% e fósforo digestível (PDi) de 0,5; 0,8 e 1,4\%, e as temperaturas médias serão de 21, 25 e $29^{\circ} \mathrm{C}$, para determinação de cenários de capacidade de suporte para produção de pescados. Verificaram-se diferenças de lançamento de resíduos de 2,7 a 22,2 $\mathrm{kg}$ de P por tonelada de peixe produzido entre os cenários estudados. $\mathrm{O}$ uso de rações de melhor eficiência e menor impacto ambiental $\left(0,8 \%\right.$ de PT e $0,5 \%$ de PDi cultivada a $\left.25^{\circ} \mathrm{C}\right)$ proporcionaram um incremento produtivo de $77.6 \%$ em relação ao cenário utilizado atualmente pela Agência Nacional de Água e um decrécimo de $70 \%$ com o uso de rações com PT de $2,1 \%$, PDi de $1,4 \%$ e temperatura de $25^{\circ} \mathrm{C}$. A adoção desta abordagem permite avaliar cada processo ou fazenda compartimentalizado e determinar a real contribuição de resíduos no ambiente aquático, medidas que auxiliam no monitoramento da eficiência zootécnica e no aprimoramento da análise de outorga, além da possibilidade de incentivar produtores e indústria aquícola na utilização de rações de melhor qualidade nutricional e menor impacto ambiental.

Palavras-chave: aquicultura sustentável, balanço de massas, capacidade de suporte, modelagem hidrodinâmica, modelagem bioenergética, tilápia. 


\begin{abstract}
Regarding the increasing use of lakes and reservoirs for the practice of aquaculture, it is necessary to use monitoring tools, observation and simulation of the real impact of this activity in the aquatic environment. In this context, this study aims to estimate launch scenarios effluent (phosphorus and nitrogen) of Nile tilapia (Oreochromis niloticus) commercial production in a tropical reservoir through the integration of nutritional bioenergetic model Fish-PrFEQ ${ }^{\circledR}$ with hydrodynamic model from Dillon and Riegler (1974), considering Brazilian commercial diets with different percentage of total phosphorus (TP) of $0.8 ; 1.2$ and $2.1 \%$ and digestible phosphorus (PDi) of $0.5 ; 0.8$ to $1.4 \%$, grown under temperatures of 21,25 and $29^{\circ} \mathrm{C}$ for determining the carrying capacity scenarios for fish production. There were differences waste releases varying from 2.7 to $22.2 \mathrm{~kg} \mathrm{P}$ per tonne of fish produced among the scenarios studied. The use of higher efficiency and lower environmental impact diets $\left(0.8 \% \mathrm{Pt}\right.$ and $0.5 \%$ PDi cultured at $\left.25^{\circ} \mathrm{C}\right)$ caused an increase of $77.6 \%$ in the production compared to the scenario currently used by National Water Supply and a decrease of $70 \%$ by the use of diets with $2.1 \% \mathrm{E} 1.4 \% \mathrm{PDi}$ temperature and $25^{\circ} \mathrm{C}$. The adoption of this approach allows to evaluate each compartmentalized process or farm, and determine the actual waste contribution in the aquatic environment. These measures help to monitor the zootechnical efficiency and the improvement of water grant analysis, plus the ability to encourage producers and aquaculture industry for the use of better nutritional quality diets and with less environmental impact.
\end{abstract}

Keywords: sustainable aquaculture, mass balance, carrying capacity, hydrodynamic modeling, bioenergetic modeling, tilapia. 


\section{INTRODUÇÃO}

A aquicultura é considerada uma fonte viável e de baixo custo de proteína de alta qualidade, principalmente em países em desenvolvimento, que sofrem com a falta deste alimento (El-Gayar e Leung, 2000). Por esta razão, as áreas inundadas de lagos artificiais e lagoas estão sendo cada vez mais utilizadas para a produção de peixes (Ayer e Tyedmers, 2009; Barton e Fløysand, 2010). Além da produção de alimentos, a expansão dessa atividade em reservatórios gera benefícios para as economias regionais, na forma de emprego e renda em toda a cadeia de produção da aquicultura (Ross et al. 2011), constituindo uma importante alternativa produtiva para as populações afetadas por barragens, por exemplo (Abery et al. 2005).

A utilização dos reservatórios para usos múltiplos no Brasil, entre eles a aquicultura, foi estabelecida pela Política Nacional de Recursos Hídricos, em 1997, com a Lei no 9.433. Este quadro legal foi complementado pelo Decreto $\mathrm{n}^{\circ} 4.895$, de 2003, e a Instrução Normativa Interministerial nº 6, de 2004 que regulam o uso de águas brasileiras e espaços públicos, isto é, as "águas da união", para a prática da aquicultura. Em adição a isto, a Instrução Normativa Interministerial $\mathrm{N}^{\mathrm{O}} 7$ de 2005 , especifica que até $1 \%$ da área da superfície das águas da união está disponível para fins de aquicultura, desde que seja respeitado os limites da capacidade de suporte dos reservatórios (ANEEL, 2011).

Atualmente, a emissão da outorga de uso da água para projetos aquícolas no Brasil é realizada pela Agência Nacional de Águas (ANA), a qual define o valor máximo permissível de produção de pescado em determinado reservatório, por meio do modelo hidrodinâmico Dillon e Rigler (1974) que determina a capacidade de suporte do ambiente aquático (ANA, 2009). Porém, as análises de outorga não consideram os fatores zootécnicos específicos para cada espécie, condição de cultivo e região do país, assim, pode estar sub ou superestimando a situação real dos efluentes originários da produção de peixes em tanques-rede. Como consequência, a ausência de valores 
mensuráveis mais adequados, pode vir a comprometer a integridade dos recursos hídricos onde os sistemas produtivos são instalados. Neste cenário, o empreendedor, cada vez mais, tem desistido da atividade ou praticado de forma irregular.

Portanto, os resíduos sólidos lançados pela aquicultura tornam-se uma preocupação para o desenvolvimento sustentável da atividade. Assim, vários pesquisadores (Cho e Bureau, 1998; Lupatsch e Kissil, 1998; Yi, 1999; Bureau e Hua, 2010; Azevedo et al., 2011) têm demonstrado que os produtos residuais provenientes de diferentes tipos de cultivos aquáticos podem ser estimados por meio de modelos matemáticos fatoriais, que podem ser incorporados aos estudos de monitoramento e determinação do impacto ambiental aquícola.

Diante disto, o presente estudo tem como objetivo integrar o modelo bioenergético nutricional Fish-PrFEQ ${ }^{\circledR}$ com o modelo hidrodinâmico Dillon e Riegler (1974) para simulações de cenários de lançamento de resíduos a partir do uso de rações comerciais com diferentes percentuais de fósforo total $(0,8 ; 1,5$ e 2,4\%) e determinar a capacidade de suporte do reservatório de Chavantes para produção de pescados. 


\section{MATERIAL E MÉTODOS}

\subsection{Coleta de dados}

Considerou-se o histórico de 2005 a 2015 dos dados hidrológicos de profundidade média (m), cota máxima e mínima (m), vazão média afluente (Qmlt, $\left.\mathrm{m}^{3} \mathrm{~s}^{-1}\right)$, tempo de residência (dias) por meio do Sistema de Informação do Potencial Hidrelétrico Brasileiro (SIPOT/ANEEL, 2015) e dos dados disponíveis nos estudos para demarcação de parques aquícolas do Ministério da Pesca e Aquicultura (MPA, 2013) para o reservatório de Chavantes, localizado no rio Paranapanema, estado de São Paulo, Brasil.

Utilizaram-se os dados de composição centisimal de 152 dietas comerciais para tilápia obtidas no Ministério da Agricultura, Pecuária e Abastecimento (MAPA) e na indústria brasileira de rações. A partir destes dados, aplicou-se a metodologia proposta por Silverston et al. (1997) onde classificaram-se as dietas de acordo com as respectivas fases de juvenil I (30 a 100g), juvenil II (100 a 500g) e peso de mercado (>500g), com os respectivos percentuais de fósforo total de 0,8; 1,2 e 2,1\% nas dietas (variável depente), para posterior aplicação da meta-análise de acordo com o preconizado por Lovatto et al. (2007).

Utilizaram-se os valores obtidos do desempenho, composição corporal, coeficiente de crescimento térmico (TGC), energia e oxigênio da $O$. niloticus cultivada em tanques-rede para o reservatório de Chavantes, SP de acordo com apresentado por Bueno (2015) e aplicou-se a modelagem bioenergética fatorial e a determinação dos resíduos $(\mathrm{N}$ e $\mathrm{P})$ do cultivo de peixes em tanques-rede. 


\subsection{Cálculo da Capacidade de Suporte (CP)}

Aplicou-se o modelo de Dillon e Rigler (1974), o qual considera que a concentração de fósforo na água ([P], em $\mathrm{mg} / \mathrm{m}^{3}$ ) é uma função da carga anual de fósforo (La, em $\mathrm{mg} / \mathrm{m}^{2}$.ano), do coeficiente de retenção de fósforo $(\mathrm{Rp})$, da profundidade média (z, em m), e da taxa de renovação da água do reservatório $\left(\rho\right.$, em $\left.\operatorname{anos}^{-1}\right)$, Equação 1:

$$
[\mathrm{P}]=\mathrm{La}(1-\mathrm{Rp}) /(\mathrm{z} \cdot \rho)
$$

Onde: (z) é a profundidade média calculada pela razão entre o volume e a área do corpo hídrico; $(\rho)$ é a taxa de renovação,calculada pela razão entre a vazão média e o volume máximo do reservatório; $R p$ é o coeficiente de retenção do fósforo calculado pela Eq. 2, proveniente do estudo realizado por Larsen e Mercier (1976, apud Beveridge, 2004) com modificações feitas por Canfield e Bachmann (1981, apud Beveridge, 2004).

$$
\mathrm{Rp}=1 /\left(1+0,614 \cdot \rho^{0,491}\right)
$$

$\mathrm{O}$ parâmetro da concentração de fósforo ([P]) na Eq. 1 refere-se ao $\Delta[\mathrm{P}]$, que é o incremento na concentração de fósforo na água para uma determinada carga La por meio da Eq.3.

$$
\mathrm{La}=(\Delta[\mathrm{P}] \cdot \mathrm{z} \cdot \rho) /(1-\mathrm{R})
$$

Onde: $\Delta[\mathrm{P}]$ é dado pela subtração da concentração atual de fósforo na água do reservatório em

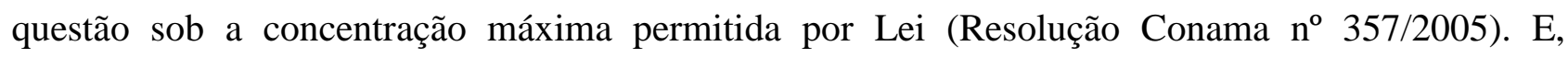
conhecendo-se o máximo $\Delta[\mathrm{P}]$ autorizável, calcula-se o La máximo autorizável, ou seja, o quanto de fósforo pode ser adicionado à água (Eq.3).

Segundo o preconizado pela ANA (2009) considerou-se o incremento máximo de 1/6 da concentração permitida de fósforo pela Resolução Conama ${ }^{\circ}$ 357/2005 para corpos hídricos de Classe II, a qual enquadra-se a aquicultura. Isso corresponde a $5 \mathrm{mg} / \mathrm{m}^{3}$. Os $5 / 6$ restantes ficariam reservados a outros usos onde haja aportes de fósforo à água, como a diluição de esgotos domésticos e industriais, além do aporte natural de fósforo. Assim, calcula-se o La em função de um $\Delta[\mathrm{P}]$ de $5 \mathrm{mg} / \mathrm{m}^{3}$.

Em seguida, calculou-se a carga de fósforo autorizável no reservatório todo (Lr), que estará em mg/ano, utilizando o La, que representa a máxima carga de fósforo autorizável por metro 
quadrado, multiplicando o valor obtido pela área de superfície d'água $\left(\mathrm{A}, \mathrm{em} \mathrm{m}^{2}\right)$ do reservatório, Eq. 4:

$$
\mathrm{Lr}=\mathrm{La} . \mathrm{A}
$$

Utilizou-se a cota com $90 \%$ de permanência da água obtido pela fórmula: $\operatorname{Lr}=\left(\Delta[\mathrm{P}] . \mathrm{V}_{90}\right.$. p) / ( 1 - Rp), onde $\mathrm{V}_{90}$ é o volume na cota com $90 \%$ de permanência da água (ANA, 2009).

Em seguida, converteu-se o Lr em produção anual autorizável de peixes (B). Para isso, deve-se estimar a proporção de fósforo na água para cada tonelada de peixe produzida (item 2.3).

\subsection{Determinação da proporção de resíduos da aquicultura}

Aplicou-se o modelo bioenergético nutricional Fish-PrFEQ ${ }^{\circledR}$ (Cho e Bureau, 1998) para quantificação do fósforo e nitrogênio sólido e dissolvido lançados pelo cultivo de peixes. Para tanto, determinaram-se: $i$ ) Cálculo do coeficiente de crescimento térmico dos peixes (TGC); ii) Cálculo do metabolismo basal da espécie e iii) Cálculo da carga de resíduos gerado pelo do cultivo (P e N).

Utilizaram-se os dados de desempenho zootécnico da O.niloticus cultivada neste reservatório por Bueno (2015) e determinou-se a curva de crescimento do peixe por meio do TGC de acordo com o proposto por Iwama e Tautz (1981), adaptado por Cho (1992) dado pela equação:

$$
P f(g)=\left[P i^{(1-\mathrm{b})}+\frac{T G C}{100} \sum t * d\right]^{\frac{1}{(1-\mathrm{b})}}
$$

Onde: $P i$ e $P f$ é o peso inicial e final corporal, respectivamente, $d$ é dia, $t$ é temperatura $\left({ }^{\circ} \mathrm{C}\right)$, e $(1-b)$ é o expoente do peso corporal utiliza-se $0.65 ; 0,48$ e 1,00 para as fases de juvenil I (30 a 100g) juvenil II (100 a 500g) e peso de mercado (>500g), respectivamente (Bueno, 2015).

$\mathrm{O}$ metabolismo basal ( $\mathrm{HeE}, \mathrm{kJ}$ peixe ${ }^{-1}$ ) determinou-se em função da temperatura metabólica e peso corporal (potência de 0,8 do peso vivo do peixe) de acordo com o recomendado por Cho e Bureau (1998):

$$
H e E=(a+b T) * \text { Peso Corporal }{ }^{0.8} \quad \text { (Eq. 6) }
$$

Em que, $(\mathrm{a}+\mathrm{bT})$ é a relação da temperatura $(\mathrm{T})$ com HeE e do peso corporal metabólico $\left(\mathrm{BW}^{0.8}\right)$ seguindo o preconizado por Cho e Bureau (1998) e Dumas et al. (2010). 
A determinação do incremento calórico da alimentação (HiE, $\mathrm{kJ}$ peixe $\mathrm{e}^{-1}$ ) e a energia retida (RE) foi obtida por meio dos valores calculados por Bueno (2015) para O. Niloticus cultivada em tanques-rede sob as condições deste reservatório. O qual considerou a diferença entre a ingestão energética (IE, $\mathrm{kJ}$ peixe ${ }^{-1}$ ), a energia para o metabolismo basal (HeE, $\mathrm{kJ}$ peixe ${ }^{-1}$ ), fezes (FE, $\mathrm{kJ}$ peixe $^{-1}$ ), fezes não-fecais $\left(\mathrm{UE}+\mathrm{ZE}, \mathrm{kJ}\right.$ peixe $\mathrm{e}^{-1}$ ) e a perda de energia. O RE foi obtido a partir da diferença entre a energia bruta do peso final e inicial. O custo de energia da urina (UE) e da brânquias (ZE) foi considerado como $24,9 *(\mathrm{UN}+\mathrm{ZN}) \mathrm{kJ}$ peixe $\mathrm{e}^{-1}$ onde, $\mathrm{UN}$ e $\mathrm{ZN}$ são as perdas de nitrogênio urinário e branquial, respectivamente de acordo com o proposto por Kaushik (1998) na equação 7:

$$
H i E=I E-F E-R E-(U E+Z E)-H e E
$$

O total de resíduos liberados pela piscicultura refere-se aos resíduos sólidos (RS) gerados pela alimentação durante a produção, pelos resíduos da ração e os resíduos dissolvidos (RD). Desta forma, a saída de resíduos sólidos e dissolvidos foram estimados utilizando as equações 8 e 9, respectivamente.

$$
R S=M S \text { ingerido } x(1-C D A M S)
$$

Onde TRS é o total de resíduos sólidos, a CDA é o coeficiente de digestibilidade aparente, e MS é matéria seca. Equação semelhante foi utilizada para estimar a saída de resíduos sólidos de $\mathrm{N}$ e $\mathrm{P}$. Os resíduos dissolvidos de $\mathrm{N}$ e $\mathrm{P}$ foram estimados a partir da diferença entre os valores que foram digestíveis e retidos nos peixes (Eq. 9).

$R D N$ ou $R D P=($ ingerido $N$ ou $P x C D A$ do $N$ ou $P)-$ Nou $P$ retido (Eq. 09) Onde RDN e RDP são os resíduos dissolvidos nitrogenanados e fosfatados, respectivamente.

Obtendo-se a carga de fósforo (RS) e Lr, calculou-se a produção autorizável de peixes (B, em $\left.\mathrm{t} \mathrm{ano}^{-1}\right)$ a partir da carga autorizável de fósforo no reservatório $(\mathrm{Lr}$, em $\mathrm{kg}$ ano-1 $)$, Equação 10:

$$
\mathrm{B}=\mathrm{Lr} / \mathrm{RS}
$$




\section{RESULTADOS}

A temperatura da água apresentou oscilações características do reservatório de $21^{\circ} \mathrm{C}$ no período de inverno e média de $29^{\circ} \mathrm{C}$ durante o verão. O potencial hidrogeniônico $(\mathrm{pH})$ obteve mínima de 6,2 e máxima de 8,5 em períodos distintos. Os valores de fósforo e nitrogênio totais apresentaram-se estáveis com valores médios de 0,54 e $0,018 \mathrm{mg} \mathrm{L}^{-1}$ de $\mathrm{N}$ e $\mathrm{P}$, respectivamente. $\mathrm{O}$ oxigênio dissolvido $\left(\mathrm{O}_{2} \mathrm{D}\right)$ na superfície da água (3 m) manteve-se entre 6,20 a $9,51 \mathrm{mg} \mathrm{L}^{-1}$ para todo o período avaliado.

Na Tabela 12, verifica-se a meta-análise das rações comerciais brasileiras as quais foram distribuídas em três grupos distintos de acordo com o nível de fósforo nas rações $(0,8 ; 1,2$ e $2,1 \%$ de PT).

Tabela 12. Conteúdo nutricional calculado para dietas comerciais recomendadas para tilápia do Nilo obtido na indústria aquícola brasileira $(\mathrm{N}=152 *)$.

\begin{tabular}{|c|c|c|c|c|c|c|c|c|c|}
\hline \multirow{2}{*}{ Composição } & \multicolumn{3}{|c|}{ Juvenil I } & \multicolumn{3}{|c|}{ Juvenil II } & \multicolumn{3}{|c|}{ Peso de Mercado } \\
\hline & $0,8 \% P$ & $1,2 \% \mathrm{P}$ & $2,1 \% \mathrm{P}$ & $\mathbf{0 , 8 \%} \mathrm{P}$ & $1,2 \% \mathrm{P}$ & $2,1 \% \mathrm{P}$ & $0,8 \% P$ & $1,2 \% \mathrm{P}$ & $2,1 \% \mathrm{P}$ \\
\hline MS & $90,7 \pm 12.3$ & $89,3 \pm 9.4$ & $91,5 \pm 7.8$ & $89,4 \pm 11.7$ & $90,8 \pm 8.1$ & & $89,4 \pm 13.5$ & & $91,6 \pm 7.2$ \\
\hline DMS, \% & $63,6 \pm 41.4$ & $60,6 \pm 22.2$ & $68,2 \pm 25.2$ & $64,5 \pm 35.1$ & $64,5 \pm 37.1$ & $62,4 \pm 28.8$ & $63,2 \pm 32.7$ & $64,5 \pm 29.6$ & $59,1 \pm 31.1$ \\
\hline $\mathrm{EB}, \mathrm{MJ} / \mathrm{kg}^{-1}$ & $19,5 \pm 48.2$ & $19,5 \pm 33.0$ & $20,2 \pm 38.8$ & $18,1 \pm 48.2$ & $18,1 \pm 39.9$ & $18,3 \pm 44.2$ & $18,5 \pm 41.0$ & $17,8 \pm 37.7$ & $18,4 \pm 38.6$ \\
\hline $\mathrm{ED}, \mathrm{MJ} / \mathrm{kg}^{-1}$ & $15,1 \pm 53.5$ & $13,7 \pm 49.5$ & $15,2 \pm 43.2$ & $14,6 \pm 50.0$ & $12,6 \pm 42.2$ & $15,1 \pm 49.9$ & $14,6 \pm 49.7$ & $13,9 \pm 47.9$ & $14,2 \pm 42.9$ \\
\hline $\mathrm{PB}, \%$ & $39,5 \pm 23.7$ & $27,6 \pm 32.1$ & $46,8 \pm 20.0$ & $21,6 \pm 38.3$ & $20,5 \pm 39.4$ & $35,6 \pm 38.7$ & $21,6 \pm 19.2$ & $20,5 \pm 27.8$ & $26,5 \pm 30.1$ \\
\hline $\mathrm{PD}, \%$ & $32,2 \pm 18.9$ & $24,4 \pm 20.0$ & $41,0 \pm 22.3$ & $19,4 \pm 23.4$ & $18,3 \pm 28.9$ & $31,4 \pm 30.4$ & $19,4 \pm 12.5$ & $18,3 \pm 13.3$ & $22,4 \pm 28.5$ \\
\hline & & & & & & & & & \\
\hline PTD, \% & $0,6 \pm 4.3$ & $0,8 \pm 2.3$ & $1,5 \pm 3.3$ & $0,5 \pm 4.1$ & $0,7 \pm 6.9$ & $1,4 \pm 5.2$ & $0,5 \pm 3.7$ & $0,1 \pm 4.1$ & $1,4 \pm 3.3$ \\
\hline DP/DE & $21,3 \pm 7.0$ & $17,8 \pm 7.3$ & $26,9 \pm 4.5$ & $13,3 \pm 6.6$ & $14,6 \pm 7.1$ & $20,7 \pm 4.2$ & $13,3 \pm 6.2$ & $13,1 \pm 6.9$ & $15,7 \pm 4.0$ \\
\hline
\end{tabular}

MS =Matéria Seca; MSD - Matéria Seca Digestível; PB = Proteína bruta; PD = Proteína bruta digestível; EB = Energia bruta; ED = Energia digestível; $\mathbf{P}=$ Fósforo total - total phosphorus; PDi = Fósforo digestível; Relação PD/ED.

* Ministério da Agricultura, Pecuária e Abastecimento (MAPA), indústria brasileira de rações e Montanhini Neto e Ostrensky (2015). 
Para a determinação da carga de resíduos gerados pela produção de tilápia em tanques-rede neste reservatório $(\mathrm{Pa})$, aplicou-se o modelo bioenergético com os valores zootécnicos para a espécie obtidos por Bueno (2015), os quais permitiram a simulação da estimativa de resíduos (N e P) do cultivo (Tabela 13).

Tabela 13. Estimativa de resíduos da produção de tilápia do Nilo (Oreochromis niloticus) em tanques-rede alimentadas com dietas contendo diferentes níveis de fósforo calculado pelo modelo nutricional bioenergético.

\begin{tabular}{|c|c|c|c|c|c|c|c|c|c|}
\hline \multirow{3}{*}{ Parâmetros } & \multicolumn{3}{|c|}{$0,8 \%$ P-total } & \multicolumn{3}{|c|}{ 1,2\% P-total } & \multicolumn{3}{|c|}{ 2,1\% P-total } \\
\hline & \multicolumn{9}{|c|}{ Temperatura $\left({ }^{\circ} \mathrm{C}\right)$} \\
\hline & 21 & 25 & 29 & 21 & 25 & 29 & 21 & 25 & 29 \\
\hline \multicolumn{10}{|c|}{ Kg de resíduo por tonelada de peixe produzido } \\
\hline \multicolumn{10}{|c|}{ Resíduo Sólido } \\
\hline Nitrogênio, kg/t & 4,55 & 5,23 & 5,94 & 4,20 & 4,75 & 5,48 & 7,39 & 8,31 & 8,84 \\
\hline Fósforo, kg/t & 2,50 & 2,81 & 3,06 & 5,36 & 6,02 & 6,89 & 7,33 & 8,18 & 8,59 \\
\hline \multicolumn{10}{|c|}{ Resíduo Total (Sólido + Dissolvido) } \\
\hline Nitrogênio, kg/t & 11,4 & 16,9 & 21,1 & 12,6 & 18,0 & 24,3 & 28,0 & 40,4 & 42,3 \\
\hline Fósforo, kg/t & 2,7 & 3,7 & 4,4 & 8,8 & 10,9 & 13,0 & 17,9 & 22,6 & 22,2 \\
\hline
\end{tabular}

Tendo-se a Pa, calculou-se à carga de fósforo autorizável em todo o reservatório (Lr) por meio da Equação 4 em que: o La (representa a máxima carga de fósforo autorizável por metro quadrado) e multiplica-se o valor obtido por A (área de espelho d'água, em $\mathrm{m}^{2}$ ).

Em seguida, utilizando o $\mathrm{Lr}$ e Pa calculou-se a produção autorizável de peixes e a integração do modelo bioenergético e hidrodinâmico para simulação da capacidade de suporte do reservatório de Chavantes considerando a temperatura média de $25^{\circ} \mathrm{C}$ (Tabela 12).

Tabela 14. Aplicação do modelo bioenergético integrado com modelo hidrodinâmico para a determinação da capacidade de suporte para produção de pescados no reservatório de Chavantes, São Paulo, Brasil.

\begin{tabular}{llr}
\hline Parâmetros $^{1}$ & & Valores \\
\hline \multirow{2}{*}{ Cota } & Máxima & 474,00 \\
& Mínima & 465,23 \\
Área & Máxima & 400,00 \\
& Mínima & 294,97 \\
Volume & Máximo & $8.795,00$ \\
& Mínimo & $5.754,00$ \\
Tempo de Residência & Anos & 0,87 \\
$\Delta[\mathrm{P}]\left(\mathrm{mg} / \mathrm{m}^{3}\right)^{*}$ & Dias & 315,78 \\
Coeficiente de retenção (R)*** & & 5,00 \\
Temperatura Média da Água & & 0,76 \\
Profundidade média na cota mínima (Pf.med), m & $26^{\circ} \mathrm{C}$ \\
Vazão média afluente - Qmlt $\left(\mathrm{m}^{3} \mathrm{~s}^{-1}\right)$ & 19,51 \\
\hline
\end{tabular}


Capacidade de suporte para produção de pescados

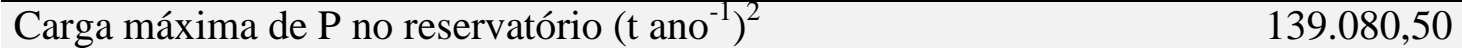

Produção máxima ANA (t/peixe/ano) ${ }^{2}$

$21.009,14$

Prod. Máx. Bioenergetic. (t/peixe/ano) $-0,8 \% \mathrm{P}$ a $25^{\circ} \mathrm{C}$

$37.327,94$

Prod. Máx. Bioenergetic. (t/peixe/ano) $-1,2 \% \mathrm{P}$ a $25^{\circ} \mathrm{C}$

$12.770,22$

Prod. Máx. Bioenergetic. (t/peixe/ano) $-2,1 \% \mathrm{P}$ a $25^{\circ} \mathrm{C}$

$6.163,80$

${ }^{\top}$ Dados Sistema de Informação do Potencial Hidrelétrico Brasileiro (SIPOT, ANEEL) e MPA (2013).

${ }^{2}$ Cenário utilizado pela ANA: taxa de conversão alimentar 1,60. Fóforo total $10 \mathrm{~kg} / \mathrm{t}$ de peixe produzido e $\mathrm{P}$ corporal (Pp) obtido em Dantas e Attayde (2007).

$* \operatorname{Lr}=(\Delta[\mathrm{P}] * \operatorname{Vmin} *(1 / \mathrm{td})) /(1-\mathrm{R})$. Adaptado de Dillon e Rigler (1974).

$* * \mathrm{R}=0,761 *(1-\mathrm{EXP}(-0,0282 *(\operatorname{td} * 365)))$. Fonte: Straskraba (1996). 


\section{DISCUSSÕES}

Os valores da temperatura da água e $\mathrm{pH}$ mantiveram-se de acordo com o preconizado por Ono e Kubitza (2003) para O. niloticus cultivada em tanques-rede. Corroborando com o citado por Pomari (2010); Ayroza et al. (2013) e Garcia et al. (2013), que obtiveram desempenho satisfatório (TCA média 1,8 e peso ao abate de $800 \mathrm{~g}$ ) em estudos com esta espécie em reservatórios brasileiros. O fósforo e o nitrogênio total apresentaram valores abaixo do máximo permissível $\left(0,030 \mathrm{mg} \mathrm{L}^{-1} \mathrm{de}\right.$ P total) para corpos de água de classe 2, de acordo com o recomendado pela Resolução CONAMA357/2005 para ambientes lênticos.

A concentração de oxigênio dissolvido $\left(\mathrm{O}_{2} \mathrm{D}\right)$ na água oscilou entre 6,20 a $9,51 \mathrm{mg} \mathrm{L} \mathrm{L}^{-1}$, valores próximos ao obtido por Jorcin e Nogueira (2005) e por Pomari (2010) em piscicultura também no reservatório de Chavantes (próximo a 8,81 $\mathrm{mg} \mathrm{L}^{-1} \mathrm{de}_{2} \mathrm{D}$ ), apresentando-se no nível considerado ótimo (acima de 4,0 $\mathrm{mg} \mathrm{L}^{-1}$ de $\mathrm{O}_{2} \mathrm{D}$ ) para a produção de Oreochromis sp. (Milstein et al., 1992).

As rações comerciais apresentaram variação na composição centesimal (Tabela 12) principalmente nos valores de densidade energética e nos teores de proteína e fósforo entre as fases de cultivo JVI, JVII e PM, valores similares ao observado por Furuya et al. (2010) e Montanhini Neto e Ostresnky (2015) para dietas de tilápias.

Cho e Bureau (2001) enfatizam que peixes confinados demandam rações com adequado balanço de nutrientes e energia para o crescimento e reprodução. Segundo o NRC (2011), a relação de energia digestível e proteína digestível na ração para tilápia é de $10 \mathrm{kcal} \mathrm{g}^{-1}$ de proteína, desta forma, com o crescimento do peixe ao longo do cultivo, sua eficiência alimentar diminui e observase maior exigência em energia e menor em proteína (Jobling, 2011). 
Neste cenário, além de considerar a fase da vida e a dieta fornecida, as condições ambientais irão influenciar diretamente na eficiência alimentar e lançamento de resíduos oriundos do metabolismo do peixe, conforme se demonstra na Tabela 13 as diferenças de lançamento de resíduos de 2,7 a 22,2 $\mathrm{kg}$ de $\mathrm{P}$ por tonelada de peixe produzido entre os cenários estudados. Chowdbury et al. (2013) também avaliando O. niloticus alimentadas sob diferentes níveis de proteína na dieta $\left(40,38\right.$ e $35 \%$ ) demonstraram haver aumento na excreção de 4,2 para $5,0 \mathrm{~kg} \mathrm{ton}^{-1}$ de $\mathrm{P}$ e decréscimo nos valores de $\mathrm{N}$ de 46,2 para 40,9 $\mathrm{kg}$ por tonelada de tilápia produzida.

Neste contexto, a redução dos níveis de fósforo na ração é uma estratégia que pode ser utilizada com eficiência, sem prejudicar o desempenho zootécnico dos animais, pois estudos demonstram que a exigência de fósforo para a tilápia apresenta uma faixa de valores menores do que os praticados pela indústria de ração brasileira (Tabela 12), principalmente pelo fato de serem utilizadas fontes protéicas de origem animal com elevado teor de cinzas (Furuya et al., 2008).

Portanto, a análise das rações comerciais e a determinação das exigências de $\mathrm{P}$ são essenciais para minimizar os resíduos e proporcionar ajustes na capacidade de suporte de determinado ambiente de cultivo. Além disto, fatores como o uso de fontes de origem vegetal, adição de fitase nas rações e o correto balanço entre cálcio e fósforo influenciarão na absorção e digestibilidade deste mineral pelos peixes (Hua e Bureau, 2010).

$\mathrm{O}$ requisito de $\mathrm{P}$ digestível da tilápia está em torno de 0,4 a 0,8\% (Watanabe et al. 1988; NRC, 2011; Miranda et al., 2000; Boscolo et al., 2003; Boscolo et al. 2005; Furuya et al. (2010). Neste cenário, aconselha-se a utilização de valores inferiores a $0,8 \%$ de fósforo total na dieta da $O$. niloticus.

Quando avaliada a capacidade de suporte do reservatório de Chavantes pelo modelo Dillon e Riegler (1974) utilizando as cargas de P simuladas pelo modelo Fish-PrFEQ ${ }^{\circledR}$ (Cho e Bureau, 1998) para diferentes cenários (Tabela 13), observou-se que o uso de rações de melhor eficiência e menor impacto ambiental $\left(0,8 \%\right.$ de PT e $0,5 \%$ de Pdi cultivada a $\left.26^{\circ} \mathrm{C}\right)$ proporcionou um incremento produtivo de $77.6 \%$ em relação ao cenário utilizado atualmente pela Agência Nacional de Água e um decrécimo de $70 \%$ com o uso de rações com PT de $2,1 \%$ e PDi $1,4 \%$ temperatura de $26^{\circ} \mathrm{C}$ (Tabela 14).

Esta diferença relaciona-se ao uso de dados pontuais de PT empregado pela ANA, que utiliza dados empíricos de $\mathrm{P}$ na ração. Os dados de $\mathrm{P}$ incorporado no peixe, que são utilizados pela ANA, foram baseados em um estudo realizado por Dantas e Attayde (2007), sendo um dado pontual e não representativo.

Com esses dados, realizam-se as análises de outorgas e se determina a capacidade de suporte, pelo modelo Dillon e Riegler (1974), tal fato compromete a análise das outorgas em 
cenários distintos, exemplo: fazendas que utilizam dietas de alta ou baixa qualidade apresentam distinto grau de impacto ambiental.

Entretanto, a escolha do modelo não deve ser única e padronizada, mas sim levar em consideração o banco de dados disponível, a consistência dos dados e a calibração de acordo com a finalidade e sua empregabilidade. Esses fatores devem ser considerados devido à consequência da limitação de dados e da relativa simplicidade em se estimar os parâmetros e condições dos lagos e reservatórios.

Johansson e Nordvarg (2002) realizaram um estudo de relevância na área de capacidade de suporte de reservatórios na Suécia onde comparando os modelos de Vollenweider e de Dillon e Rigler (1974) para avaliar as cargas de fósforo da aquicultura, concluíram-se que a biomassa produzida nesses ambientes pode ser maior do que a estimada pelos modelos testados, sem que isso cause alterações ambientais significativas. Fato observado na Tabela 14 quando aplicado a modelagem bioenergética considerando diferentes teores de $\mathrm{P}$ nas rações comercias para o cultivo de $O$. Niloticus.

A influência dos resíduos oriundos da aquicultura em reservatórios também foi estudada por Hakanson (2005) por meio do modelo Lakeweb, o qual considera as interações fundamentais da cadeia alimentar e suas relações bióticas e abióticas. O estudo considerou que $27 \%$ do total do fósforo lançado no ambiente encontram-se na forma dissolvida, e o restante na forma particulada. Além disto, os resultados demonstraram que houve um significativo aumento na biomassa de peixes do lago, sem que ocorresse aumento na biomassa algal.

Estudos realizados por Bueno et al. (2008), Buschmann et al. (2009) e Carvalho et al. (2012) mostraram que o cultivo de peixes em tanques-rede afetou diretamente a produtividade secundária do que a primária. Mesmo que essa afirmação seja um paradoxo, está relacionada ao fato de que a ictiofauna presente no lago consome diretamente os restos de ração e fezes liberadas pelos peixes do cultivo, reduzindo a eutrofização e o crescimento da biomassa algal, aumentando a ictiofauna associada do reservatório (Ramos et al., 2014).

Gyllenhammaret al. (2008) estudando o impacto de fazendas de peixes em um mesocosmo, utilizou um modelo dinâmico de balanço de massa para simular fluxos de $\mathrm{P}$ e $\mathrm{N}$, concluindo que é possível analisar a interação dos nutrientes no mesocosmo, contudo, a concentração de nutrientes na ração é um dos dados mais importantes, sendo que a ausência desta informação pode acarretar na imprecisão do modelo. Além desta variável, o padrão de crescimento (tamanho) dos peixes influencia na concentração de nutrientes da água e a ictiofauna associada aos tanques contribui para a diminuição nas emissões dos dejetos dos peixes nos tanques-rede. 
Xie et al. (1997) enfatizam que a eficiência alimentar associada à utilização de nutrientes de alta qualidade minimizam o potencial poluidor, além de permitir um aumento na produção por unidade de área que, em geral, é maior do que o aumento dos custos de produção associados, conforme demonstra Bechara et al. (2005).

Segundo Johansson et al. (1998), a emissão de P proveniente de cultivos de peixes em tanques-rede se diferencia das demais entradas de fósforo alóctone devido à sua distribuição espacial, temporal e disponibilidade biológica. Tais diferenças afetam a taxa de sedimentação, a remoção de $\mathrm{P}$ nas diferentes estações do ano, a remoção de $\mathrm{P}$ pela pesca e pássaros piscívoros, $\mathrm{O}$ consumo de $\mathrm{P}$ pela ictiofauna associada aos tanques, organismos bentônicos, fitoplâncton, zooplâncton e bactérias.

Contudo, o desenvolvimento de métodos analíticos para o cálculo da capacidade de suporte em reservatórios é um assunto que necessita ser estudado intensamente devido ao fato da aquicultura ser considerada uma atividade impactante, por utilizar rações ricas em nutrientes, que são potenciais fontes de poluição do meio ambiente. 


\section{CONCLUSÕES}

A integração do modelo bioenergético com o hidrodinâmico complementa as análises e a torna mais precisa, possibilitando considerar diversos fatores zootécnicos e ambientais de forma dinâmica, inserido às peculiaridades de cada região e operação aquícola. A adoção desta abordagem permite avaliar cada processo ou fazenda compartimentalizado e determinar a real contribuição de resíduos aquícolas e, em conjuto com ações de monitoramento da qualidade da água, das rações e da eficiência zootécnica das fazendas de peixe, realizar o aprimoramento da análise de capacidade de suporte para a produção de pescados em lagos e reservatórios. Além disso, há a possibilidade de incentivar produtores e indústria na utilização de boas práticas de manejo e rações de melhor qualidade nutricional que promovam o menor impacto ambiental. 


\section{AGRADECIMENTOS}

Ao Conselho Nacional de Desenvolvimento Científico e Tecnológico - CNPq, a International Science and Technology Partnerships Canada (ISTP Canadá) pelos recursos financeiros e a Coordenação de Aperfeiçoamento de Pessoal de Nível Superior - Capes pelo apoio com bolsas de pesquisa. À piscicultura Cristalina Ltda e aos Laboratórios de Análises Avançadas e Biotecnologia da Universidade Federal de Lavras - UFLA e de Nutrição de Peixes (FNRL) da Universidade de Guelph, Ontário, Canadá pela disponibilização das estruturas e apoio para o desenvolvimento desta pesquisa. 


\section{REREFÊNCIAS BIBLIOGRÁFICAS}

Abery NW, Sukadi F, Budhiman AA, Kartamihardja ES, Koeshendrajana S, De Silva SS (2005) Fisheries and cage culture of three reservoirs in west Java, Indonesia; a case study of ambitious development and resulting interactions. Fisheries Management and Ecology, 12, 315-330.

Agência Nacional das Águas - ANA. 2009. Nota Técnica n.009/2009/GEOUT/SOF-ANA: Atualização na metodologia de análise de pedidos de outorga para piscicultura em tanquesrede, 1-3.

Agência Nacional de Energia Elétrica - ANNEL. 2011. Relatórios Anuais. Brasília. 536p.

Ayer NW, Tyedmers PH (2009) Assessing alternative aquaculture technologies: life cycle assessment of salmonid culture systems in Canada. Journal of Cleaner Production, 17, 362373.

Ayroza, D.M.M.R.; Nogueira, M.G.; Carvalho, E.D.; Ferraudo, A.S.; Camargo, A.F.M. 2013. Temporal and Spatial Variability of Limnological Characteristics in Areas under the Influence of Tilapia Cages in the Chavantes Reservoir, Paranapanema River, Brazil. Journal of the world aquaculture society, v.44, n. 06: 814-825.

Azevedo, P.A.; Podemski, C.L.; Hesslein, R.H.; Kasian, S.E.M; Findlay, D.L, Bureau, D.P. 2011. Estimation of waste outputs by a rainbow trout cage farm using a nutritional approach and monitoring of lake water quality. Aquaculture, 311, 175-186.

Bechara J.A., Roux J.P., Diaz F.J.R., Quintana C.I.F.; De Meabe C.A.L. (2005) The effect of dietary protein level on pond water quality and feed utilization efficiency of pacu, Piaractus mesopotamicus (Holmberg, 1887). Aqua- culture Research 36, 546-553. 
Beveridge, MCM. Cage aquaculture. 3a ed. Oxford: Blackwell Publishing, 2004; 368 p.

Boscolo, W.R.; Feiden, A.; Bombardelli, R.A. et al. Exigências de fósforo para alevinos de tilápiado-nilo (Oreochromis niloticus). Acta Scient. Anim. Sci., v.27, p.87-91, 2005.

Boscolo, W.R.; Feiden, A.; Reidel, A. et al. Exigências de fósforo da tilápia-do-nilo (Oreocrhomis niloticus) na fase de crescimento. Varia Scient. Agrária, v.3, p.115-124, 2003.

Brasil. Decreto $\mathrm{n}^{\circ} 4.895$, de 25 de novembro de 2003. Dispõe sobre a autorização de uso de espaços físicos de corpos d'água de domínio da União para fins de aquicultura, e dá outras providências.

Brasil. Instrução Normativa Interministerial $n^{\circ}$ 07, de 28 de abril de 2005. República Federativa do Brasil, Brasília.

Brasil. Lei Federal n. 9.433, de 08 de janeiro de 1997, Institui a Politica e Sistema Nacional de Gerenciamente de Recursos Hídricos.

Bueno, G.W. Modelo bioenergético nutricional e balanço de massas para o monitoramento e estimativa de efluentes da produção comercial de tilápia do Nilo (Oreochromis niloticus) em reservatório tropical. Brasília: Faculdade de Agronomia e Medicina Veterinária, Universidade de Brasília, 2015, 118p. Tese (Tese em Ciências Animais) - Faculdade de Agronomia e Medicina Veterinária da Universidade de Brasília - 2015.

Bueno G.W., Marengoni N.G., Gonçalves A.C., Boscolo W.R.; Teixeira R.A. (2008). Trophic level and bioaccumulation of total phosphorus in cage fish rearing in the aquaculture area at Itaipu reservoir. Acta Scientiarum. Biological Science 30, 237-243.

Bureau, D.P.; Hua, K. 2010. Towards effective nutritional management of waste outputs in aquaculture, with particular reference to salmonid aquaculture operations. Aquaculture Research, 41: 777-792.

Buschmann AH, Cabello F, Young K, Carvajal J, Varela DA, Henríquez L (2009) Salmon aquaculture and coastal ecosystem health in Chile: Analysis of regulations, environmental impacts and bioremediation systems. Ocean \& Coastal Management, 52, 243-249.

Canfield, D.E.; Bachmann, R.W. 1981. Prediction of total phosphorus concentrations, chlorophyll a and Secchi depths in natural and artificial lakes. Canadian Journal of Fisheries and Aquatic Science, 38: 414-123. 
Carvalho, E.D.; Silva, R.J.; David, G.S. 2012. Health and Enviromnment in Aquaculture. Rijeka: INTECH Open Acess Publisher, 428p.

Cho, C. Y.; Bureau, D. P. 1998. Development of bioenergetic models and the Fish-PrFEQ software to estimate production, feeding ration and waste output in aquaculture. Aquatic Living Resources, 11(4): 199-210.

Cho, C.Y.; Bureau, D.P. 2001. A review of diet formulation strategies and feeding systems to reduce excretory and feed wastes in aquaculture. Aquaculture Research, 32: 349-360.

Cho, C.Y.; Slinger, S.J.; Bayley, H.S. Bioenergetics of salmonid fishes: energy intake, expenditure and productivity, Comp. Biochem. Physiol. 73B (1982) 25-41.

Chowdhury, K.M.A.; Siddiqui, S.; Hua, K; Bureau, D.P. 2013. Bioenergetic-based Factorial Model to Determine Feed Requirement and Waste Output of Tilapia Produced under Commercial Conditions. Aquaculture, 410-411, 138-147.

CONAMA - BRASIL. Conselho Nacional de Meio Ambiente. Resolução Conama nº 357, de 17 de março de 2005.2 Disponível em: <http://www.mma.gov.br/port/conama/res/res05/res35705.pdf>. Acesso em: 19 fev. 2015.

Dantas, M.C.; Attayde, J.L. 2007. Nitrogen and phosphorus content of some temperate and tropical freshwater fishes. Journal of Fish Biology, 70:100-108.

Dillon, P.J.; Rigler, F.H. 1974. A test of a simple nutrient budget model predicting the phosphorus concentration in lake water. J. Fish. Res. Board Can. 31:1771-1778.

Dumas, A.; France, J; Bureau, D.P. 2010. Modelling growth and body composition in fish nutrition: where have we been and where are we going? Aquaculture Research, 41, 161-181.

El-Gayar OF, Leung P (2000) ADDSS: a tool for regional aquaculture development. Aquacultural Engineering, 23, 181-202.

Furuya et al. 2010. Tabelas brasileiras para a nutrição de tilápias. Toledo: GFM, 100p.

Furuya, W.M.; Fujii, K.M.; Dos Santos, L.D. et al. 2008. Exigência de fósforo disponível para tilápia-do-nilo (35 a 100g). Rev. Bras. Zootec., v.37, p.961-966.

Garcia, F; Romera, D. M.; Gozi, K. S.; Onaka, E. M.; Fonseca, F. S.; Schalch, S. H. C.; Candeira, P. G.; Guerra, L. O. M.; Carmo, F. J.; Carneiro, D. J.; Martins, M. I. E. G.; Portella, M. C. 2013. Stocking density of Nile tilapia in cages placed in a hydroelectric reservoir. Aquaculture, v. 419, p.51-56. 
Guo, L.; Li, Z. Effects of nitrogen and phosphorus from fish cage-culture on the communities of a shallow lake in middle Yangtze River basin of China. Aquaculture, Amsterdam, vol. 226, p. 201-212, 2003.

Gyllenhammar, A.; HAKANSON, L.; Lehtinen, K. A mesocosm fish farming experiment and its implications for reducing nutrient load on a regional scale. Aquacultural Engineering, v. 38, p.117-126, 2008.

Hakanson, L. Changes to lake ecosystem structure resulting from fish cage farm emissions. Lake \& Reservoirs: Research and Management, vol. 10, p.71-80, 2005.

Jobling, M. 2011. Bioenergetics in aquaculture settings. In: Farrell, A.P. (Ed.), Encyclopedia of Fish Physiology: From Genome to Environment. Elsevier, Oxford, pp. 1664-1674.

Johansson, T; Hakanson, L.; Borum, K. Direct flows of phosphorus and suspended matter from a fish farm to wild fish in Lake Southern Bullaren, Sweden. Aquacultural Engineering. v. 17, p.111-137, 1998.

Jorcin, A.; Nogueira, M. G. 2005. Temporal and spatial patterns based on sement and sedimentwater interface characteristics along a cascade of reservoirs (Paranapanema River, south-east Brazil). Lakes \& Reservoirs: Research and Management, 10: 1-12.

Kaushik, S. J. 1998. Nutritional bioenergetics and estimation of waste production in non-salmonids. Aquatic Living Resources, 11(4): 211- 217.

Larsen, D.P.; Mercier, H.T. 1976. Phosphorus retention capacity of lakes. Journal of the Fisheries Research Board of Canada, 33: 1742-1750.

Lovatto, P.A.; Lehnen, C.R.; Andretta, I.; Carvalho, A.D; Hauschild, L 2007. Meta-analysis in scientific research: A methodological approach. Brazilian Journal of Animal Science, 36: 285294.

Lupatcsh, I.; Kissil, G.W.; Slan, D.; Pfeffer, E. 1998. Energy and protein requirements for maintenance and growth in gilthead seabream (Sparus aurata L.) Aquaculture Nutr. 4: 165-173.

Mallasen, M., H. P. Barros, D. P. Traficante, and A. L. S. Camargo. 2012. Influence of a net cage tilapia culture on the water quality of the Nova Avanhandava reservoir, São Paulo State, Brazil. Acta Scientiarum. Biological Sciences 34:289-296.

Miranda, E.C.; Pezatto, C.A.; Pezzato, L.E. et al. 2000. Disponibilidade aparente de fósforo em ingredientes pela tilápia-do-nilo (Oreochromis niloticus). Acta Scient., v.22, p.669-675. 
Montanhini Neto, R. ; Ostrensky, A. 2014. Evaluation of commercial feeds intended for the Brazilian production of Nile tilapia (L.): nutritional and environmental implications. Aquaculture Nutrition (Print), v. I, 1-9.

Montanhini Neto, R.; Ostrensky, A. 2013. Nutriente load estimation in the waste of Nile tilápia Oreochromis niloticus (L.) reared in cages in tropical climate conditions. Aquaculture Research, 1-14.

National Research Council - NRC. 2011. Nutrient Requirements of Fish and Shrimp. National Academy Press, Washington, DC.392p.

Ono, E. A.; Kubtiza, F. Cultivo de peixes em tanque-rede. 3ed. Jundiaí: E.A.Ono, 2003. 112p.

Penczak T., Galicka W., Molinski M., Kusto E. \& Zalewski M. (1982) The enrichment of a mesotrophic lake by carbon, phosphorus and nitrogen from the cage aqua- culture of rainbow trout, Salmo gairdneri. Journal of Applied Ecology 19, 371-393.

Pomari, J. 2010. Efeitos da tilapicultura em tanques-rede sobre as assembléias zooplanctônicas do reservatório de Chavantes, rio Paranapanema (SP/PR) Dissertação (mestrado) - Universidade Estadual Paulista, Instituto de Biociências, Botucatu, 2010, 205p.

Ramos, I.P.; Franceschini, L.; Zica, É.O.P.; Carvalho, E.D.; Silva, R.J.The influence of cage farming on infection of the corvine fish Plagioscion squamosissimus (Perciformes: Sciaenidae) with metacercariae of Austrodiplostomum compactum (Digenea: Diplostomidae) from the Chavantes reservoir, São Paulo State, Brazil. Journal of Helminthology, v. 88, p. 342-348, 2014.

Ross, L.G.; Falconer, L.L.; Campos Mendoza A, Martinez Palacios CA (2011) Spatial modelling for freshwater cage location in the Presa Adolfo Mateos Lopez (El Infiernillo), Michoacan, Mexico. Aquaculture Research 42: 797-807.

Silverston, L., Inmon, W.H., Graziano, K. 1997. The Data Model Resource Book: A Library of Logical Data Models and Dataware house Designs. John Wiley and Sons, NY, 355.

SIPOT, ANEEL - CENTRAIS ELÉTRICAS BRASILEIRAS - ELETROBRAS. Sistema de informação do potencial hidrelétrico brasileiro - SIPOT. Rio de Janeiro, mai. 2015.

Straskraba, M. 1996. Lake and reservoir management. Verh. Internat. Verein. Limnol. 26:193-209.

Watanabe, T.; Satoh, S.; Takeuchi, T. Availability of minerals in fish meal to fish. Asian Fish. Sci., v.1, p.175-195, 1988. 
Xie S., Cui Y., Yang Y. \& Liu J. (1997a) Energy budget of Nile tilapia, Oreochromis niloticus, in relation to ration size. Aquaculture 154, 57-68.

Yi, Y. 1999. A bioenergetics growth model for Nile tilapia (Oreochromis niloticus) based on limiting nutrients and fish standing crop in fertilized ponds. Aquacultural Engineering, 18: $157-173$. 